\title{
AVALIAÇÃO DA MICRODUREZA KNOOP E DO GRAU DE CONVERSÃO DE DOIS CIMENTOS DE IONÔMERO DE VIDRO MODIFICADOS POR RESINA EM FUNÇÃO DO TIPO DE POLIMERIZAÇÃO E DO TEMPO
}

\section{LEANDRO DE MOURA MARTINS}

Dissertação apresentada à Faculdade de Odontologia de Bauru, da Universidade de São Paulo, como parte dos requisitos para a obtenção do título de Mestre em Odontologia, na área de Dentística, opção Materiais Dentários.

\section{Bauru}




\section{AVALIAÇÃO DA MICRODUREZA KNOOP E DO GRAU DE CONVERSÃO DE DOIS CIMENTOS DE IONÔMERO DE VIDRO MODIFICADOS POR RESINA EM FUNÇÃO DO TIPO DE POLIMERIZAÇÃO E DO TEMPO}

\section{LEANDRO DE MOURA MARTINS}

Dissertação apresentada à Faculdade de Odontologia de Bauru, da Universidade de São Paulo, como parte dos requisitos para a obtenção do título de Mestre em Odontologia, na área de Dentística, opção Materiais Dentários.

Orientador: Prof. Dr. Paulo Afonso Silveira Francisconi 


\begin{tabular}{|c|c|}
\hline \multirow[t]{3}{*}{ M366a } & $\begin{array}{l}\text { Martins, Leandro de Moura } \\
\text { Avaliação da microdureza Knoop e do grau de conversão de dois } \\
\text { cimentos de ionômero de vidro modificados por resina em função do tipo } \\
\text { de polimerização e do tempo / Leandro de Moura Martins. - Bauru, } 2007 . \\
\text { 97p. : il. ; } 30 \mathrm{~cm} \text {. }\end{array}$ \\
\hline & $\begin{array}{l}\text { Dissertação. (Mestrado) -- Faculdade de Odontologia de Bauru, } \\
\text { Universidade de São Paulo. }\end{array}$ \\
\hline & Orientador: Prof. Dr. Paulo Afonso Silveira Francisconi. \\
\hline
\end{tabular}

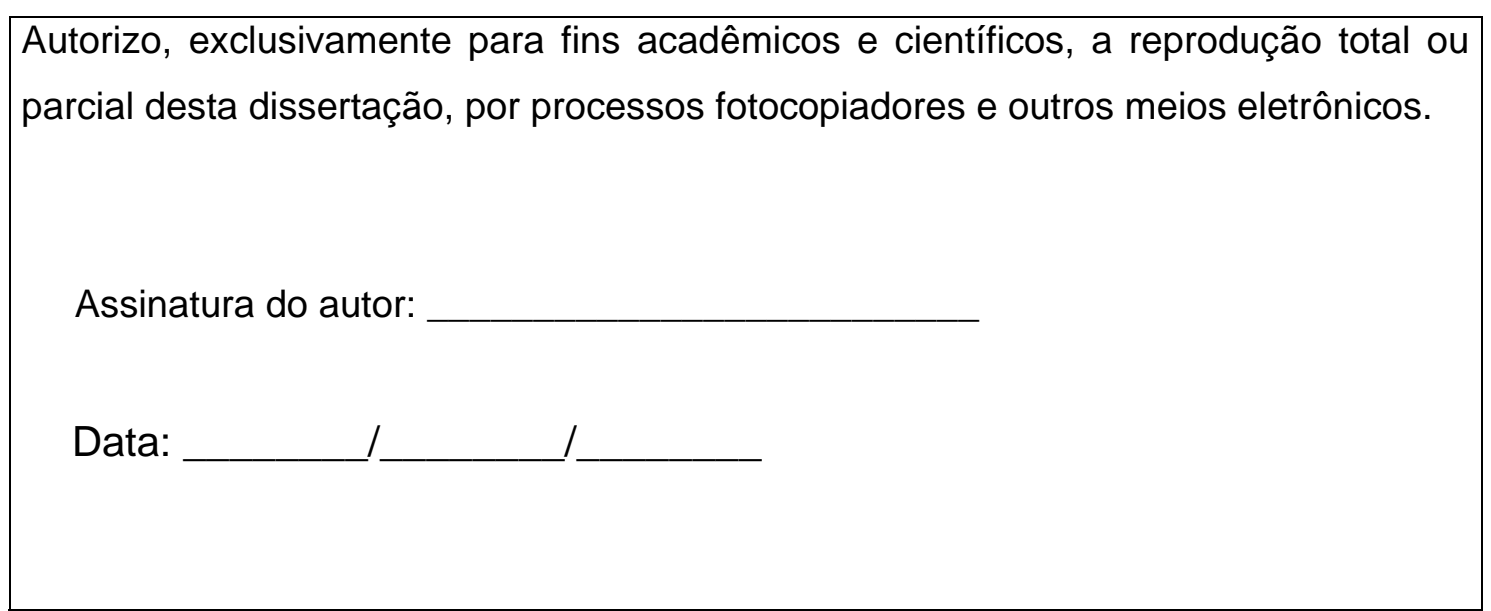




\section{DADOS CURRICULARES}

\section{LEANDRO DE MOURA MARTINS}

Rio de Janeiro

16 de junho de 1979

Filiação

1998-2002

2002-2003

2003-2005

2005-2007

2006

Associações
Nascimento

João Teixeira Martins

Marleni de Moura Martins

Graduação em Odontologia,

Universidade Gama Filho - RJ.

Especialização em Dentística Restauradora, Faculdade de Odontologia de Bauru - USP.

Especialização em Prótese Dental, PROFIS, Bauru - SP.

Curso de pós-graduação em Dentística, opção Materiais dentários, nível de mestrado, Faculdade de Odontologia de Bauru - USP.

Membro Honorário da Sociedade Paraguaia de Prótese, Assunção - Paraguai.

GBPD - Grupo Brasileiro de Professores de Dentística.

SBPqO - Sociedade Brasileira de Pesquisa Odontológica. 


\section{DEDICATÓRIA}

A Deus, do qual todas as coisas dependem.

Aos meus pais João e Marleni que, na segurança de um lar bem estruturado, esculpiram minha personalidade e meu caráter, além do amor incondicional e doação de suas vidas.

Aos meus irmãos Luciano e Claudia, amigos, companheiros, pela confiança que me concederam e a certeza de ter com quem contar.

À minha sobrinha-afilhada Julia, por seu amor sincero e inocente e por mostrar que a renovação faz parte da vida. Você é a alegria da minha vida.

Às minhas avós Nair e Custodia† pelos ensinamentos de que existem diferenças entre inteligência e conhecimento e que a humildade é o conhecimento exato do que não somos.

À Luciana, minha doce companheira, pelo apoio despretensioso, pela compreensão das minhas falhas, pela cumplicidade incondicional, pela luz que me guia, por ser minha inspiração e acima de tudo pelo amor mais intenso que jamais sonhei existir.

"Nada fiz de merecedor, todas as minhas realizações foram inteiramente as Tuas ações" (Rei David para Deus). 


\section{AGRADECIMENTOS}

Ao meu Orientador, Prof. Dr. Paulo Afonso Silveira Francisconi, minha eterna gratidão pela confiança ao permitir que desenvolvesse minhas idéias com extrema liberdade, apoio e paciência e pelo exemplo de pessoa e profissional. Sinto muito orgulho não só de ser seu orientado, mas também de ser seu amigo.

Ao amigo, Prof. Dr. César Antunes de Freitas por ter me acolhido como parte de sua própria família, dando a mim os mesmos conhecimentos e oportunidades que ofereceu a seus filhos.

Ao Prof. Dr. Paulo Amarante de Araújo pelo ensinamento de que para ser bom professor deve-se olhar além da odontologia, pois um país se muda pela cultura.

À Profa. Dra. Alessandra Rastelli por me adotar em São Carlos, dando todos os subsídios para que fosse possível essa pesquisa, compartilhando conhecimento e amizade. Te devo mais do que meus agradecimentos.

A todos os meus Professores da Faculdade de Odontologia de Bauru, especialmente ao Prof. Dr. Carlos Eduardo Francischone, Prof. Dr. Eduardo Batista Franco, Prof. Dr. José Mondelli, Prof. Dr. José Carlos Pereira, Profa. Dra. Maria Fidela de Lima Navarro, Profa. Dra. Maria Teresa Atta e 
Prof. Dr. Rafael Francisco Lia Mondelli, pelos conhecimentos transmitidos e apoio para minha evolução desde a minha chegada a essa Universidade.

Ao Prof. Dr. José Mondelli que sempre será um exemplo de profissional.

Aos funcionários da disciplina de Materiais Dentários: Alcides Costa, Lourisvalda Celestino e Sandra Azuaga, por ser minha família quando esta estava longe e pelos favores inesgotáveis que nenhuma retribuição será suficiente.

Ao Prof. Dr. José Roberto Lauris, pela sua calma peculiar e ponderação no auxílio e ensinamento desse mundo desconhecido da biologia, a matemática.

Ao amigo Prof. Dr. Gerson Bonfante que, além de ser uma fonte inesgotável de conhecimento, me proporcionou em Bauru um ambiente acolhedor e seguro.

Ao amigo Prof. Dr Accácio Lins do Valle, pela confiança em meu trabalho e apoio em minhas decisões.

Ao amigo Prof. Dr. Vinícius Carvalho Porto, por demonstrar que com esforço e humildade é possível alcançar nossos objetivos.

Às amigas Raquel Ramos Castello e Erika Bustamante Magalhães, por serem as irmãs que não tive estando sempre presentes, ainda que distantes. 
Ao amigo Prof. Leovirgílio Furtado por estender a mão quando precisei de um incentivo para seguir a carreira acadêmica.

Aos meus Professores Raquel Ramos Castello, Leovirgílio Furtado, Gisele Damiana, Rogério Fulgêncio, Denise Cortêz, Cleber Ferreira, Ana Bela e Ivo Carlos Corrêa pelo incentivo à pesquisa.

Aos amigos Rozenaldo Tavares da Silva e Eliany Mendonça da Silva por me acolherem como filho.

Aos afilhados Fabíola e Danilo por confiarem a mim a responsabilidade de padrinho.

Aos meus amigos e colegas do Mestrado, Breno Silva, Cristiane Nishiyama, Fabiane Toledo, Ian Vieira, Juan Valdivia, Marcela Calábria, Márcia Freitas, Renata Louro e Wagner Baseggio pela amizade e convivência, respeitando sempre meus limites e minhas fraquezas.

Aos meus amigos e colegas do Doutorado, Renato Cilli, Anuradha Prakki, Patrícia Caldeiron e Rosana Pereira, por dividirem suas experiências, sucessos e conhecimentos.

Aos amigos Adriana Corrêa de Queiroz, Gustavo Henrique Diniz Pimentel e Andréa Mello de Andrade, por permitirem que a amizade compartilhada com 
minha namorada se estendesse a mim tornando-se muito mais que amigos, partes integrantes da minha família.

Aos amigos Amilkar Javier Rocha Aguila, Mônica Pereira e Santiago, pela amizade e cumplicidade de todos os momentos. Lembrem-se de que vocês são minha família boliviana.

Ao amigo Breno Mont'Alverne Haddade Silva pelos momentos de intermináveis conversas e conselhos, principalmente nas idas e vindas de São Carlos.

Ao amigo lan Matos Vieira pela amizade ingênua e presente fazendo renovar a crença de amizade verdadeira.

À amiga Cristiane Nishiyama e família que me permitiram ter uma convivência familiar e amiga.

À amiga Fabiane Toledo e família, pelo companheirismo e por serem sempre solidários aos meus pedidos.

Aos amigos Márcia Antunes de Freitas e José Sergio Tosi que me adotaram como irmão e cunhado.

Aos amigos Fernando Antunes de Freitas e Paola Guzman pelos momentos de alegria que vocês me proporcionaram. 
À amiga Dafna Geller, pela disposição de ajudar nas minhas traduções e no microdurômetro, mesmo que isso significasse menos horas de sono.

Ao amigo Wagner Baseggio por tornar possível minha locomoção a São Carlos para a realização desta pesquisa.

Aos amigos Paulo Maurício Batista da Silva e Ricardo Virgolino Carvalho da Silva, militantes da Dentística Restauradora, por compartilharem momentos de alegrias e brincadeiras sem fim.

Ao funcionário da Disciplina de Bioquímica Ovídio dos Santos Sobrinho, pela paciência e presteza na utilização do microdurômetro.

Ao corpo de funcionários da biblioteca, especialmente a Rita, Vera, Valeira, César, Ademir e Ana Paula.

Aos funcionários da Pós-Graduação, especialmente à Giane, Maria Margareth, Ana Letícia e Geyce.

A todas as pessoas que de alguma forma contribuíram, direta ou indiretamente, para a conclusão deste trabalho, a vocês minha eterna gratidão. 


\section{AGRADECIMENTOS INSTITUCIONAIS}

À Universidade Gama Filho que me fez um cirurgião-dentista.

À Faculdade de Odontologia de Bauru, da Universidade de São Paulo, pela oportunidade de crescer profissionalmente e de ajudar o país a desenvolver seus próprios recursos, com um curso sinônimo de qualidade.

Ao Departamento de Dentística, Endodontia e Materiais Dentários da Faculdade de Odontologia de Bauru, pelo ambiente de trabalho prazeroso e pela amizade proporcionados durante a minha estadia.

À Disciplina de Bioquímica da Faculdade de Odontologia de Bauru, na pessoa da Profa. Dra. Marília Afonso Rabelo Buzalaf, por possibilitar a utilização do microdurômetro.

Ao Instituto de Química de São Carlos, da Universidade de São Paulo, por permitir a utilização do espectrofotômetro.

Ao Grupo de Ótica do Instituto de Física de São Carlos - USP, em nome do Prof. Dr. Vanderlei Salvador Bagnato, pela possibilidade da análise dos dados desta pesquisa e pelos bons momentos de convivência. 
A Coordenação de Aperfeiçoamento de Pessoal de Nível Superior (CAPES) pelo fundamental suporte financeiro que tornou essa pesquisa possível.

Ao Programa de Aperfeiçoamento em Ensino (PAE) pelo complemento financeiro imprescindível para a minha dedicação exclusiva ao curso.

A Divisão de produtos dentários da 3M ESPE, pela doação dos materiais para a presente pesquisa.

MUITO OBRIGADO 


\section{SUMÁRIO}

LISTA DE FIGURAS ….................................................................. XIII

LISTA DE TABELAS

LISTA DE ABREVIATURAS E SÍMBOLOS ….......................................... XVI

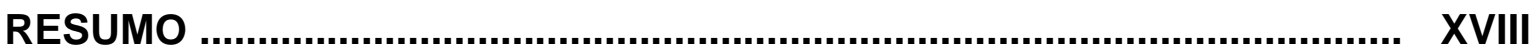

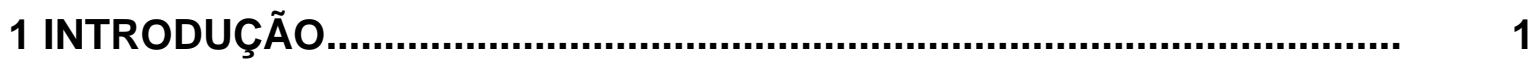

2 REVISÃO DE LITERATURA...............................................................

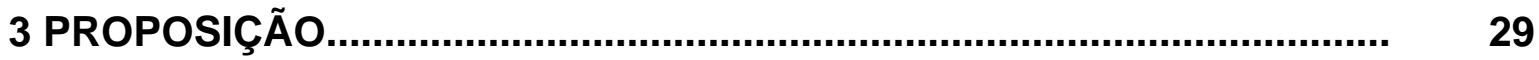

4 MATERIAL E MÉTODOS..................................................................

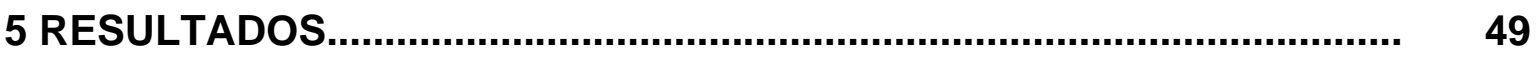

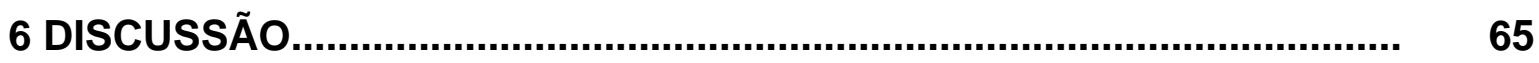

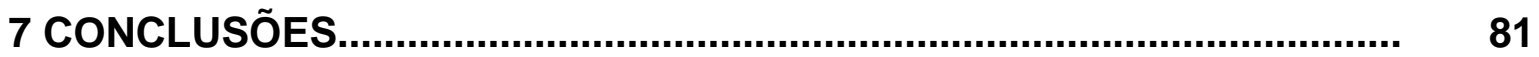

REFERÊNCIAS BIBLIOGRÁFICAS.......................................................

ABSTRACT 


\section{LISTA DE FIGURAS}

Figura 4.1- Aparelhos fotopolimerizadores - LED (esquerda) e Halógena (direita)

Figura 4.2- Politriz Metalográfica )

Figura 4.3- Espectrofotômetro FT-IR BOMEM................................. 38

Figura 4.4- Penetrador Knoop............................................. 39

Figura 4.5- Microdurômetro................................................ 39

Figura 4.6- Espécime no pastilhador para ser triturado ........................ 45

Figura 4.7- Gral e pistilo de ágata.................................................... 45

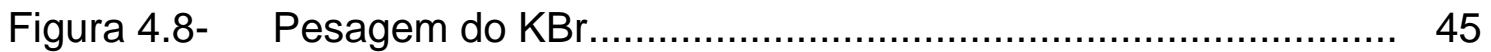

Figura 4.9- Pesagem do cimento............................................ 45

Figura 4.10- Pastilhador na prensa........................................... 46

Figura 4.11- Pastilha pronta para análise...................................... 46

Figura 4.12- Dispositivo para pastilha............................................ 47

Figura 4.13- Gráfico das bandas de absorção....................................... 47

Figura 4.14- Espécimes embutidos no acrílico............................... 48

Figura 4.15- Distância entre as impressões................................... 48

Figura 4.16- Medida da diagonal............................................ 48

Gráfico 5.1- C Curva de intensidade do LEC 1000 (LED) ....................... 51

Gráfico 5.2- Curva de intensidade do Ultralux EL (halógena) .................. 52

Gráfico 5.3- Médias da microdureza Knoop nos diferentes tempos de armazenagem........................................................... 56

Gráfico 5.4- Médias do grau de conversão nos diferentes tempos de armazenagem

Gráfico 5.5- Correlação dos valores de dureza e correlação da lâmpada halógena. 
Gráfico 5.6- Correlação dos valores de dureza e correlação do LED........ 62

Gráfico 5.7- Correlação dos valores de dureza e correlação do cimento autopolimerizável..................................................... 63

Gráfico 6.1- Formula estrutural dos monômeros Bis-GMA, TEGDMA e

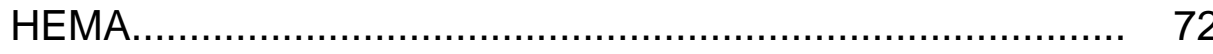




\section{LISTA DE TABELAS}

Tabela 4.1- Composição dos cimentos de ionômero de vidro modificados por resina................................................ 35

Tabela 4.2- $\quad$ Características das unidades fotoativadoras....................... 36

Tabela 4.3- Divisão dos grupos e suas siglas...................................... 40

Tabela 5.1- Valores unitários da microdureza Knoop (KHN) de todos espécimes............................................................... 54

Tabela 5.2- Valores das médias e respectivos desvios padrão da microdureza Knoop $(\mathrm{KHN})$ referentes à interrelação tipo

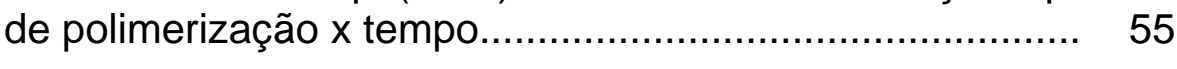

Tabela 5.3- $\quad$ Análise de variância da microdureza Knoop........................ 55

Tabela 5.4- Teste de TUKEY para comparações múltiplas entre as médias dos valores de microdureza Knoop (KHN) entre todos os grupos*. (médias com letras iguais são semelhantes)

Tabela 5.5- Valores unitários do grau de conversao (\%) de todos espécimes.

Tabela 5.6- Valores das médias e respectivos desvios padrão do grau de conversão (\%) referente à interrelação tipo de polimerização $\mathrm{x}$ tempo.

Tabela 5.7- Análise de variância do grau de conversão.

Tabela 5.8- Teste de TUKEY para comparações múltiplas entre as médias dos valores do grau de conversão (\%) entre todos os grupos* (médias com letras iguais são semelhantes)... 60

Tabela 5.9- Coeficiente de correlação de Pearson da lâmpada

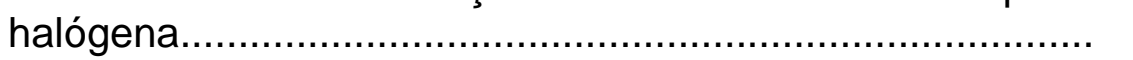

Tabela 5.10- Coeficiente de correlação de Pearson do LED..................... 61

Tabela 5.11- Coeficiente de correlação de Pearson do cimento autopolimerizável.. 


\section{LISTA DE ABREVIATURAS E SÍMBOLOS}

\begin{tabular}{ll}
$\mathrm{cm}$ & Centímetro \\
$\mathrm{h}$ & Hora \\
$\mathrm{d}$ & Dia \\
$\mu \mathrm{m}$ & Nanômetros \\
$\mathrm{mm}$ & Micrômetros \\
$\mathrm{KHz}$ & Milímetros \\
${ }^{\circ} \mathrm{C}$ & Quilohertz \\
$\mathrm{mw} / \mathrm{cm}{ }^{2}$ & Grau Celsius \\
$\mathrm{g}$ & Miliwatts por centímetro quadrado \\
$\mathrm{T}$ & gramas \\
$\mathrm{I}$ & Tonelada \\
$\mathrm{P}$ & Intensidade \\
$\mathrm{A}$ & Potência \\
$\mathrm{MPa}$ & Área \\
$\mathrm{N}$ & Mega Pascal \\
$\mathrm{mM}$ & Newton \\
$\mathrm{C}$ & Milimolar \\
$\mathrm{FT}-\mathrm{IR}$ & Unidade arbitrária \\
$\mathrm{GC}$ & Infravermelho com transformada de Fourier \\
$\mathrm{KHN}$ & Grau de Conversão \\
$+/-$ & Mais ou menos \\
$\mathrm{CIV}$ & Cimento de ionômero de vidro convencional \\
\hline $\mathrm{M}$ & Cimômero de vidro modificado por resina
\end{tabular}




\begin{tabular}{|c|c|}
\hline CIVMRs & Cimentos de ionômero de vidro modificados por resina \\
\hline HEMA & 2 hidroxi-etil-metacrilato \\
\hline TEGDMA & Trietileno Glicol di-Metacrilato \\
\hline Bis-GMA & Bisfenol-glicidil metacrilato \\
\hline UDMA & Uretano di-Metacrilato \\
\hline MMA & Metil-metacrilato \\
\hline DPICL & Difenil-iodo-cloro \\
\hline DP & desvio padrão \\
\hline$\%$ & Porcentagem \\
\hline $\mathrm{H}$ & Lâmpada halógena \\
\hline $\mathrm{L}$ & LED \\
\hline LED & Diodo emissor de luz \\
\hline $\mathrm{KBr}$ & Brometo de Potássio \\
\hline Al & Alumínio \\
\hline $\mathrm{Ca}$ & Cálcio \\
\hline $\mathrm{Na}$ & Sódio \\
\hline In-Ga-N & Î́ndio-Gálio-Nitrogênio \\
\hline VT & Vitremer \\
\hline $\mathrm{RL}$ & Rely X Luting \\
\hline
\end{tabular}


RESUMO 


\section{RESUMO}

Os ionômeros de vidro vêm sendo utilizados largamente na odontologia com diversas funções. Suas formulações sofreram alterações durante os anos, como a incorporação de componentes resinosos, para a melhoria de suas propriedades físicas e aumento do tempo de trabalho. Com isso, o estudo teve como objetivo avaliar o grau de conversão e a microdureza Knoop dos cimentos de ionômero de vidro modificados por resina (Rely $X$ Luting $\mathrm{e}$ Vitremer, ambos da 3M ESPE) de acordo a forma de polimerização (química ou fotopolimerável por lâmpada halógena Ultralux EL - Gnatus e LED LEC 1000 MMOptics) e o tempo de armazenagem. Três espécimes de cada material, autopolimerizável e fotopolimerizável, e tipo de fotopolimerização (por luz halógena e LED) foram confeccionados para cada tempo experimental de 6 horas, 1 , 2, 3, 5, 7 ,11 e 14 dias ( $n=72)$. Os espécimes foram armazenados em ambiente escuro a $37^{\circ} \mathrm{C}$ durante esses períodos. Os 72 espécimes foram analisados pela espectroscopia FT-IR para a medição do grau de conversão (GC). Três espécimes de cada material e tipo de polimerização $(n=9)$ foram confeccionados para a medição da microdureza, com um penetrador diamantado piramidal, tipo Knoop, carga estática de 50 gramas por 30 segundos. Os resultados encontrados demonstraram que 0 material fotopolimerizado com LED apresentou os maiores valores do grau de conversão e da microdureza. O grau de conversão aumentou com o tempo de armazenagem enquanto a microdureza obteve os maiores resultados entre 2448 horas. Os resultados permitiram concluir que para os cimentos de ionômero de vidro modificados por resina, Vitremer e Rely $X$ Luting, o material fotopolimerizável onde se utilizou o LED apresentou os melhores resultados e que a microdureza Knoop foi ineficaz para predizer o grau de conversão.

Palavras-chave: Cimento de ionômero de vidro modificado por resina. Espectroscopia FT-IR. Microdureza Knoop. Polimerização. Tempo de armazenagem. 


\section{INTRODUÇÃO}

A busca incessante por materiais com características físico-químicas cada vez mais próximas das estruturas dentais levou, em 1971 na Inglaterra, ao desenvolvimento de um cimento com propriedades de adesividade, coeficiente de expansão térmica linear semelhante ao do esmalte e da dentina, compatibilidade biológica e liberação de flúor. Este cimento tem sido empregado como material para restauração, cimentação, selamento de fóssulas e forramento desde o final da década de 70. O cimento de ionômero de vidro é constituído geralmente por um pó de sílica, alumina e fluoreto de cálcio, e uma solução aquosa de ácidos polialcenóicos. A partir de uma reação de presa do tipo ácido-base é desencadeada a formação de um sal de hidrogel que atua como matriz de ligação para a completa maturação do cimento (WILSON \& KENT ${ }^{53}, 1971, \mathrm{KIDD}^{30}, 1978, \mathrm{CHAIN}^{11}, 1990$, e NAVARRO ${ }^{37}$, 1997).

Algumas alterações ocorreram em relação à composição durante os anos seguintes e melhorias em suas propriedades físicas foram conseguidas, em 1988 por ANTONUCCI; McKINNEY e STANSBURY ${ }^{3}$, quando da inclusão de componentes resinosos e, em 1989 por MITRA $^{35}$, com a adição de fotoiniciadores, o que trouxe também a possibilidade do aumento do tempo de trabalho. As modificações, através de uma mistura de água/HEMA (2-hidroxietil metacrilato), proporcionaram aos cimentos de ionômero de vidro a classificação em três tipos de acordo com a polimerização: o sistema quimicamente ativado, onde ocorre a reação ácido/básica convencional e a polimerização química dos componentes resinosos; o sistema de presa dual, o qual além da reação ácido/básica e da foto-polimerização, possui iniciadores químicos para polimerizar os componentes metacrilatos na ausência de luz; e o sistema fotoativado (CHAIN $\left.{ }^{11}, 1990\right)$.

Os cimentos de ionômero de vidro fotoativados e duais possuem fotoiniciadores que absorvem a luz visível dentro da faixa azul do espectro de 400-550nm (HOFMANN et al. ${ }^{21}$, 2000). Essa absorção, por meio dos fótons, gera radicais livres pela ativação das moléculas dos monômeros iniciando, 
assim, o processo de polimerização, dando ao material uma resistência inicial e permitindo a maturação do corpo através da convencional e lenta reação ácidobase. Essa energia luminosa é gerada a partir de unidades fotoativadoras que evoluíram ao longo dos anos, desde o sistema com luz ultravioleta, presente numa faixa de luz invisível, que apresentou deficiências e perigos aos usuários, até as fontes atuais de luz visível com espectro, intensidade e modos de emissão variados.

As lâmpadas incandescentes do tipo halógena são largamente utilizadas na odontologia e funcionam com o aquecimento de um filamento espiralado de tungstênio que produz luz branca e, com um sistema de filtros óticos faz-se a seleção do espectro a ser emitido. Estes filtros controlam a absorção de radiação infravermelha geradora de calor, que pode ser transmitido ao órgão dental e provocar aumento da temperatura intrapulpar, e radiação ultravioleta, que é capaz de provocar alterações biológicas em tecidos conjuntivos e em tecidos moles da cavidade oral (RUEGGEBERG ${ }^{41,42}, 1999$ e 2000). A passagem por esse filtro gera uma emissão de luz azul, entre 380 e 520nm, sendo aproveitado no processo de fotoativação somente $0,5 \%$ do total da energia.

Com o grau de calor gerado pelas lâmpadas halógenas, diversos estudos foram feitos com o intuito de conseguir uma fonte segura e eficaz de produção de luz fria ou luminescente. Com a descoberta da eletroluminescência, emissão de luz visível por uma junção de semicondutores (p-n) através da qual é aplicada uma voltagem, em 1968, surgiu uma nova fonte de luz denominada LED (Ligth Emiting Diode) ou diodo emissor de luz, cujo comprimento de onda é dependente dos semicondutores que serão energizados e conseqüentemente ocorre a emissão da cor que será emitida (KANCA III ${ }^{27}$, 2003). Utilizado na odontologia, desde 1999, esses semicondutores Índio-Gálio-Nitrogênio (In-Ga-N) são capazes de produzir luz azul numa faixa de comprimento de onda entre 430 e 490nm (KURACHI ${ }^{31,32}$, 2000). Isso proporcionou uma fonte de energia para a fotopolimerização com pequeno espectro de emissão, baixa produção de calor e baixo consumo de energia.

Diversos autores (HAMID et al. ${ }^{20}, 1998$, PALMER et al. ${ }^{38}, 1999$, SCHUSTER; CAUGHMAN e RUEGGEBERG ${ }^{43}$, 2000, ABOUT et al. ${ }^{1}, 2002$, 
MICHELSEN et al. $^{34}, 2003$, e SOUZA et al. ${ }^{46}$, 2006) relataram os possíveis efeitos citotóxicos dos cimentos de ionômero de vidro modificados por resina devido à liberação do monômero HEMA hidrofílico e à alta difusibilidade (baixo peso molecular) presente em sua composição. Acredita-se que, se não houver monômero residual para ser lixiviado, não existirá o principal componente promovedor de efeitos deletérios, o que demonstra a importância de se obter uma polimerização tão completa quanto possível de todo o material, para que suas propriedades sejam mantidas, assim como, sejam minimizadas as reações da polpa decorrentes desses resíduos. Com a existência de diversas opções de materiais e a pouca informação disponível ao clínico, torna-se imprescindível a compreensão das características dos cimentos de ionômero de vidro modificados por resina e das fontes emissoras de luz (unidades fotoativadoras), por terem influência no processo reacional do material e, conseqüentemente, nos seus efeitos sobre a conversão dos monômeros contidos nos ionômeros híbridos e nas suas propriedades mecânicas.

A espectroscopia de infravermelho para a verificação das substâncias presentes nos materiais é um método consagrado e utilizado desde os estudos iniciais dos cimentos de ionômero de vidro convencionais realizados por CRISP et al. $^{14}$, em 1973, ao estudar a reação de presa desses materiais. A quantificação de monômeros residuais por meio da espectroscopia de infravermelho com Trasformada de Fourier, que apresenta vantagens por não utilizar monocromadores, permitir ganho de tempo, ter altas resoluções e espectros de boa qualidade com pequena quantidade de espécimes, é realizada pelo estudo dos espectros infravermelhos absorvidos dos espécimes (SILVERSTEIN \& WEBSTER ${ }^{44}$, 2000). A vibração espectral de uma molécula é considerada uma propriedade única e característica, tal como o espectro infravermelho pode ser usado como uma característica individual para identificação de grupos funcionais (COATES ${ }^{12}$, 2000). O espectrofotômetro registra picos entre 4000 e $400 \mathrm{~cm}^{-1}$ (espectro eletromagnético entre a luz visível e microondas). A dupla ligação $C=C$ alifática apresenta uma vibração espectral em $1638 \mathrm{~cm}^{-1}$ que representa a ligação presente nos monômeros e a quantidade de monômeros residuais é calculada utilizando a quantidade dessa ligação nos materiais não polimerizados (como base) e polimerizados. 
Alguns autores como RUEGGEBERG \& CRAIG $^{40}$, em 1988, relataram que os ensaios mecânicos, além de avaliarem a resistência dos materiais poliméricos, são hábeis para predizer a conversão monomérica. Observaram também a similaridade entre o FT-IR e a dureza Knoop como os melhores preditores da conversão.

A eficácia curadora da tecnologia LED e dos ensaios mecânicos para predizer o grau de conversão são temas de muitas controvérsias. Além disso, há pouca informação sobre o grau de conversão monomérica dos cimentos de ionômero de vidro modificados por resina. Portanto, estudos esclarecedores sobre esses temas se fazem necessários. 


\section{REVISÃO DE LITERATURA}

CRISP et al. ${ }^{14}$, em 1974, avaliaram a reação dos cimentos de ionômero de vidro e reportaram a trasmitância e espectro de reflectância total de um cimento odontológico formado por um vidro aluminosilicato e solução aquosa do ácido poliácrilico (ASPA). Por meio de um estudo de espectroscopia de FT$\mathrm{IR}$, a interpretação do espectro mostrou que um hidrogel silicoso $\left(1050 \mathrm{~cm}^{-1}\right)$ é formado junto com sais poliacrilato de cálcio e de alumínio $\left(1600 \mathrm{~cm}^{-1}\right)$. Os autores puderam concluir que alguns grupos $\mathrm{COOH}$ livres permanecem não reagidos, possivelmente devido aos mesmos serem inacessíveis e os sais de alumínio, responsáveis pelo endurecimento final do cimento, serem formados mais tardiamente.

KAWAHARA, IMANISHI e OSHIMA ${ }^{29}$, em 1979, se preocupavam com os possíveis efeitos citotóxicos dos cimentos de ionômero de vidro. Quando o pó e o líquido do CIV são misturados, o líquido erosiona o pó e íons metálicos de $\mathrm{Al}^{+3}, \mathrm{Ca}^{+2}, \mathrm{Na}^{+2}$, e outros, são movidos por íons hidrogênio do radical carboxil no líquido. Cada molécula de ácido poliacrílico reage com metal e são unidos dentro de uma estrutura de rede, formando um cimento de estrutura insolúvel. Neste cimento, foi avaliado o crescimento celular, contando o número de núcleos por um hemocitômetro, e as mudanças morfológicas das células de polpa humana, com um microscópio. Os resultados mostraram que houve influência da citotoxicidade de todos os cimentos não curados no crescimento celular (a citotoxidade dos cimentos não curados foi reconhecida em todos os cimentos para o crescimento celular), entretanto, para o CIV, após 4 dias, as células cresceram normalmente como o controle.

INOUE \& HAYASHI ${ }^{25}$, em 1982, realizaram uma cuidadosa investigação ao perceberem a grande utilização dos di-acrilatos, tais como BIS-GMA, nos materiais restauradores baseados em resina, e a ocorrência de reações adversas ao tecido causadas pelo monômero residual no material curado. Com o objetivo de mensurar a quantidade de monômero residual nos compósitos e determinar a porcentagem de material lixiviado na água durante os períodos de tempo (imediatamente, 3, 7 e 13 dias após a manipulação), foi utilizado o 
método da cromotografia. O BIS-GMA foi detectado em todos os materiais, assim como os outros monômeros adicionados à resina composta. Essa concentração variou de 0,4 a $1,24 \%$ do peso original da resina curada e as menores quantidades de monômeros lixiviados foram encontradas após 12 dias depois da polimerização.

HUME \& MOUNT ${ }^{23}$, em 1988, preocupados com a citotoxidade dos materiais odontológicos, avaliaram in vitro os efeitos de 4 CIV na dentina. Terceiros molares tiveram as oclusais preparadas, separando os grupos da seguinte forma: grupo 1, com cavidades de 1,8-2 mm de espessura de dentina seladas com cimento de ionômero de vidro sem condicionamento; grupo 2, seguiu os mesmos procedimentos que o grupo 1, porém com condicionamento; grupo 3, igual ao primeiro, apenas com a espessura de dentina diferente $(0,3-$ $1 \mathrm{~mm}$ ); e grupo 4, com polpa exposta. Os cimentos lixiviados em contato direto foram altamente citotóxicos, mas os colocados em dentina tiveram pouca ou nenhuma citotoxicidade. Os cimentos de ionômero de vidro não apresentaram potencial citotóxico à polpa quando em dentina, mas não devem ser postos diretamente em contato com ela.

As sensibilidades do FT-IR, dureza Knoop, sorpção de água e lixiviação de resina, foram comparadas por RUEGGEBERG \& CRAIG $^{40}$, em 1988, pelas habilidades de distinguir diferenças entre amostras de compósitos curados, com diferentes espessuras de resina sobrepostas. O dispositivo desenvolvido permitiu produzir amostras de compósito fotopolimerizados com parâmetros controlados para os testes, eliminando efeitos da resina como perda da fluidez durante o polimento ou um aumento da conversão como resultado do calor gerado durante a manipulação. A sensibilidade dos diferentes testes foi maior e igual para a espectroscopia FT-IR e microdureza Knoop, enquanto a resina lixiviada provou ter uma sensibilidade moderada, e a sorpção de água não apresentou sensibilidade. A habilidade destes parâmetros para predizer a conversão monomérica mensurada pelo FT-IR também foi determinada, sendo que a dureza Knoop mostrou ser o melhor preditor da conversão. Os valores da sorpção de água não variaram com mudanças na conversão do monômero.

MITRA $^{36}$, em 1991, determinou a adesão à dentina e propriedades físicas do Vitrebond (3M), cimento de ionômero de vidro fotocurado para forro/base, comparando estes valores com o CIV convencional 3MGI (3M). Os 
valores de resistência da força adesiva à dentina bovina, após 24 horas em água destilada, foram de $12 \pm 3 \mathrm{MPa}$ para o Vitrebond, enquanto para o $3 \mathrm{MGI}$ foram de $4 \pm 2 \mathrm{MPa}$. As falhas observadas foram coesivas na dentina ou no ionômero. A adesão imediata do material fotocurado foi também significantemente maior que dos CIV convencionais. A ciclagem térmica mostrou que a união do Vitrebond à dentina foi estável. Estudos de adesão feitos em dentina humana mostraram altos valores de adesão. A resistência à compressão e tração diametral do Vitrebond foram determinados imediatamente após a fotopolimerização e também após armazenagem em água por 24 horas, 1 semana, 1 mês e 7 meses. Não houve diferença significante nos valores da resistência à compressão e tração diametral obtidos imediatamente após a cura e após os tempos de armazenagem em água a $37^{\circ} \mathrm{C}$.

Em 1992, WOOLFORD \& CHADWICK $^{54}$ realizaram estudos relacionados à sensibilidade pós-operatória com o desenvolvimento dos cimentos de ionômero de vidro conhecidos como fotoativados, ou modificados por resina, que têm sido produzidos em resposta à demanda clínica de um material para base com uma presa comandada. Este estudo monitorou o $\mathrm{pH}$ superficial de 3 CIVMR comercialmente disponíveis por um período de 60 minutos após a manipulação ou manipulação com 30 segundos de exposição a uma lâmpada curadora. Os resultados indicaram que cada material comportase de maneira única. Para todos os materiais e condições, o pH alcançado após um período de 60 minutos foi significantemente maior que o valor inicial. A fotoativação aumentou significantemente $\mathrm{opH}$ superficial de dois materiais (Baseline VLC e Vitrebond) quando comparado ao estado não curado. No caso do XR-Ionomer, entretanto, nenhum efeito significante da fotopolimerização sobre o pH superficial foi observado. As consequências clínicas de um baixo pH superficial não são claras, mas pode ser um fator etiológico de sensibilidade pulpar pós-operatória e todo esforço deve ser feito para assegurar a efetiva fotopolimerização.

A proposta do estudo realizado por ELIADES \& PALAGHIAS ${ }^{16}$, em 1993, foi de caracterizar o desempenho in vitro de 3 cimentos de ionômero de vidro modificados por resina para forramento. Os forros contendo 2-HEMA 
mostraram resistência à compressão, resistência à tração diametral e dureza Vickers significantemente maiores que os forros sem 2-HEMA. A reação ácidobase foi atrasada após a fotopolimerização em todos os materiais testados. Foram encontradas correlações significantes entre as propriedades do forro e diferenças na extensão da conversão das superfícies de topo e base, bem como entre a fenda marginal na interface dentina/forro e a resistência adesiva com dentina e compósito. Esta correlação sugere as seguintes hipóteses para o mau comportamento: incorporação de ácido polialcenóico de baixo peso molecular ou agentes aceleradores para aumentar a união inicial do carboxilato; aumento na trasmitância total e redução em difusa reflectância para aumentar a conversão em profundidade; e reforço da interface dentina/forro para prevenir a formação da fenda.

HOTTA \& HIRUKAWA ${ }^{22}$, em 1994, realizaram um estudo comparativo da dureza Knoop e desgaste por escovação de agentes de proteção superficiais aplicados à superfície do cimento de ionômero de vidro. O teste de microdureza foi feito com uma carga de 25 gramas durante 30 segundos nos períodos de 10 minutos, 24 e 48 horas e 7 dias. Os resultados mostraram que o agente de glaze fotopolimerizado provou ser significantemente mais duro que outros agentes. O agente adesivo Occlusin foi removido pela abrasão comparativamente rápida, entretanto, o Bellfeel Brightener foi significantemente mais resistente à abrasão. As análises da dureza superficial e observações do microscópio eletrônico de varredura das superfícies escovadas das amostras sugeriram que o Bellfeel Brightener foi efetivo como material de glaze para restaurações de cimento de ionômero de vidro.

LI, BEETZEN e SUNDSTROM ${ }^{33}$, em 1995, estudaram as propriedades mecânicas dos cimentos de ionômero de vidro modificados por resina. Neste estudo avaliaram a resistência à traçao diametral, resistência à fratura, microdureza e espectroscopia de infra-vermelho com o objetivo de investigar a resistência e comportamento da presa de 3 cimentos de ionômero de vidro modificados por resina, o Photac-fil Aplicap (ESPE), Vitremer (3M) e K71 (DeTrey), um cimento de ionômero de vidro convencional, Fuji ionomer type II (GC), e 1 compósito, P50 (3M). Para a realização do teste de microdureza utilizaram um microdurômetro com a ponta do tipo Vickers, carga de 100 gramas e tempo de 15 segundos. A espectroscopia foi realizada com um 
espectroscópio FT-IR. Os resultados obtidos em relação à microdureza foram similares entre os CIVMR e os compósitos e significantemente maiores que dos CIV convencionais. O infra-vermelho mostrou que o Photac-fil Aplicap tem características dos espectros de um Ester, tais como um pico forte nas ligações $\mathrm{C}=\mathrm{O}\left(1720 \mathrm{~cm}^{-1}\right), \mathrm{C}-\mathrm{O}\left(1180 \mathrm{~cm}^{-1}\right)$ e também C-H $\left(2865-2975 \mathrm{~cm}^{-1}\right)$. A absorção do $\mathrm{C}=\mathrm{C}\left(1636 \mathrm{~cm}^{-1}\right)$ pode ser vista em todos os materiais. Entretanto, o $\mathrm{C}=\mathrm{C}$ $\left(1606 \mathrm{~cm}^{-1}\right)$ referente a um anel aromático não existe em nenhum desses materiais. Os autores concluíram que o desenvolvimento do CIV é possível, mas os compósitos também têm limitações em resistência.

A cura de todos os cimentos de ionômero de vidro modificados por resina depende em algum grau da ativação de luz. Entretanto, os materiais têm mecanismos de cura química que poderiam aumentar a profundidade de cura. Então, em 1995, um estudo foi conduzido por SWIFT JR et al ${ }^{47}$. para avaliar a profundidade de cura de cinco CIVMR (Fuji II LC, Geristore, Photac-fil, Variglass e Vitremer. Cinco espécimes de cada material foram confeccionados em moldes de Teflon. Cada material foi foto-ativado por 40 segundos e a microdureza Knoop, com carga de 10 gramas e 12 segundos, foi mensurada a $1 \mathrm{~mm}$ abaixo da superfície de cada espécime nos períodos de 10 minutos, 1 dia e 7 dias após a fotopolimerização. Aos 10 minutos as camadas do topo (0$1 \mathrm{~mm}$ ) de cada material se mostraram significantemente mais duras que as camadas mais profundas (4-5 mm). Todavia, em 1 dia, os cimentos Geristore, Photac fil, Vitremer e Fuji II LC tinham durezas uniformes e independentes das profundidades. Em contrapartida, a dureza do Variglass diminuiu significantemente com a profundidade passando de 43,3KHM na superfície de topo para 11,3 a 5KHM. Com 7 dias, os cimentos Photac fil, Vitremer e Fuji II LC tinham durezas mais uniformes independente das profundidades. Imediatamente após a fotoativação, as camadas superiores de cada material estavam mais duras que as camadas mais profundas, mas o grau de cura em camadas mais profundas melhorou com o tempo. O Variglass foi o único material em que a dureza da base e do topo foi significantemente diferente em 1 dia, sugerindo que o Variglass tem (tem ou sofre?) menor efeito do mecanismo de cura química que os outros materiais testados.

Considerando que a reação de presa dos cimentos de ionômero de vidro é iniciada pela fotopolimerização, ocorre liberação de calor pela reação 
exotérmica. Com isso, KANCHANAVASITA, PEARSON e ANSTICE ${ }^{28}$, em 1996, investigaram o aumento da temperatura de dois cimentos de ionômero de vidro para base/forro (Vitrebond e Fuji Lining) e dois para restauração (Fuji II LC e Vitremer), e os efeitos da espessura do espécime, do tempo de exposição e temperatura do ambiente, assim como, da difusibilidade térmica dos cimentos. As temperaturas foram medidas utilizando um dispostivo termoelétrico. Os tempos de exposição para a cura dos espécimes variou de 15 a 60 segundos. A temperatura aumentou devido à reação de polimerização no campo de 11 a $26^{\circ} \mathrm{C}$ para os cimentos de base/forro e de 8 a $17^{\circ} \mathrm{C}$ para os materiais restauradores. O aumento da espessura reduziu o aumento da temperatura somente quando inadequados tempos de exposição foram utilizados. A difusibilidade térmica mostrou menores valores para os cimentos de base/forro.

KAKABOURA, ELIADES e PALAGHIAS ${ }^{26}$, em 1996, avaliaram o mecanismo de presa dos CIVMR de dupla cura (Fuji II LC, Photac-Fil, Variglass) e tripla cura (Vitremer) tanto na reação ácido-base como na resinosa. Para isso, cada cimento foi dividido em 4 grupos. No grupo $A$, os cimentos foram apenas manipulados; nos grupos B e C, foram manipulados, irradiados por 60 segundos e depois armazenados por 20 minutos em ambiente seco e escuro, sendo que os espécimes do grupo B foram examinados no topo e os do grupo $C$ examinados na base; no grupo D, os cimentos foram manipulados, armazenados por 20 minutos em ambiente seco e escuro e depois irradiados por 60 segundos. Foi utilizado um espectroscópio FT-IR para determinar a eficiência de cura dos materiais imediatamente após a polimerização, o efeito da irradiação após 20 minutos de armazenagem na eficácia da cura e a extensão da reação ácido-base nos materiais irradiados e não irradiados. Foi constatado que a eficácia de cura imediatamente após a irradiação foi determinada pela porcentagem de dupla ligação $C=C\left(1638 \mathrm{~cm}^{-1}\right)$, que variou entre $33-50 \%$ para estes materiais e o pico da ligação $C=0$ $\left(1712 \mathrm{~cm}^{-1}\right)$ foi usado como frequência de referência. A irradiação após 20 minutos de armazenamento reduziu significantemente a eficiência de cura em todos os produtos, exceto no Variglass, que não mostrou reação ácido-base sob as condições testadas. Espécimes não irradiados após a armazenagem demonstraram maiores concentrações de carboxilatos comparados aos seus 
análogos irradiados. Espécimes não irradiados do Vitremer tiveram as maiores concentrações de carboxilatos e eficácia de cura de 50\% de monômeros residuais. Isto levou à conclusão de que a polimerização pareceu reduzir grandemente a reação ácido-base durante os estágios iniciais da presa do CIVMR. A taxa de formação de radicais livres é menor nos materiais de polimerização química, mas produz adequada conversão e alta taxa de sal de carboxilato.

É sabido que monômeros liberados pelos compósitos e adesivos em meio aquoso são difundidos através da dentina e que tais resinas podem ter efeito citotóxico direto nas células pulpares in vivo, além de causarem respostas alérgicas aos profissionais e pacientes. O estudo de HAMID et al. ${ }^{20}$, em 1998, teve o objetivo de identificar e quantificar qualquer componente liberado por sete CIVMRs e compômeros fotocurados disponíveis comercialmente. As amostras dos materiais foram armazenadas em água destilada por um período de 30 dias. Todas as amostras foram analisadas por um cromatógrafo líquido de alto desempenho. Somente o componente Hidroxietil Metacrilato (HEMA) foi encontrado. Análises da difusão do HEMA através da dentina mostraram um relativo movimento dentro do espaço pulpar durante o primeiro dia, com exponencial declínio mais tarde. Os resultados mostraram que o HEMA foi liberado de todos os CIVRM estudados e do compômero, ambos diretamente dentro da água e através da dentina. Esta liberação pode ser relevante tanto pelo risco de respostas pulpares adversas nos pacientes quanto pelo risco de alergia dos profissionais e pacientes.

No mesmo ano de 1998, DE GEE et al. ${ }^{15}$ investigaram os efeitos na integridade estrutural do Fuji II LC, Photac-Fil e Vitremer pelo atraso ou omissão da fotoativação comparados com a integridade quando a fotoativação é realizada 2 minutos após a manipulação. O estudo foi realizado com o teste de desgaste de 3 corpos, conduzido 8 horas após a preparação das amostras, para estabelecer a integridade na fase inicial do endurecimento, bem como após uma semana e 4 meses, acompanhando o processo de maturação. Quando a fotoativação foi atrasada por uma hora, a integridade estrutural do Fuji II LC e do Photac-Fil melhoraram significantemente nos estágios iniciais de presa. No caso do Vitremer, uma hora de atraso na fotoativação representou significante diminuição da intregidade, que declinou mais quando a fotoativação 
foi omitida. O Fuji II LC não foi afetado pela omissão da fotoativação, enquanto o Photac-Fil foi marcadamente enfraquecido. Após 4 meses de envelhecimento, os cimentos alcaçaram integridade estrutural igual independente do modo de polimerização, com exceção do Vitremer não polimerizado que manteve os menores valores. A integridade estrutural dos cimentos de ionômero de vidro modificados por resina beneficia-se da integração química do polialcenoato ao poliHEMA (ligação cruzada), como no Vitremer. Melhorias na integridade estrutural, na fase inicial dos cimentos com um emaranhado mecânico das matrizes, requerem uma reação ácido-base em uma porção considerável da qual possa tomar lugar antes da ativação da polimerização do HEMA.

Ainda em 1998, GEURSTSEN ${ }^{19}$, percebendo o aumento no número de cavidades na dentição primária e permanente restauradas com materiais resinosos e ionoméricos, estudou as substâncias liberadas por esses materiais. A maioria das substâncias orgânicas pode ser extraída da resina polimerizada por solventes orgânicos como o metanol e etanol. Além disso, em muitos estudos, o co-monômero TEG-DMA tem sido identificado como o principal componente liberado das resinas compostas polimerizadas em meio aquoso. Entretanto, pequenas quantidades dos monômeros (BIS-GMA, UDMA) e outros co-monômeros, bem como aditivos, podem ser também liberadas na água. Pouca informação tem sido publicada sobre substâncias liberadas de vários tipos de CIV, exceto a liberação de flúor. Estudos de erosão têm revelado que existe uma considerável desintegração dos cimentos de ionômero de vidro em baixos valores de $\mathrm{pH}$. Entretanto, a natureza de substâncias erosionadas ainda não está clara e a informação presente nesta revisão indica que estudos que qualifiquem e quantifiquem as substâncias segregadas destes materiais são necessários. Com isso, foi possível concluir que quantidades extraíveis de monômeros residuais e aditivos podem ser minimizadas pela redução da mobilidade entre o material polimerizado por um maior grau de conversão ou pela aplicação de menos monômeros solúveis a água.

Cimentos de ionômero de vidro modificados por resina eram materiais recentes em 1999, quando WAN, YAP e HASTINGS ${ }^{52}$ avaliaram a reação ácido-base na presença de componentes resinosos. Os CIVMR são materiais que combinam as propriedades desejáveis dos cimentos de ionômero de vidro 
convencionais com as das resinas compostas. Entretanto, a presença da resina pode retardar a reação ácido-base do componente ionomérico. Para investigar este assunto, o método de espectroscopia FT-IR foi usado para monitorar a complexa reação ácido-base no CIVMR (Fuji II LC) e no CIV convencional (Fuji II CAP). Este método envolve a subtração do espectro da resina do Fuji II LC e subsequente aplicação de uma linha base para obter o platô de absorbância (área) no campo do comprimento de onda de 1685 a $1510 \mathrm{~cm}^{-1}$ (carboxil complexo) para o campo de 1750 a $1685 \mathrm{~cm}^{-1}$ (carboxil livre). Este estudo demonstrou evidência de uma reação ácido-base para o CIVMR durante 168 horas após a manipulação. Em contrapartida, a reação do CIV convencional terminou essencialmente em 24 horas.

PALMER, ANSTICE e PEARSON ${ }^{38}$, em 1999, investigaram os efeitos do grau de polimerização e maturação dos espécimes na liberação de HEMA de 4 cimentos de ionômero de vidro modificados por resina. Os materiais foram fotoativados de acordo com as recomendações dos fabricantes, ou não foram fotoativados. Alguns, ainda, foram sub ou sobreirradiados. Os espécimes foram armazenados para maturação por 10 e 40 minutos e 24 horas. O HEMA liberado foi determinado pela sua concentração na água, por cromatografia. A presa sem irradiação do Vitremer, Fuji II LC e Fuji Lining LC em menos de 6 minutos e a liberação de HEMA foi baixa. O Vitrebond levou 15 minutos e a liberação do HEMA foi alta, indicando que esse material tem somente presa pela reação ácido-base, quando não é fotoativado. Liberação de HEMA dos fotoativados Vitremer e Vitrebond não foi afetada pela sub ou sobre fotoativação, mas a liberação do Fuji II LC foi reduzida pela sobre-fotoativação e o Fuji Lining LC causou um significante aumento na liberação do HEMA, quando fotoativado por menos tempo. Tempos de maturação dos espécimes de 10 minutos, ou mais, têm pouco efeito na medida de liberação do HEMA. Todos os materiais liberaram HEMA dentro da solução de armazenagem. Na ordem de minimizar a liberação de HEMA, os CIVMRs devem sempre ser fotoativados por pelo menos o tempo recomendado pelo fabricante a uma espessura não maior que o máximo recomendado.

SCHUSTER, CAUGHMAN e RUEGGEBERG ${ }^{43}$, em 2000, estudaram os efeitos do HEMA sobre as mudanças no metabolismo fosfolipídico da células. O HEMA, um comum componente em agentes adesivos dentários, pode 
produzir mudanças em lipídios e levar à formação de fosfatidiletileno glicol (PtEG). Células expostas ao metacrilato podem produzir citotoxicidade ou outras mudanças metabólicas. O HEMA prontamente se difunde pela dentina a uma taxa dependente da espessura dentinária, concentração de HEMA e pressão. O estudo mostrou também que, mesmo na ausência de citotoxicidade, o HEMA pode causar significante alteração celular, tal como alterar o metabolismo e o crescimento. Portanto, os efeitos dos componentes resinosos nos tecidos celulares deveria ser considerado mesmo quando em concentrações consideradas não citotóxicas.

Em 2001, IMAZATO et al. $^{24}$ compararam os resultados do DTA (Differential Thermal Analysis) e do FT-IR e avaliaram o possível uso do DTA. Por meio de uma resina experimental contendo $\mathrm{SiO}_{2}$ como carga e TEGDMA (irradiadas por 60 segundos) e 3 compósitos contendo partículas híbridas ou pré-polimerizadas (irradiados por 20 ou 60 segundos), o grau de conversão de cada compósito com 60 segundos de irradiação foi determinado pelos dois métodos. Para o DTA e o FT-IR, o grau de conversão de compósitos experimentais aumentou com a proporção do aumento do TEGDMA, embora o DTA tenha mostrado valores de 3-10\% maiores que o FT-IR. Já para os compósitos que contêm partículas híbridas, os valores de 20 segundos de ativação entre os métodos não foram significantes. Maior tempo de irradiação resultou em maior grau de conversão para os 2 métodos e o DTA mostrou valores de $5-7 \%$ maiores que do FT-IR. Os autores puderam concluir que os valores do grau de conversão determinado por ambos os métodos mostrou boa concordância para a maioria dos materiais e que o DTA pode ser mais utilizado que o FT-IR para medir o grau de conversão de compósitos com partículas de resina pré-polimerizada.

YAP et al. ${ }^{56}$, em 2001, investigaram as propriedades mecânicas (dureza, resistência flexural e resistência à compressão) de um CIVMR (Fuji II LC - GC) e avaliaram também o efeito do aumento da proporção pó/líquido. As medidas foram realizadas após 1, 7 e 30 dias de armazenagem em água destilada a $37^{\circ} \mathrm{C}$. Para a medição da microdureza foi utilizada a ponta do tipo Knoop com uma carga de 500 gramas e um tempo de 15 segundos. Os resultados encontrados mostraram que o máximo das propriedades mecânicas foi atingido após uma semana e uma queda foi observada após 1 mês. As propriedades 
mecânicas foram afetadas pelo aumento da proporção pó/líquido, não sendo recomendado sua alteração.

Por meio da microdureza Vickers, em 2001, KURACHI et al. ${ }^{32}$ compararam a eficácia de cura de uma resina composta fotopolimerizada com LED e lâmpada halógena. As resinas foram fotoativadas por 20, 40, 60, 120 e 180 segundos com cinco tipos de LED e por 40 segundos com a unidade de lâmpada halógena tradicional. As amostras foram fotoativadas em diversas espessuras e a dureza foi avaliada pelo lado não polimerizado (base) com 5 identações para cada amostra e carga de 50 gramas, por 30 segundos. Os resultados encontrados mostraram que todas as amostras curadas pelo LED obtiveram dureza inferior quando comparadas à lâmpada halógena no tempo típico de 40 segundos. O LED composto por 6 lâmpadas foi o mais eficiente entre eles, com uma intensidade de $79 \mathrm{~mW} / \mathrm{cm}^{2}$, enquanto a lâmpada halógena possuía uma intensidade de $475 \mathrm{~mW} / \mathrm{cm}^{2}$. Apesar das diferenças da irradiação, quando comparados com lâmpadas halógenas, os LEDs mostraram ser um instrumento de cura promissor.

Em 2001, CEFALY et al. ${ }^{10}$ analisaram a resistência à tração diametral de 3 cimentos de ionômero de vidro modificados por resina (Vitremer, Fuji II LC e Photac-Fil) e um compômero (Dyract). Os materiais foram testados em intervalos de tempo de 1 hora, 24 horas e 7 dias avaliando seu efeito. Para isso, espécimes de $6 \mathrm{~mm}$ de diâmetro e $3 \mathrm{~mm}$ de altura foram submetidos aos testes em uma máquina de ensaios universais Kratos. Os resultados mostraram que existe aumento da resistência entre 1 hora e 7 dias (Vitremer de 19,22 a 27,29 MPa, Fuji II LC de 23,91 a 28,67 MPa, Phota-Fil de 19,35 a 22,86 MPa e Dyract de 28,83 a 46,95 MPa). Foi observado que a polimerização nestes tipos de materiais ocorre mais lentamente, levando a uma mudança durante uma semana.

Apesar de os cimentos resinosos serem geralmente indicados para cimentação de restaurações cerâmicas, alguns fabricantes de cimentos odontológicos propuseram também o uso do cimento de ionômero de vidro modificado por resina para este fim. Um estudo de BRAGA, CONDON e FERRACANE $^{8}$, em 2002, foi realizado para comparar o desgaste por abrasão e atrição in vitro de 2 cimentos duais e 2 CIVMR, quando colocados entre a cerâmica e o esmalte para simular a margem de uma restauração. O grau de 
conversão das resinas foi medido pelo FT-IR. Os resultados mostraram que não houve diferença significante no desgaste por abrasão e atrição e nem entre os modos de ativação (dual ou auto). No entanto, estudos in vitro apresentam uma fraca correlação entre grau de conversão e desgaste.

BASTING, SERRA e RODRIGUES JR. ${ }^{7}$, em 2002, devido à influência do $\mathrm{pH}$ da saliva e dos alimentos, avaliaram in situ a microdureza de uma resina composta (Z100), dois CIVMR (Fuji II LC e Vitremer) e dois compômeros (Dyract e Freedom) em diferentes tempos de pós-irradiação. As amostras foram presas a um aparelho de acrílico intra-oral (palatal) e utilizados por 24 voluntários pelos tempos de 30 minutos, 1, 2, 4, 8, 24 e 48 horas, e 7, 10, 14, 17 e 21 dias após a polimerização. $O$ teste de microdureza foi realizado com um identador Knoop, com carga de 25 gramas por 5 segundos. Os resultados só mostraram diferença significante após 48 horas. Não houve mudanças significantes nos níveis de microdureza das resinas compostas com o tempo.

Ainda em 2002, YOUNG ${ }^{59}$ investigou a cinética de polimerização e a neutralização ácida dos cimentos de ionômero de vidro modificados por resina por meio de um espectrofotômetro FT-IR. O material usado foi o Fuji II LC, onde foram observadas as mudanças no espectro por um minuto após 20 segundos de irradiação. A comparação com as mudanças espectrais vistas durante a reação de presa do CIV convencional, Fuji IX, mostrou que esta poderia ser provocada pela sorpção de água e/ou neutralização ácida. Qualquer mudança na absorbância devido a reação ácido-base exibiu duas regiões lineares quando ocorrida contra o tempo. Tal comportamento sugere dois separados mecanismos de difusão para a neutralização ácida, a mais rápida cessa em 30 minutos e a outra em 150 minutos após a mistura no Fuji IX e Fuji II LC respectivamente. Estes foram os tempos necessários para toda a água (um requerido componente da reação) na formulação ser utilizada. A taxa inicial de absorbância devido à neutralização ácida mudou 17 vezes mais rapidamente para o Fuji IX em relação ao Fuji II LC. Por 4 dias, entretanto, o total de absorbância muda devido à neutralização ácida para o Fuji IX somente 4 vezes mais rapidamente que no Fuji II LC. Esses resultados ajudam a explicar mudanças nas propriedades dos cimentos ocorridas com o tempo.

Odontoblastos são células pós-mitóticas altamente diferenciadas que, sob condições patológicas tais como lesões e injúrias dentais, podem 
degenerar e ser substituídas por outras células pulpares. ABOUT et al. ${ }^{1}$, em 2002, avaliaram os efeitos dos monômeros sobre a diferenciação do odontoblasto in vitro. Polpas de terceiros molares humanos extraídos foram colocadas em um meio de cultura com beta-glicerofosfato $(2 \mathrm{mM})$ e utilizadas para avaliação dos efeitos do TEGDMA, HEMA, UDMA, e Bis-GMA na diferenciação de fibroblastos pulpares em odontoblastos. O espectrofotômetro FT-IR foi utilizado para detectar a composição mineral e orgânica de nódulos na dentina. Quando os monômeros foram adicionados em concentrações não tóxicas, os efeitos do HEMA e do Bis-GMA foram mais evidentes que do TEGDMA e UDMA sobre as células.

CORRÊA $A^{13}$, em 2003, avaliou o grau de conversão de uma resina fotopolimerizável experimental variando os fotoiniciadores incorporados à resina e as fontes de luz. Para isso, foram utilizados 3 corpos-de-prova para cada condição experimental e o grau de conversão obtido por meio a espectroscopia FT-Raman pela comparação da altura dos sinais relativos à dupla ligação $C=C$ aromática $\left(1609 \mathrm{~cm}^{-1}\right)$ e alifática $\left(1639 \mathrm{~cm}^{-1}\right)$, antes e após a fotoativação. Os resultados mostraram que uma fonte polimerizadora halógena e outra LED apresentaram valores similares na conversão das resinas com canforoquinona.

ANDRZEJEWSKA et al. ${ }^{2}$, em 2003, avaliaram os efeitos da solução aquosa poliácida na fotopolimerização de componentes polimerizáveis (HEMA e TEGDMA) dos CIVMR. Durante a reação de presa, o processo de polimerização e a reação ácido-base afetam um ao outro. A polimerização foi iniciada pelos sistemas co-inicadores canforoquinona e dimetoxi fenilacetofenona e monitorada sob o ar por um calorímetro de varredura diferencial isotérmico. Os resultados encontrados mostraram que a adição de solução aquosa de poliácidos tem um efeito benéfico na polimerização do HEMA e na conversão.

Em 2003, ELLAKURIA et al. ${ }^{17}$ compararam o efeito de 12 meses de armazenagem em água na microdureza superficial Vickers entre os CIV convencionais (Ketac-Fil, Ketac-Molar e Ketac Silver) e CIVMR (Photac-Fil, Fuji II LC e Vitremer). A microdureza foi realizada com carga de 200 gramas por 20 segundos e as medidas foram tomadas em 1,7, 15, 30, 90, 180 e 365 dias. Os resultados demonstraram que existem diferenças na microdureza entre os 
materiais estudados e entre cada material pelo tempo de armazenagem. Os cimentos de ionômero de vidro demonstraram maior microdureza ao longo de todo período do estudo. Os resultados sugerem que a adição de resinas ao CIV pareceu não melhorar a microdureza destes materiais.

O estudo de SOH, YAP e SIOW ${ }^{45}$, em 2003, comparou a efetividade da cura de dois LEDs e três lâmpadas halógenas em diferentes profundidades de cavidade e com diferentes modos de ativação e intensidade. A efetividade foi determinada pela medida da dureza do topo e da base com um identador Knoop com uma carga de 500 gramas em 15 segundos. Para todas as luzes, a efetividade de cura foi diminuída com o aumento da profundidade. A razão da taxa de dureza para todas as luzes curadoras em uma profundidade de $2 \mathrm{~mm}$ foi maior que 0,8 (padrão mínimo aceitável). A 3mm, todas as lâmpadas halógenas produziram taxas acima do padrão, o mesmo não foi encontrado em alguns modos de ativação do LED. Em $4 \mathrm{~mm}$, nenhum atingiu o mínimo necessário. Os resultados levaram à conclusão de que a profundidade de cura associada ao LED é produto e modo dependente.

ASMUSSEM \& PEUTZFELDT ${ }^{6}$, em 2003, investigaram a influência da cura de dois passos de um polímero Bis-GMA/TEGDMA sobre o grau de conversão e sobre a dureza antes e depois de 1 dia de armazenamento no etanol. Para isso, os espécimes foram fotopolimerizados a 25, 50, 100, 200 ou $400 \mathrm{~mW} / \mathrm{cm}^{2}$ por 10, 20 e 40 segundos. A cura final, bem como a cura do grupo controle foi levada a $750 \mathrm{~mW} / \mathrm{cm}^{2}$ por 20 segundos. O grau de conversão foi determinado pela espectroscopia FT-IR usando os picos de absorção de 1640$1610 \mathrm{~cm}^{-1}$ e a dureza pelo teste de dureza Wallace com uma força de $0,98 \mathrm{~N}$ por 1 minuto. O resultado mostrou que, com uma densidade de energia intermediária da pré-polimerização, o grau de conversão foi reduzido quando comparado ao controle. A dureza antes do etanol não foi influenciada pelo modo de fotopolimerização, exceto para o menor. O modo de cura de dois passos resultou em polímeros que, após armazenados em etanol, foram mais amolecidos que o controle. Os polímeros com o mesmo grau de conversão responderam diferentemente à ação de amolecimento do etanol, mostrando que as propriedades mecânicas são insensíveis para medir a conversão final das duplas ligações. 
A lixiviação dos materiais poliméricos pode ter um impacto potencial na biocompatibilidade. Como as informações dos fabricantes sobre a composição dos materiais são frequentemente incompletas, análises dos materiais lixiviados são necessárias para o melhor entendimento sobre a possível toxicicidade desses componentes. Com esse intuito, MICHELSEN et al. ${ }^{34}$, em 2003, identificaram substâncias orgânicas lixiviadas de amostras polimerizadas de duas resinas compostas, um compômero e um cimento de ionômero de vidro modificado por resina. As amostras foram imersas em etanol ou solução de Ringer. As substâncias orgânicas lixiviáveis foram analisadas por cromatografia de massa a gás e a identificação foi confirmada com substâncias referidas, se disponíveis. Entre os componentes detectados estavam os monômeros, comonômeros, iniciadores, estabilizadores, produtos da decomposição e contaminantes. Trinta e duas substâncias foram identificadas e dezessete foram confirmadas com substâncias referidas. Da lixiviação em solução de Ringer identificaram 13 substâncias da Tetric Ceram, 18 da Z250, 21 do Dyract e 6 do Fuji II LC; HEMA e canforoquinona foram encontrados em todas as amostras. A lixiviação com etanol, identificou 12 para a Tetric, 18 para a Z250, 19 para o Dyract e 10 para o Fuji. Existe uma diversidade de substâncias lixiviadas e, mesmo que essas substâncias sejam citotóxicas in vitro, os materiais podem não ser citotóxicos e suas biocompatibilidades, incluindo o potencial alergênico, podem ser diferentes.

YOUNG, RAFEEKA e HOWLETT ${ }^{60}$, em 2004, quantificaram as taxas de polimerização e a neutralização poliácida em vários cimentos de ionômero de vidro, CIVMR e compômeros. Para isso foi utilizado o espectrofotômetro FT-IR com uma resolução de $8 \mathrm{~cm}^{-1}$ e comprimentos de onda de 800 à $1800 \mathrm{~cm}^{-1}$. Os espécimes tinham medidas de 10mm de diâmetro e $1 \mathrm{~mm}$ de profundidade. 150 segundos após o início da polimerização com uma lâmpada halógena com intensidade de $400 \mathrm{~mW} / \mathrm{cm}^{2}$ por 60 segundos, os níveis de polimerização do metacrilato nas menores superfícies dos espécimes foram de 97 e 98\% para os CIVMR (Vitremer e Fuji II LC) e para os compômeros de 47 e 37\% (Compoglass e Dyract). A taxa de neutralização ácida no CIVMR não se completou por 60 horas.

O HEMA tem sido usado como um dois maiores componentes dos cimentos de ionômero de vidro modificados por resina por atuar como solvente 
e como monômero, entretanto tem sido relatado que é citotóxico quando em contato com os tecidos pulpares e odontoblastos. Com isso, XIE et al. ${ }^{55}$, em 2004, estudaram a síntese e caracterização de derivados de acrilato e metacrilato de 6 aminoácidos, usados para formular CIVMR e avaliar suas resistências mecânicas. Para a síntese e caracterização desse materiais foram usadas as espectroscopias FT-IR e ressonância magnética. Foi feita também a avaliação das propriedades mecânicas quanto à viscosidade e resistência à compressão. Os valores dos cimentos preparados contendo derivado aminoácido obtiveram resistências mecânicas significantemente maiores, quando comparados ao cimento Fuji II LC. Este sistema pode eliminar o potencial de citotoxidade nos atuais CIVMR causadas pelo HEMA ou outras moléculas com baixo peso molecular. Assim, os cimentos contendo derivados aminoácidos parecem ser os mais promissores candidatos para avaliações futuras.

O grau de conversão das resinas dentais que contêm metacrilatos é tipicamente determinado pela espectroscopia da medida da queda da banda vinil $(C=C)$ a $1640 \mathrm{~cm}^{-1}$, racionada antes e depois da polimerização, e um padrão interno $1609 \mathrm{~cm}^{-1}$ (anel aromático). GAUTHIER et al. ${ }^{18}$, em 2005, questionaram os métodos padrões existentes para medir a intensidade dos picos das ligações $\mathrm{C}=\mathrm{C}$ e padrão interno pelos espectros FT-IR ou Raman por falharem sob certas circunstâncias na falta de uma base física, sendo puramente baseado nas características espectrais. Eles apresentaram um rigoroso método chamado isomerismo rotacional para determinar a intensidade das bandas do vinil e do anel aromático pelo FT-IR e Raman das misturas de monômeros dentais e compará-los. A acurácia do novo método para medir o grau de conversão foi adequada, e mostrou-se também capaz de ser adaptado para outros tipos de biomateriais, tendo o seu uso mais vasto que os métodos padrões.

YLI-URPO et al. ${ }^{58}$, em 2005, determinaram a resistência compressiva, o módulo de elasticidade e a dureza de superfície Vickers de cimentos de ionômero de vidro convencionais e modificados por resina após a adição de partículas de vidro bioativo. Os espécimes foram imersos em água durante os períodos de 1, 3, 7, 14, 30 e 180 dias antes dos testes mecânicos. Os resultados mostraram, para os testes de resistência à compressão, que com a 
adição do vidro (aumentando a quantidade) a resistência diminuía. Para a microdureza, realizada com uma carga de $0,25 \mathrm{~N}$ por 5 segundos, os cimentos de ionômero de vidro convencionais tiveram uma média 55\% maior que os cimentos de ionômero de vidro modificados, concluindo que a adição do vidro bioativo ao CIV compromete as propriedades do material.

Ainda em 2005, VILJANEN et al. ${ }^{51}$ investigaram o efeito da concentração de iniciador e ativador fotossensíveis sobre o grau de conversão e propriedades flexurais de um co-polímero fotopolimerizável experimental contendo dendrímero. Para a confecção da resina experimental foi misturado $80 \%$ de dendrímero e $20 \%$ de MMA (metil metacrilato) em peso, pois o dendrímero possui alta viscosidade. O iniciador e o ativador usados foram canforoquinona e etil metacrilato dimetilamina, nas concentrações que variaram individualmente de 1-4\%. O grau de conversão foi determinado com um espectroscópio FT-IR utilizando os picos $1637 \mathrm{~cm}^{-1}(C=C)$ e $1720 \mathrm{~cm}^{-1}(C=O)$ numa resolução de $4 \mathrm{~cm}^{-1}$. A resistência e 0 módulo flexurais foram determinados com o "three-point bending test". O maior grau de conversão foi obtido com 2,5\% em peso de iniciador e ativador, a maior resistência flexural com $2,5 \%$ de iniciador e $1 \%$ de ativador e o maior módulo flexural com 1\% de ambos. Com isso, pode-se concluir que o grau de conversão aumentou e a resistência e o módulo flexurais diminuíram com o aumento das concentrações do iniciador e ativador. A maior concentração do iniciador provavelmente inibiu a transmitância dos comprimentos de onda ativos para as profundidades das amostras (efeito do filtro interno), resultando em uma conversão não homogênea e na diminuição das propriedades mecânicas.

Em um estudo de revisão realizado por CASSU \& FELISBERTI ${ }^{9}$, em 2005, foi avaliado o comportamento dinâmico-mecânico e relaxações em polímeros e blendas poliméricas. A análise dinâmico-mecânica (DMA) tem como um dos principais objetivos relacionar as propriedades macroscópicas, tais como as propriedades mecânicas, às relaxações moleculares associadas às mudanças conformacionais e às deformações microscópicas geradas a partir de rearranjos moleculares, e consiste na aplicação de tensões oscilatórias, normalmente senoidais. Isso permite a separação da contribuição elástica e viscosa em materiais viscoelásticos, em função tanto da temperatura quanto do tempo. As relaxações normalmente estão associadas às mudanças 
conformacionais de grupos ou segmentos da cadeia polimérica, resultantes de rotações em torno das ligações químicas. O tempo de relaxação é uma medida da mobilidade das cadeias e depende da estrutura molecular e temperatura. Talvez, um dos efeitos mais importantes dessas relaxações sejam as mudanças de tenacidade ou a alta resistência ao impacto. Portanto, a utilização da técnica dinâmico-mecânica em sistemas poliméricos traz importantes contribuições a respeito das estruturas químicas e morfológicas desses sistemas, sendo possível determinar além das principais relaxações, a transição vítrea, fusão e cristalização.

O teste de difusão de Ágar foi usado com quatro diferentes meios para avaliar a atividade antibacteriana de seis produtos (1 cimento de ionômero de vidro convencional, 2 cimentos de ionômero de vidro modificados por resina, 2 compômeros e 1 resina composta) em Streptoccoccus mutans por VERMEERSCH et al..$^{50}$, em 2005. Suas respectivas atividades antibacterianas foram também comparadas durante e após a presa. A relação entre a acidez do produto e a atividade antibacteriana foi avaliada. Todos os CIV apresentaram propriedades antibacterianas em contraste com os compômeros e resinas compostas que não mostraram efeito antibacteriano algum. $O$ Vitrebond exibiu maior ação antibacteriana, provavelmente devido ao citotóxico fotoiniciador difeniliodocloro (DPICL). Foi observada uma relação direta entre acidez do material e inibição de crescimento de Streptoccoccus mutans.

YAZICl et al. ${ }^{57}$, em 2006, compararam o aumento da temperatura na câmara pulpar com a utilização de 2 lâmpadas halógenas, 1 LED e 1 arco de plasma, durante a polimerização da resina composta. Neste estudo, determinaram também o efeito da espessura remanescente de dentina sobre o aumento de temperatura. Para isso, cavidades classe II foram confeccionadas em molares humanos permanente extraídos, deixando 1 e $2 \mathrm{~mm}$ de dentina remanescente. Um termômetro foi colocado na câmara pulpar e a temperatura iniciou em $37^{\circ} \mathrm{C}$. O tempo de irradiação foi de 40 segundos para as lâmpadas halógenas e LED e de 3 segundos para o arco de plasma e cinco medidas foram tomadas para cada situação experimental. Assim, o aumento de temperatura foi entre $1,4-3,8^{\circ} \mathrm{C}$, sendo a maior temperatura encontrada no uso das lâmpadas halógenas (Ellipar trilight - 3M/ESPE) e a menor para o LED (Ellipar freelight - 3M/ESPE) e que a espessura de dentina remanescente 
influenciou o aumento da temperatura pulpar. Quanto menor for 0 remanescente, maior será o aumento de temperatura.

O uso da fonte de luz de baixa intensidade para polimerização, baseado na tecnologia LED, provê equivalente grau de conversão final com possível fluidez da resina composta, similar ao uso da tecnologia halógena. Ao mesmo tempo, o menor aumento de temperatura na amostra e o mais favorável desenvolvimento da cinética de contração, comparado às lâmpadas halógenas de maior intensidade, pode ajudar na manutenção da adaptação marginal enquanto evita possíveis injúrias técnicas. TARLE et al. ${ }^{48}$, em 2006, analisaram o grau de conversão, o aumento de temperatura e a contração de polimerização de 2 resinas compostas (Tetric Ceram e Filtek Z250) polimerizadas com uma lâmpada halógena usando 3 modos de ativação e um LED. O grau de conversão foi mensurado por meio de um espectrofotômetro FT-IR na superfície e em $2 \mathrm{~mm}$ de profundidade. As amostras irradiadas pela unidade halógena tiveram os seguintes modos: 40 segundos de intensidade de $750 \mathrm{~mW} / \mathrm{cm}^{2}, 40$ segundos de $400 \mathrm{~mW} / \mathrm{cm}^{2}$ e "soft-start" aumentando a intensidade de 150 a $400 \mathrm{~mW} / \mathrm{cm}^{2}$ em 15 segundos e os outros 25 segundos pulsando entre 400 e $750 \mathrm{~mW} / \mathrm{cm}^{2}$ com 2 segundos de intervalos. Com o LED 10 segundos a $50 \mathrm{~mW} / \mathrm{cm}^{2}$ e 30 segundos a $150 \mathrm{~mW} / \mathrm{cm}^{2}$. Um significante aumento na temperatura foi obtido com o uso da lâmpada halógena com alta intensidade. O LED obteve o menor aumento de temperatura quando comparado a todos os modos da halógena. O LED apresentou o menor grau de conversão em $2 \mathrm{~mm}$ de profundidade, sendo o único valor que apresentou diferenças significativas, e menor valor de contração de polimerização.

SOUZA et al. ${ }^{46}$, em 2006, avaliaram os efeitos dos CIVMR atuais aplicados em um meio cultura de células e implantados em tecidos subcutâneos de rato. Os ionômeros testados foram o Rely X luting, Vitremer e Vitrebond todos da 3M/ESPE. As amostras foram imersas num meio de cultura por 24, 48 ou 72 horas. Os extratos de todas as amostras foram aplicados na célula MDPC-23. A outra parte do experimento foi realizada colocando 54 tubos de polietileno preenchidos com os materiais e implantados no tecido subcutâneo dorsal dos ratos. Os resultados obtidos para o primeiro experimento mostraram que o tempo de lixiviação e o material influenciaram significantemente a atividade respiratória da célula. Geralmente os extratos 
obtidos nas 24 horas foram menos citotóxicos que os de 48 e 72 horas de incubação. Vitremer e Rely $X$ Luting não apresentaram citotoxidade no período de 24 horas. Já no segundo experimento, todos os cimentos apresentaram de moderada a intensa reação inflamatória, que diminuiu com o tempo. Os efeitos tóxicos deste tipo de material solúvel dependem da quantidade de componentes liberados no meio aquoso.

ARANHA et al. ${ }^{5}$, em 2006, realizaram um estudo para avaliar in vitro a citotoxicidade dos CIVMR para forro submetidos a diferentes modos de cura e aplicados a um meio de cultura de células. Para isso, foram confeccionados 40 amostras de cada material (Fuji Lining LC e Vitrebond), as quais foram fotopolimerizadas pelo tempo recomendado pelo fabricante (30 segundos), sub-curadas (15 segundos) e sobre-curadas (45 segundos) ou curadas no escuro. A citotoxicidade foi avaliada pelo metabolismo e morfologia celular. $\mathrm{O}$ fuji Lining foi menos citotóxico que o Vitrebond em todas as condições experimentais. Entretanto, a citotoxidade do Fuji Lining foi notavelmente aumentada na ausência de luz enquanto o mesmo não foi observado para o Vitrebond. O tempo de fotopolimerização não influenciou a citotoxicidade de ambos os materiais forradores quando aplicados ao meio de cultura de células. A fotoativação tem um papel importante na redução da citotoxicidade do Fuji Lining. 


\section{PROPOSIÇÃO}

Com base na diversidade de materiais existentes e devido aos poucos trabalhos encontrados na literatura sobre o grau de conversão e microdureza, este estudo propõe avaliar:

- O grau de conversão e a microdureza de dois CIVMRs frente a diferentes formas de polimerização (química e fotoativação por lâmpada halogena e LED) e tempos de armazenamento pelos métodos de espectroscopia FT-IR e microdureza Knoop;

- A eficácia da microdureza Knoop na medição do grau de conversão desses materiais. 


\section{MATERIAL E MÉTODOS}

\subsection{Material}

\subsubsection{Cimentos de lonômero de Vidro Modificado por Resina}

Foram utilizados neste estudo dois cimentos de ionômero de vidro modificados por resina do mesmo fabricante (3M ESPE, St. Paul, MN, USA), um material restaurador Vitremer (VM) e outro, para cimentação, Rely X Luting (RL) (Tabela 4.1).

Tabela 4.1 - Composição dos cimentos de ionômero de vidro modificados por resina

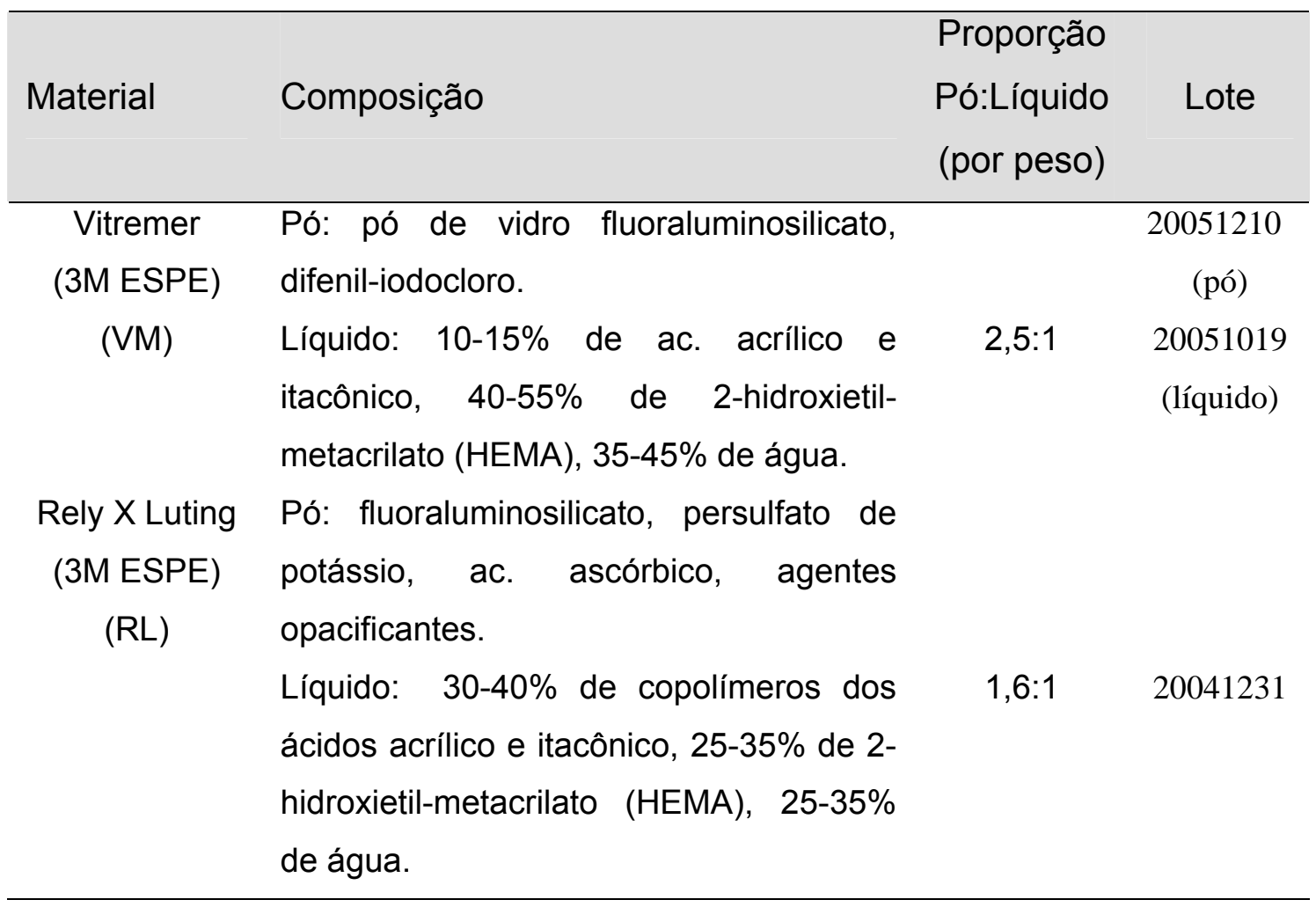




\subsubsection{Unidades fotoativadoras}

Foram testadas duas unidades destinadas à fotoativação dos espécimes dos cimentos, um aparelho de lâmpada halógena (H) (GNATUS) e um com tecnologia de diodos emissores de luz (L) (MMOptics), descritas na Tabela 4.2 e apresentadas na Figura 4.1.

Tabela 4.2 - Características das unidades fotoativadoras

\begin{tabular}{llcccc}
\hline Marca & \multicolumn{1}{c}{ Fabricante } & $\begin{array}{c}\text { Tipo de } \\
\text { Luz }\end{array}$ & $\begin{array}{c}\text { Diâmetro da } \\
\text { ponta } \\
(\mathrm{mm})\end{array}$ & $\begin{array}{c}\text { Potência } \\
(\mathrm{mW})\end{array}$ & $\begin{array}{c}\text { Intensidade } \\
\left(\mathrm{mW} / \mathrm{cm}^{2}\right)\end{array}$ \\
\hline UltraLux & Dabi Atlante & & & & \\
EL & $\begin{array}{l}\text { Ribeirão Preto/SP } \\
\text { Brasil }\end{array}$ & Halógena & 10 & 450 & 573 \\
LEC 1000 & $\begin{array}{l}\text { MMOptics } \\
\text { SãoCarlos/SP } \\
\text { Brasil }\end{array}$ & LED & 8 & 288 & 573 \\
\hline
\end{tabular}

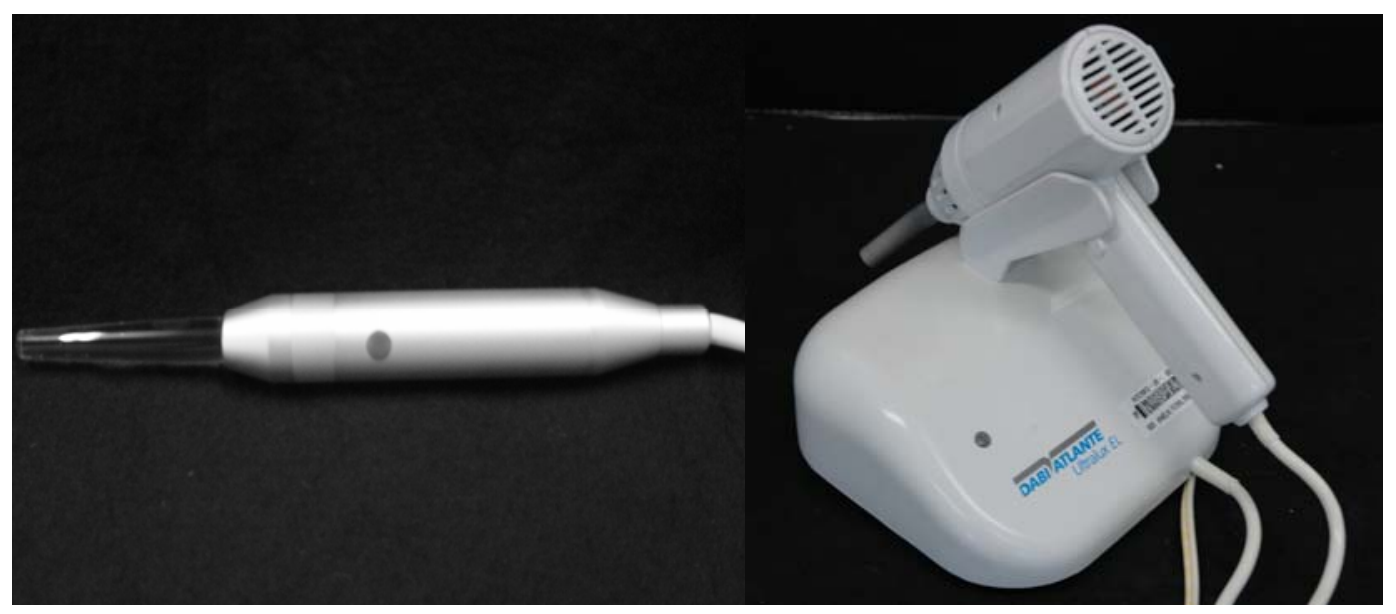

Figura 4.1 - Aparelhos fotopolimerizadores - LED (esquerda) e Halógena (direita) 


\subsubsection{Radiômetro}

As potências das luzes dos aparelhos fotopolimerizadores, dadas na unidade $\mathrm{mW}$, foram aferidas com um potenciômetro calibrado (Field Master, Coherent, USA), antes da confecção dos espécimes.

\subsubsection{Material para polimento}

O polimento dos espécimes, necessário para o teste de microdureza, foi realizado na Politriz Metalográfica (APL 4, Arotec, Cotia, SP) com sistema de polimento múltiplo capaz de realizar o polimento automático de 6 corpos de prova (Figura 4.2). Este procedimento foi feito com a sequência de lixas de silicone carbide de granulação 320, 600 e 1200 (Extec Corp.). Para evitar a interferência dos grãos das lixas anteriores, os espécimes foram submetidos à limpeza no aparelho de ultra-som Ultra Sonic Cleaner 750 (Unique Ind. e Com. de Produtos Eletrônicos Ltda., São Paulo, SP).

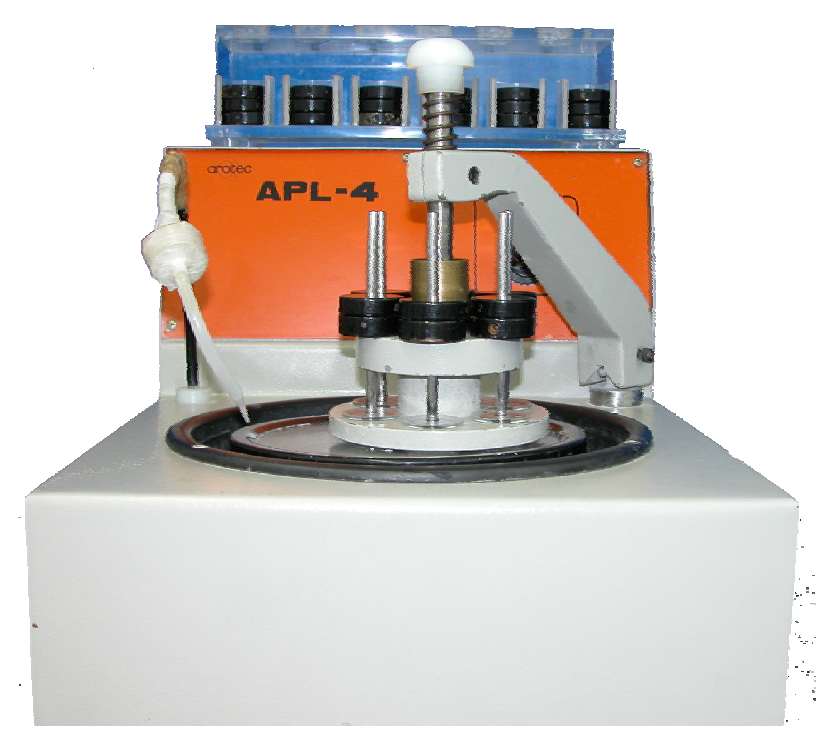

Figura 4.2 - Politriz Metalográfica 


\subsubsection{Estufa bacteriológica}

Os espécimes foram mantidos em estufa (FANEM LTDA - SP) à temperatura constante de $37^{\circ} \mathrm{C}$ e em ambiente escuro durante os intervalos de tempo deste estudo.

\subsubsection{Balança analítica}

A balança analítica $\mathrm{MARTE}^{\circledR}$ foi utilizada para pesagem do pó e do líquido dos cimentos de ionômero de vidro com intuito de utilizar a proporção por peso recomendada pelo fabricante.

\subsubsection{Espectrofotômetro}

Para as medidas dos espectros de emissão das fontes de luz utilizou-se um espectrofotômetro constituído de um monocromador controlado por computador (SPEX).

\subsubsection{Espectrofotômetro FT-IR}

O grau de conversão foi medido por meio da verificação dos picos de absorbância das duplas ligações de carbono alifáticas $\left(1638 \mathrm{~cm}^{-1}\right)$ e carbonooxigênio $\left(1720 \mathrm{~cm}^{-1}\right)$ captados pelo espectrofotômetro FT-IR (Bomen - modelo MB - 102, Quebec - Canadá) (Figura 4.3).

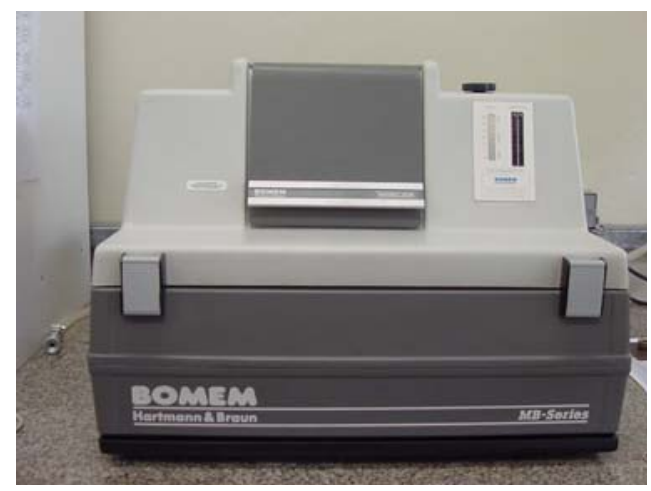

Figura 4.3 - Espectrofotômetro FT-IR BOMEM 


\subsubsection{Microdurômetro}

Para a análise da microdureza dos espécimes foi utilizado um microdurômetro (HMV-2000 Shimadzu Corporation, Japan), com um penetrador diamantado piramidal, tipo KNOOP, acoplado a um microcomputador e um "software" específico para a análise das imagens (Cams-Win-New Age Industries/ USA) (Figuras 4.4 e 4.5).

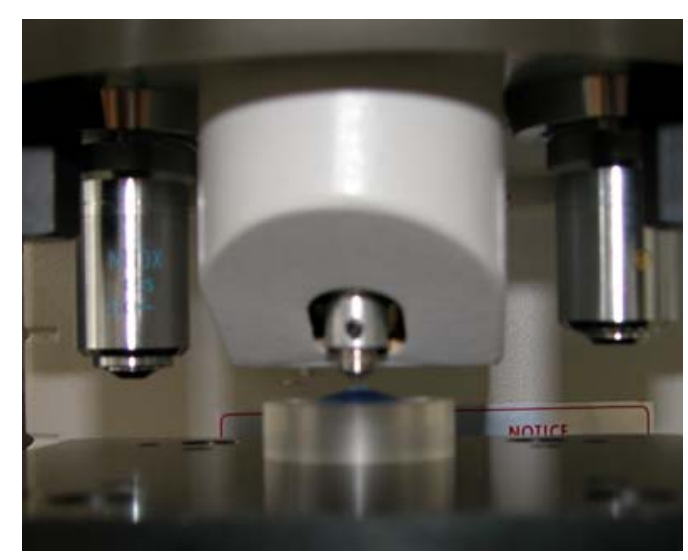

Figura 4.4 - Penetrador Knoop

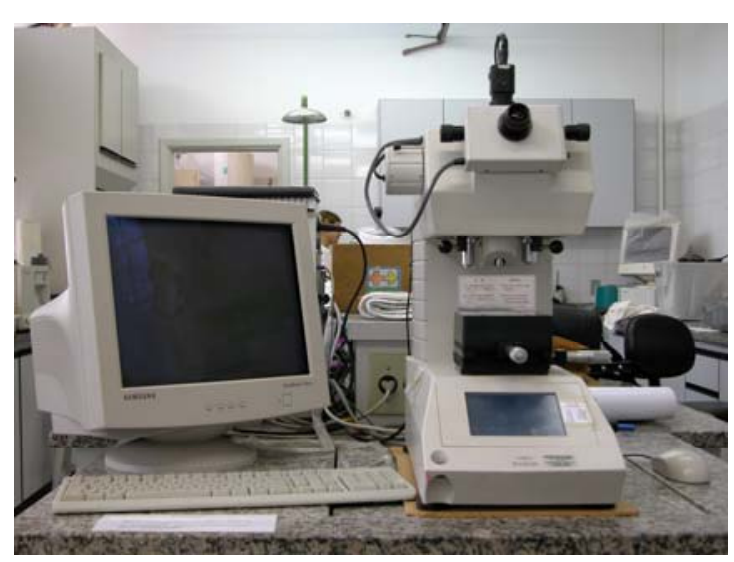

Figura 4.5 - Microdurômetro

\subsection{Método}

Em um primeiro momento, antes da confecção dos espécimes, os materiais foram divididos em 3 grupos e cada grupo subdividodo em 8 de acordo com os intervalos de tempo testados (6 horas, 1, 2, 3, 5, 7, 11 e 14 dias) (Tabela 4.3). Para ambos os métodos, as lâmpadas foram igualadas na sua intensidade. A partir do valor da potência da lâmpada halógena dada pelo radiômetro, foi calculada a intensidade necessária para o aparelho LED, uma vez que este aparelho permite realizar essa alteração. Portanto, foi utilizada a seguinte equação:

$$
\text { Intensidade }(\mathrm{I})=\frac{\text { Potência }(\mathrm{P})}{\text { Área }(\mathrm{A})}
$$

Sendo a área a ser calculada a de um circulo, a equação será então: 


$$
\frac{I=P}{(P i) r^{2}}
$$

Com a potência aferida da lâmpada halógena de $450 \mathrm{~mW}$ e a ponta com $1 \mathrm{~cm}$ de diâmetro, a intensidade calculada foi de $573 \mathrm{~mW} / \mathrm{cm}^{2}$. Para o LED, com a intensidade de $573 \mathrm{~mW} / \mathrm{cm}^{2}$, o valor da potência foi de $288 \mathrm{~mW}$.

Tabela 4.3 - Divisão dos grupos e suas siglas

Grupo Sigla (para cada intervalo de tempo)

Rely X Luting (RL) RL6h, RL1, RL2, RL3, RL5, RL7, RL11, RL14

(autopolimerizável)

Vitremer (VTH)

VTH6h, VTH1, VTH2, VTH3, VTH5, VTH7, VTH11, VTH14

(Lâmpada Halogêna)

Vitremer (VTL)

VTL6h, VTH1, VTH2, VTH3, VTH5, VTH7, VTH11, VTH14

(Lâmpada LED)

\subsubsection{Confeção dos espécimes}

Para a confecção dos espécimes para a avaliação do grau de convenção foi utilizada uma matriz metálica de aço inoxidável com dimensões internas de $1 \mathrm{~mm}$ de profundidade e $5 \mathrm{~mm}$ de diâmetro. Para avaliar a dureza Knoop, os espécimes foram confeccionados em uma matriz com dimensões de $1 \mathrm{~mm}$ de profundidade e $8 \mathrm{~mm}$ de diâmetro, sendo possível a utilização do mesmo espécime em todas as medidas.

Primeiramente o pó e o líquido dos cimentos de ionômero de vidro foram pesados com a utilização da balança analítica. Para o cimento Rely $X$ Luting foi pesado $0,05 \mathrm{~g}$ de pó e $0,032 \mathrm{~g}$ de líquido (proporção pó:líquido de 1,6 por peso) e todo o pó foi incorporado ao líquido durante 30 segundos. Para o Vitremer foi pesado $0,125 \mathrm{~g}$ de pó e $0,05 \mathrm{~g}$ de líquido (proporção pó:líquido de 2,5 por peso). 
O Vitremer foi manipulado acrescentando todo o pó ao líquido durante 45 segundos e, em seguida, fotopolimerizado por 40 segundos.

O cimento foi inserido nas matrizes posicionadas sobre uma placa de vidro. Após a inserção, foi colocada uma tira de poliéster sobre os cimentos e uma outra placa de vidro sobre eles. Para o Rely X Luting, foi aguardado um tempo de 20 minutos para a remoção dos espécimes da matriz. Para o Vitremer, a placa de vidro foi removida em seguida à homogeneização do material dentro da matriz e a fotoativação foi feita por 40 segundos. Os espécimes, após sua confecção, foram inseridos em tubos eppendorf colocados dentro de um recipiente seco e escuro, armazenados em uma estufa na temperatura de $37^{\circ} \mathrm{C}$ até o momento do teste.

Os aparelhos fotopolimerizadores foram fixados em uma haste para que fosse mantida a mesma distância entre a luz e os espécimes.

\subsubsection{Avaliação do Grau de Conversão (GC)}

Em cada situação experimental foram confeccionadas três espécimes para cada intervalo de tempo, portanto, 72 espécimes foram confeccionados no total.

As amostras citadas no item anterior foram removidas da estufa de acordo com os períodos experimentais, colocadas no pastilhador e levadas a uma prensa, onde receberam uma carga de 10 toneladas por 10 segundos (figura 4.6). Em seguida, foram trituradas, ao pó, em um gral e pistilo de ágata (Figura 4.7). Com a obtenção do pó, $5 \mathrm{mg}$ do material e $100 \mathrm{mg}$ de brometo de potássio $(\mathrm{KBr})$ foram pesados na balança (Figuras 4.8 e 4.9). Na proporção de $1 / 20$ os dois foram misturados. O KBr um sal altamente purificado é misturado ao material por ser uma substância inerte ao infravermelho (transparente ao infravermelho), não introduzindo nenhuma linha no espectro da amostra. A mistura resultante foi levada ao pastilhador e este conjunto levado à prensa, com uma carga de 10 toneladas durante 1 minuto (Figura 4.10). Desta forma as pastilhas foram confeccionadas com a espessura mais fina possível (aproximadamente $40 \mu \mathrm{m}$ ) com $10 \mathrm{~mm}$ de diâmetro, maior que o diâmetro do guia da luz, necessário para ocorrer a leitura (Figuras 4.11 e 4.12). As pastilhas foram levadas ao espectrofotômetro utilizando o método infravermelho com 
transformada de Fourier (FT-IR), o qual emite um feixe infravermelho que passa através do espécime excitando as moléculas do material produzindo o espectro infravermelho.

As vibrações específicas das ligações químicas da molécula foram captadas por um detector sensível e os dados armazenados no computador e processados em um "software" para tratamento dos dados espectrais.

O aparelho utilizado tem uma resolução de $4 \mathrm{~cm}^{-1}$, com 32 varreduras de cada espectro, e registra espectros entre os limites de $4000 \mathrm{~cm}^{-1}$ (por convenção) a $400 \mathrm{~cm}^{-1}$ (definido pelo instrumento).

Os espectros infravermelhos dos materiais captados pelo computador demonstrados em gráfico foram calculados utilizando as bandas de absorção da ligação dupla carbono-carbono alifática $\left(C=C, 1638 \mathrm{~cm}^{-1}\right)$ e a ligação dupla carbono-oxigênio $\left(\mathrm{C}=\mathrm{O}, 1712 \mathrm{~cm}^{-1}\right)$ (Figura 4.13). Esse procedimento foi realizado nos espécimes polimerizados nos tempos pré-determinados e em espécimes não polimerizados para que se pudesse servir como base de cálculo por meio da equação:

$$
G C(\%)=\left(1-\left\{\frac{C=C \text { curada }}{\frac{C=O \text { curada }}{C=C \text { não curada }}}\right\}\right) \times 100
$$

\subsubsection{Avaliação da Microdureza Knoop}

Três espécimes para cada tipo de polimerização foram utilizados e os mesmos puderam ser utilizados para todos os intervalos de tempo. Sendo assim, nove espécimes foram confeccionados para o teste de microdureza. As amostras confeccionadas foram fixadas na plataforma metálica da embutidora e o pó de acrílico foi colocado sobre os espécimes. Com a embutidora em função, o acrílico foi misturado à água e, sob pressão, foi formado um disco de acrílico cristal (30mm de diâmetro por $5 \mathrm{~mm}$ de espessura) com os espécimes fixados e com uma superfície exposta (Figura 4.14). O conjunto (disco/cimento) foi adaptado em uma Politriz Metalográfica (APL 4, Arotec, Cotia, SP), permitindo o paralelismo entre as superfícies polidas e a base de acrílico onde 
foram fixados os espécimes (Figura 4.2). Para a planificação, foi utilizada uma sequência de lixas iniciando pela lixa de silicone carbide de granulação 320 , com refrigeração com água deionizada. A politriz foi acionada em baixa velocidade, com 2 pesos padrão de $86 \mathrm{~g}$, durante aproximadamente 2 minutos, até se alcançar a lisura de superfície desejada. Na sequência, o conjunto foi desgastado com uma lixa de silicone carbide de granulação 600, com refrigeração com água deionizada, durante 20 segundos, com 2 pesos padrão de $86 \mathrm{~g}$, em velocidade baixa. Em seguida, foi feito o polimento dos cimentos com lixa silicone carbide de granulação 1200, com refrigeração com água deionizada, durante 40 segundos, com 2 pesos, em velocidade baixa. Para finalizar, foi utilizado um feltro umedecido com uma suspensão de diamante de $1 \mu \mathrm{m}$ (Buehler), durante 3 minutos, com os mesmos pesos, em velocidade alta.

Para impedir que os grãos das primeiras lixas interferissem na qualidade do polimento das seguintes, entre cada etapa de polimento, o conjunto cimento/disco foi levado a um aparelho de ultra-som Ultra Sonic Cleaner 750 (Unique Ind. e Com. de Produtos Eletrônicos Ltda., São Paulo, SP), com freqüência de $25 \mathrm{KHz}$, durante 2 minutos, com água deionizada. Ao final do polimento, os blocos foram novamente limpos, no mesmo aparelho, por 10 minutos.

Com esses procedimentos realizados, os espécimes obtiveram a superfície polida necessária para a análise da microdureza. Cada espécime foi demarcado em quadrantes e armazenados em água destilada e estufa à $37^{\circ} \mathrm{C}$ até o momento no qual cada segmento foi testado em dois períodos diferentes (quadrante 1: 6 horas e 5dias, quadrante 2: 1 e 7 dias, quadrante 3: 2 e 11 dias e quadrante 4: 3 e 14 dias) (Figura 4.14).

A microdureza superficial dos cimentos foi avaliada utilizando-se um microdurômetro acoplado a um microcomputador e um software específico para a análise das imagens (Cams-Win-New Age Industries/ USA) (FIGURA 4.3). Foi utilizado um penetrador diamantado piramidal, tipo KNOOP, com carga estática de $50 \mathrm{~g}$, aplicada por 30 segundos (Figura 4.4). Em cada corpo

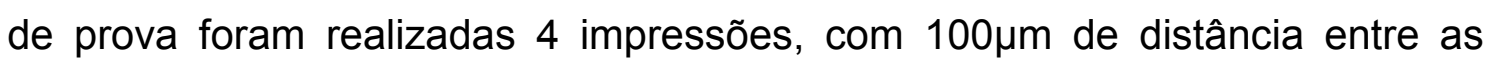
mesmas (Figura 4.15). As impressões foram realizadas nos centros de cada quadrante onde duas marcas pontilhadas que aparecem na tela do computador se sobrepõem aos vértices agudos do losango correspondente à impressão, 
utilizada para determinar o comprimento da maior diagonal (Figura 4.16).

Os resultados da dureza KNOOP foram obtidos automaticamente pelo software através do cálculo da seguinte equação:

$$
\begin{aligned}
& \qquad \mathbf{K H N}=\mathbf{C . c / \mathbf { d } ^ { 2 }} \\
& \mathrm{KHN}=\text { valor de dureza Knoop } \\
& \mathrm{C}(\text { constante })=14,230 \\
& \mathrm{C}=\text { carga } 50 \text { gramas } \\
& \mathrm{d}=\text { comprimento da maior diagonal da impressão }
\end{aligned}
$$

Após a obtenção das quatro impressões, foi realizada uma média com os valores e determinado o número resultante da dureza Knoop para cada espécime.

\subsubsection{Análise Estatística}

Como foram realizados dois métodos diferentes para verificar a capacidade curadora de duas fontes de luz, as análises foram realizadas separadamente.

Os dados da espectrofotometria (grau de conversão) e da microdureza Knoop foram submetidos à análise de variância a dois critérios (tipo de polimerização e tempo) e Teste de Tukey $(\alpha=0,05)$ para contrastes das médias. Em seguida foi realizada a correlação de Pearson para verificar a correlação entre os métodos.

As análises estatísticas foram realizadas por meio do "software" Pacotico (Pacotinho Estatístico). 


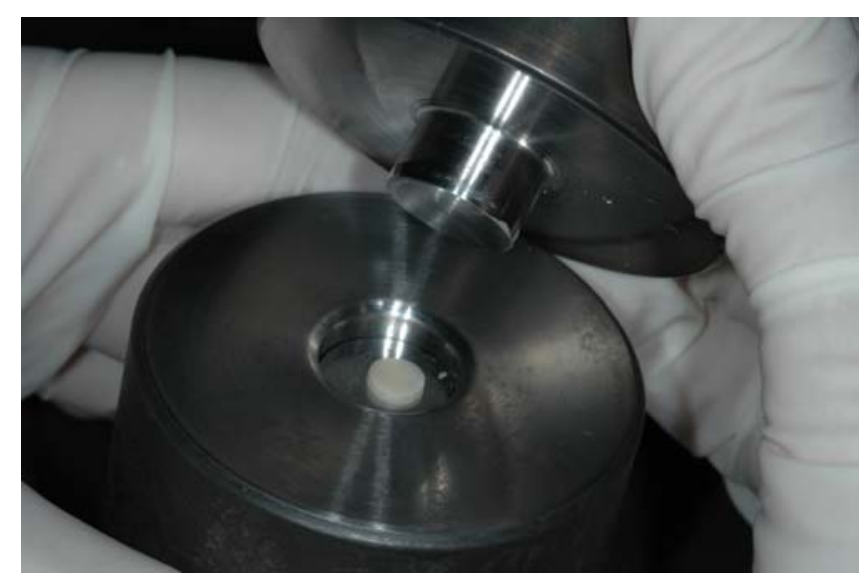

Figura 4.6 - Espécime no pastilhador para ser triturado

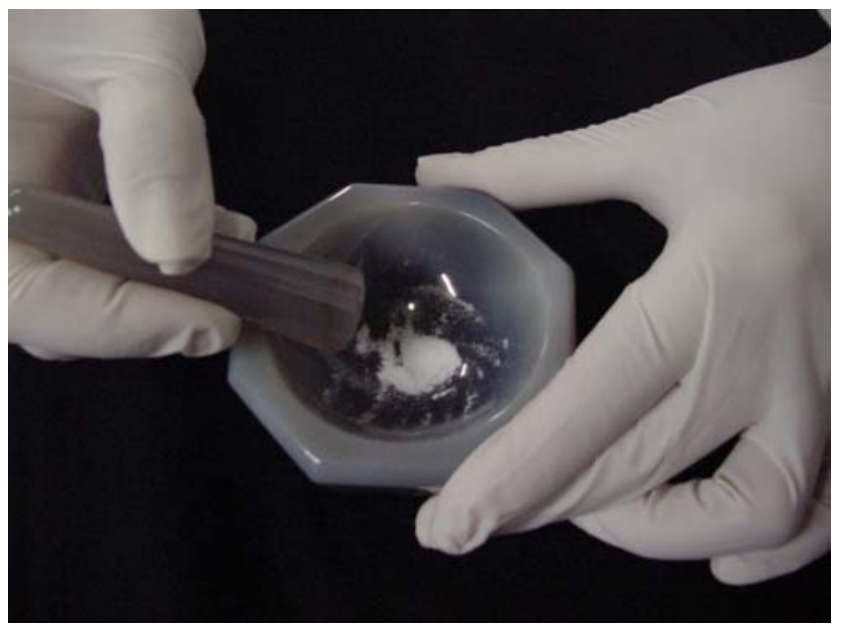

Figura 4.7 - Gral e pistilo de ágata
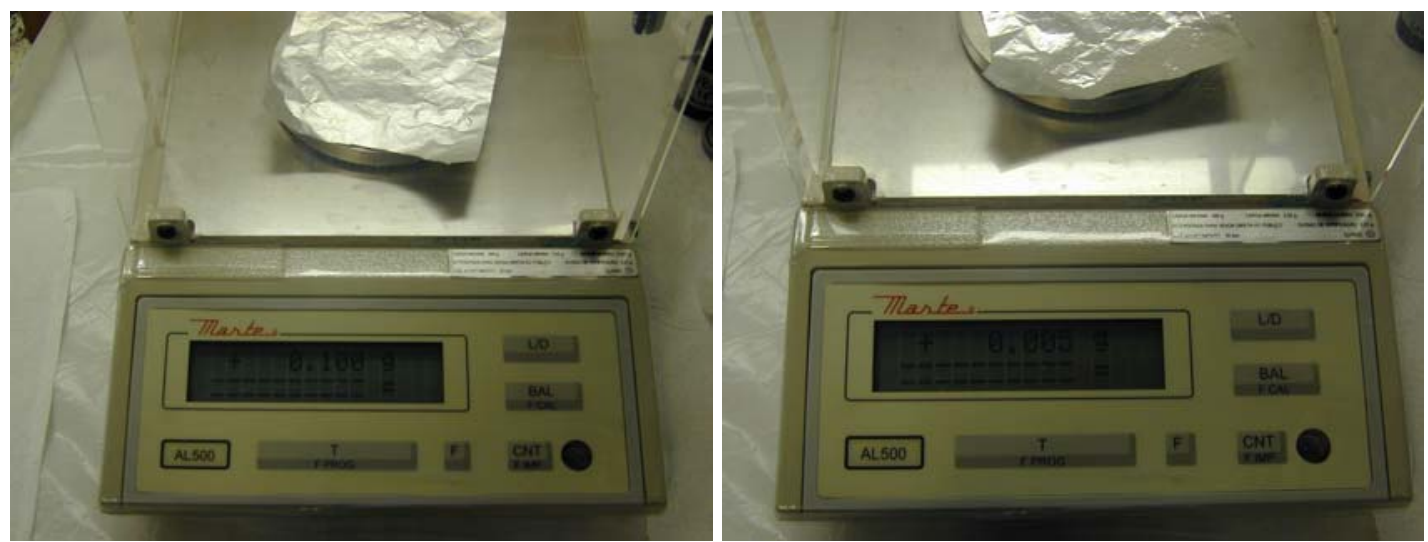

Figura 4.8 e 4.9 - Pesagem do $\mathrm{KBr}$ e do cimento 


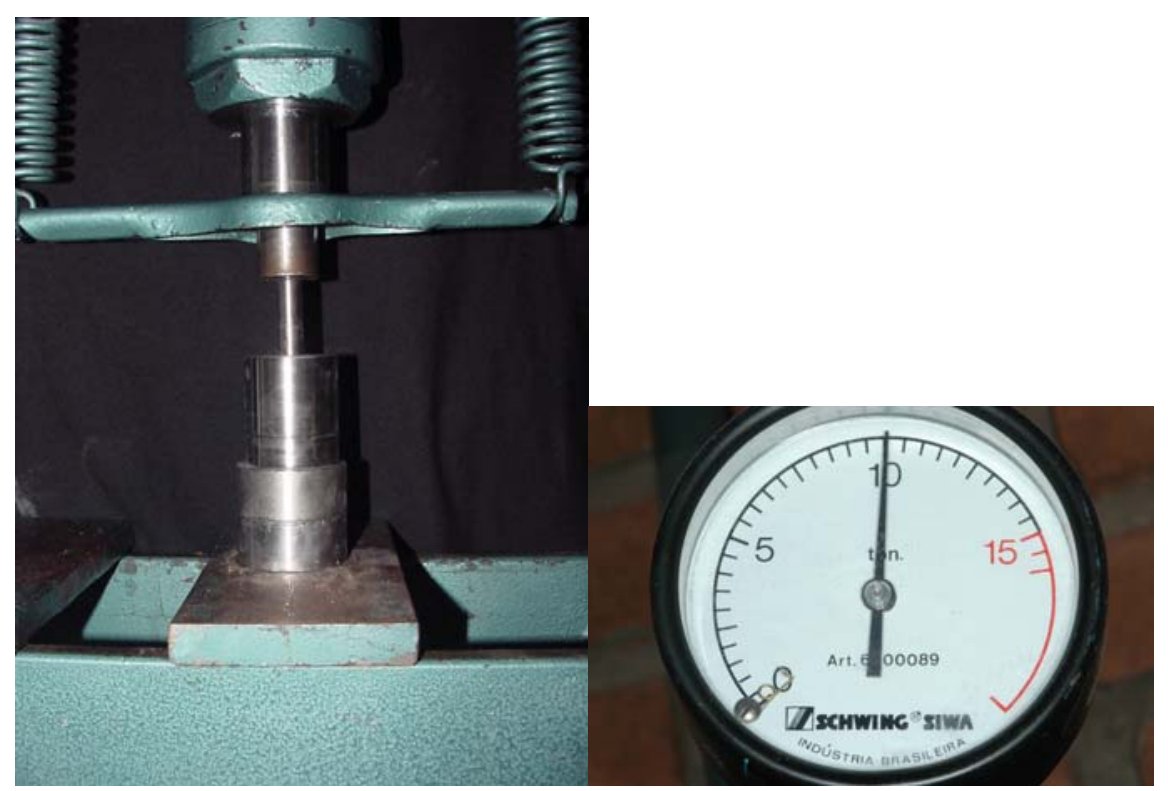

Figura 4.10 - Pastilhador na prensa

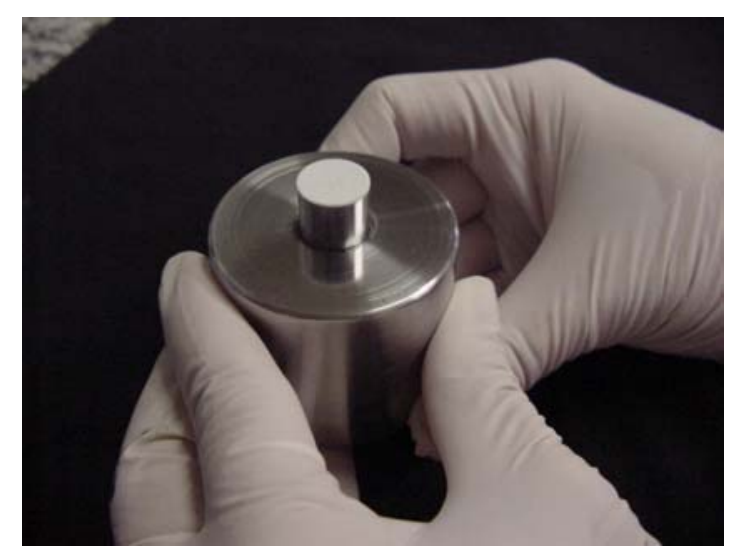

Figura 4.11 - Pastilha pronta para análise 


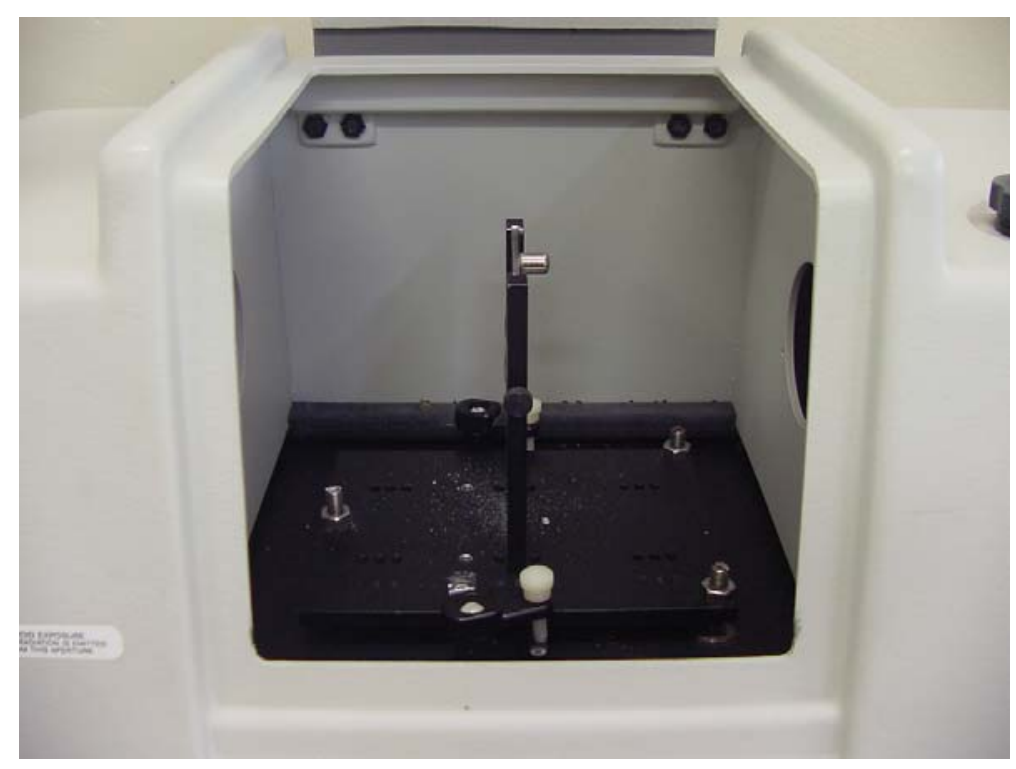

Figura 4.12 - Dispositivo para pastilha

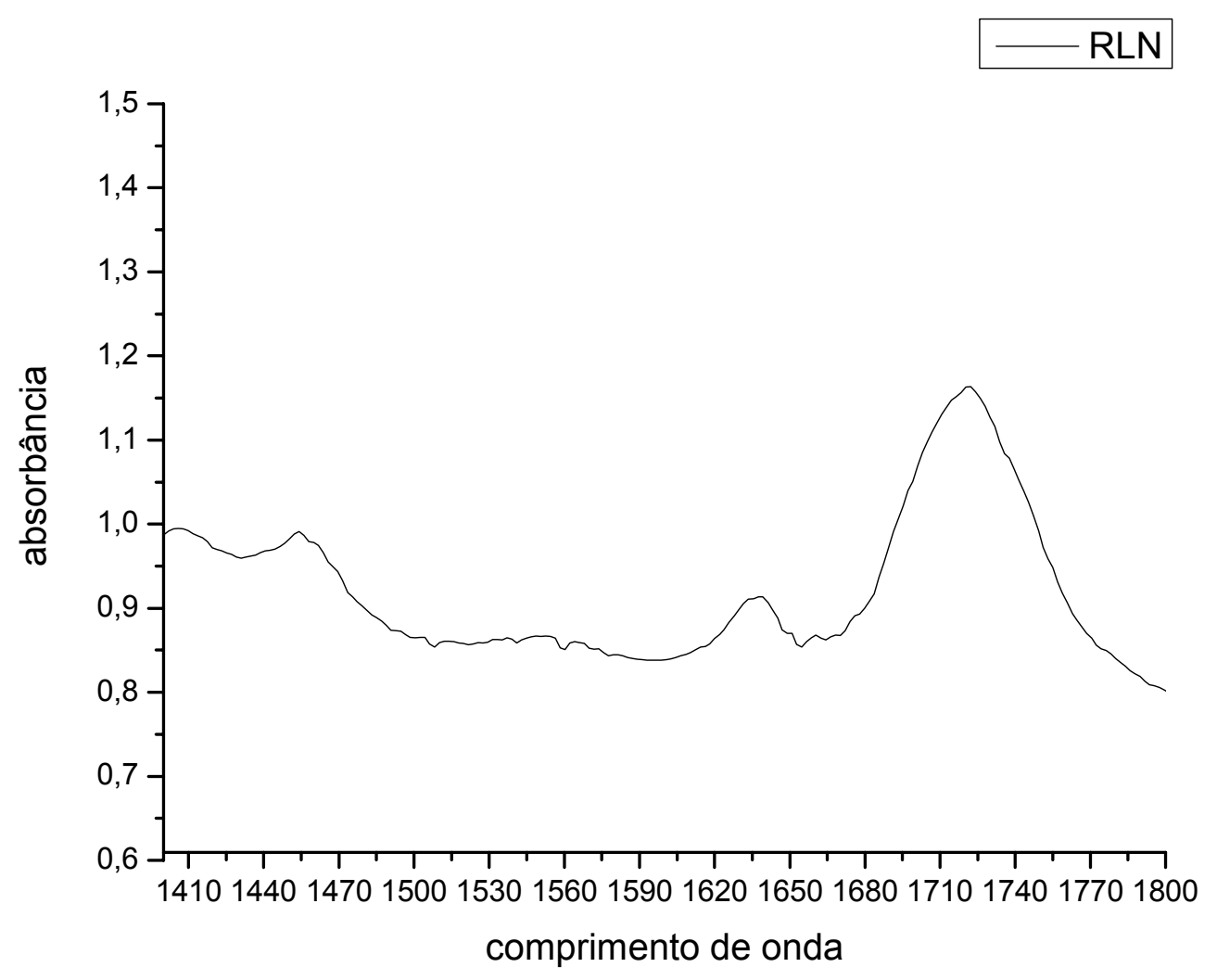

Figura 4.13 - Gráfico das bandas de absorção 


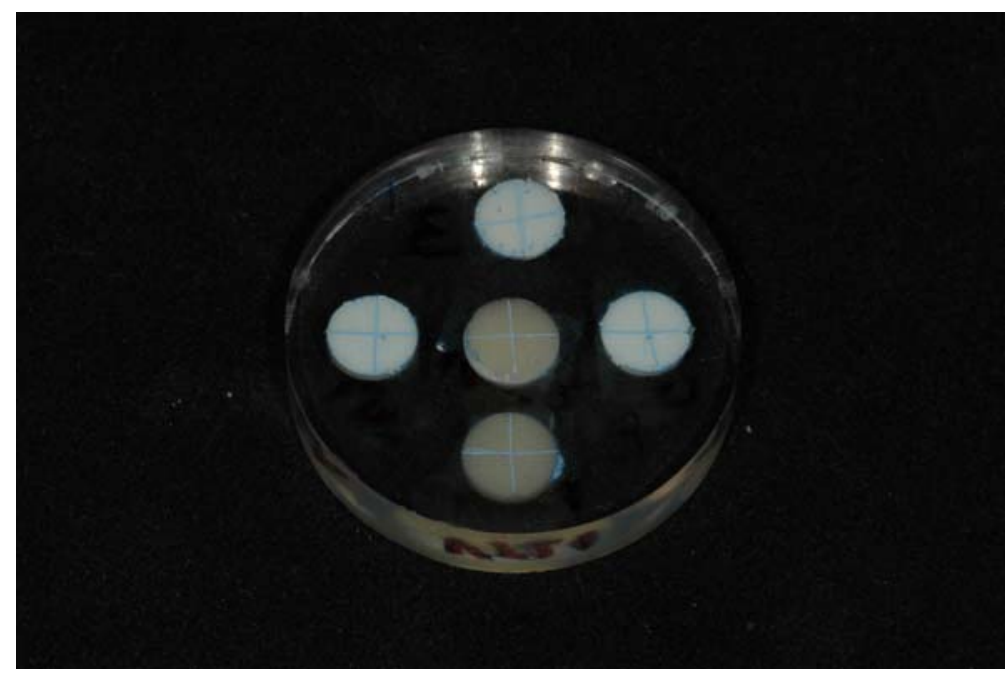

Figura 4.14 - Espécimes embutidos no acrílico

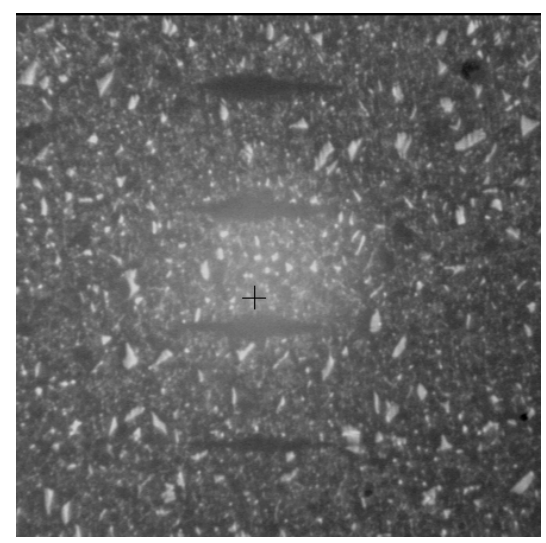

Figura 4.15 - Distância entre as impressões

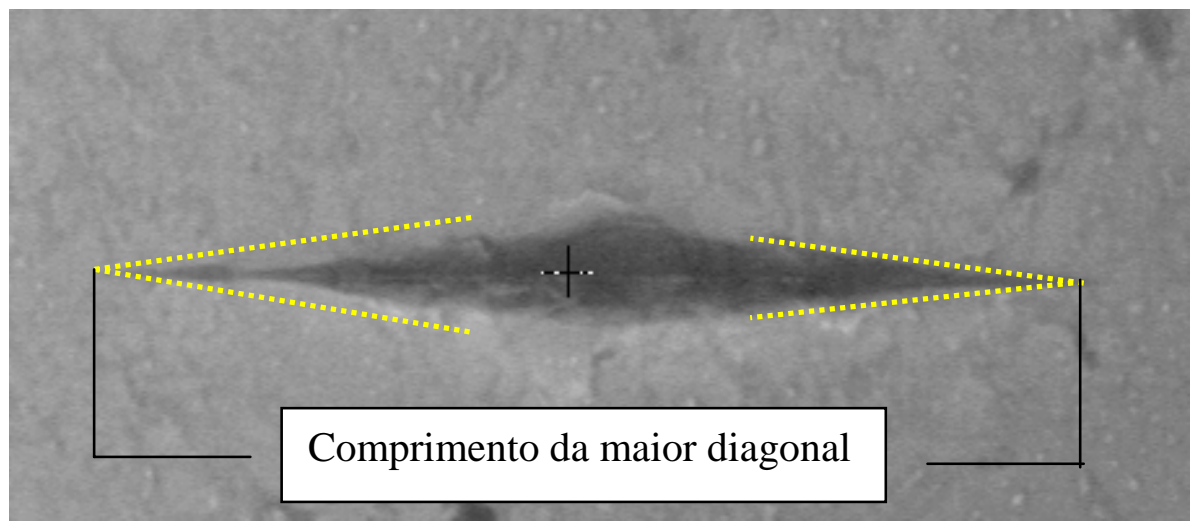

Figura 4.16 - Medida da diagonal 


\section{RESULTADOS}

\subsection{Análise das fontes de luz}

As fontes de luz avaliadas pelo espectrofotômetro foram expressas em intensidade pelo comprimento de onda. A curva de intensidade do aparelho LEC1000 (LED) teve a emissão na banda estreita do espectro azul e apresentou a sua maior intensidade próximo ao comprimento de onda de 470nm (Gráfico 5.1). Este pico de emissão foi o de maior absorção de luz pelos fotoiniciadores dos cimentos de ionômero de vidro modificados por resina (canforoquinona).

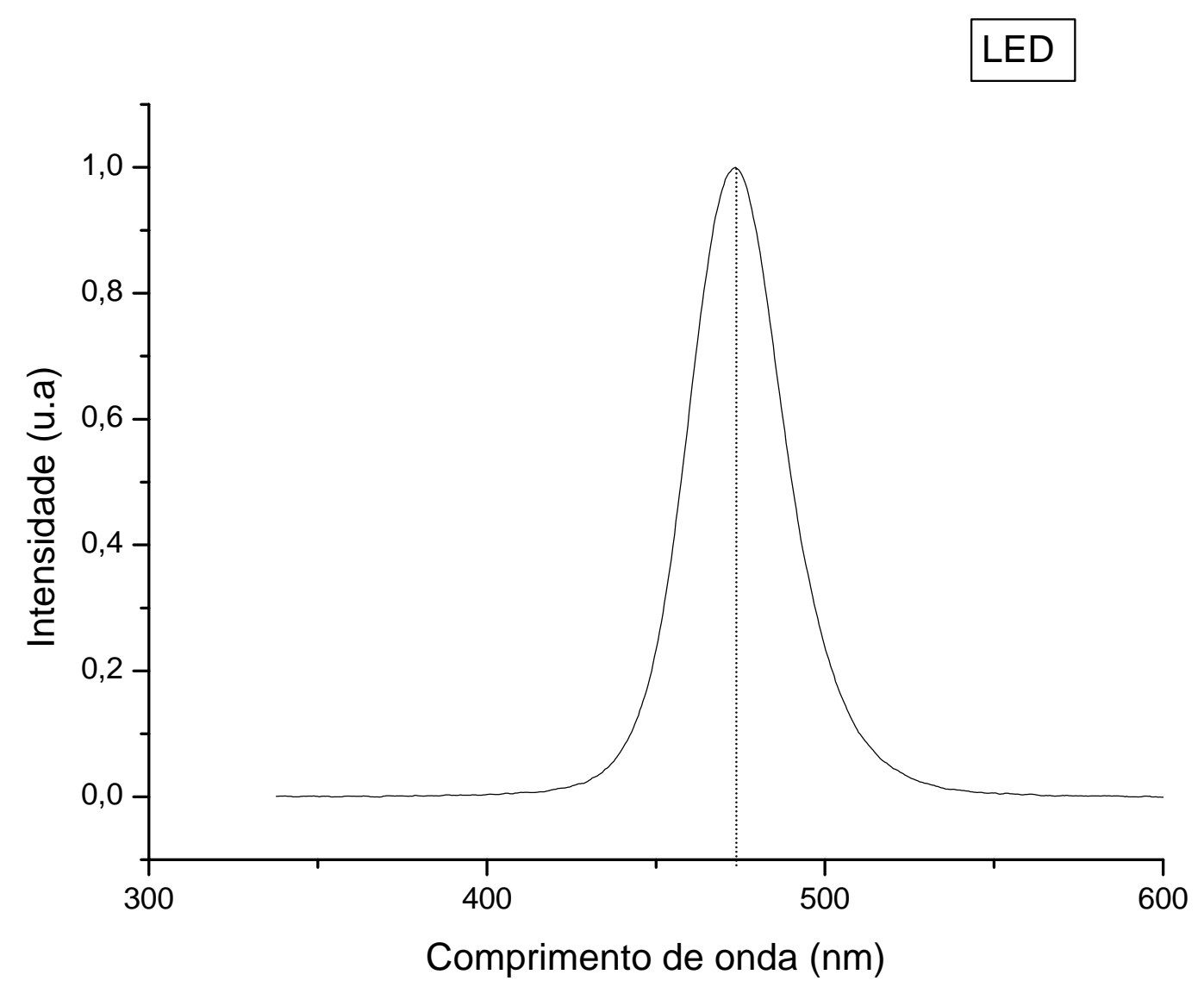

Gráfico 5.1 - Curva de intensidade do LEC 1000 (LED) 
A curva de intensidade para o aparelho Ultralux EL (lâmpada halógena) mostrou emissão no espectro entre 370 e 530nm e o pico de maior intensidade próximo ao comprimento de onda de 490nm.

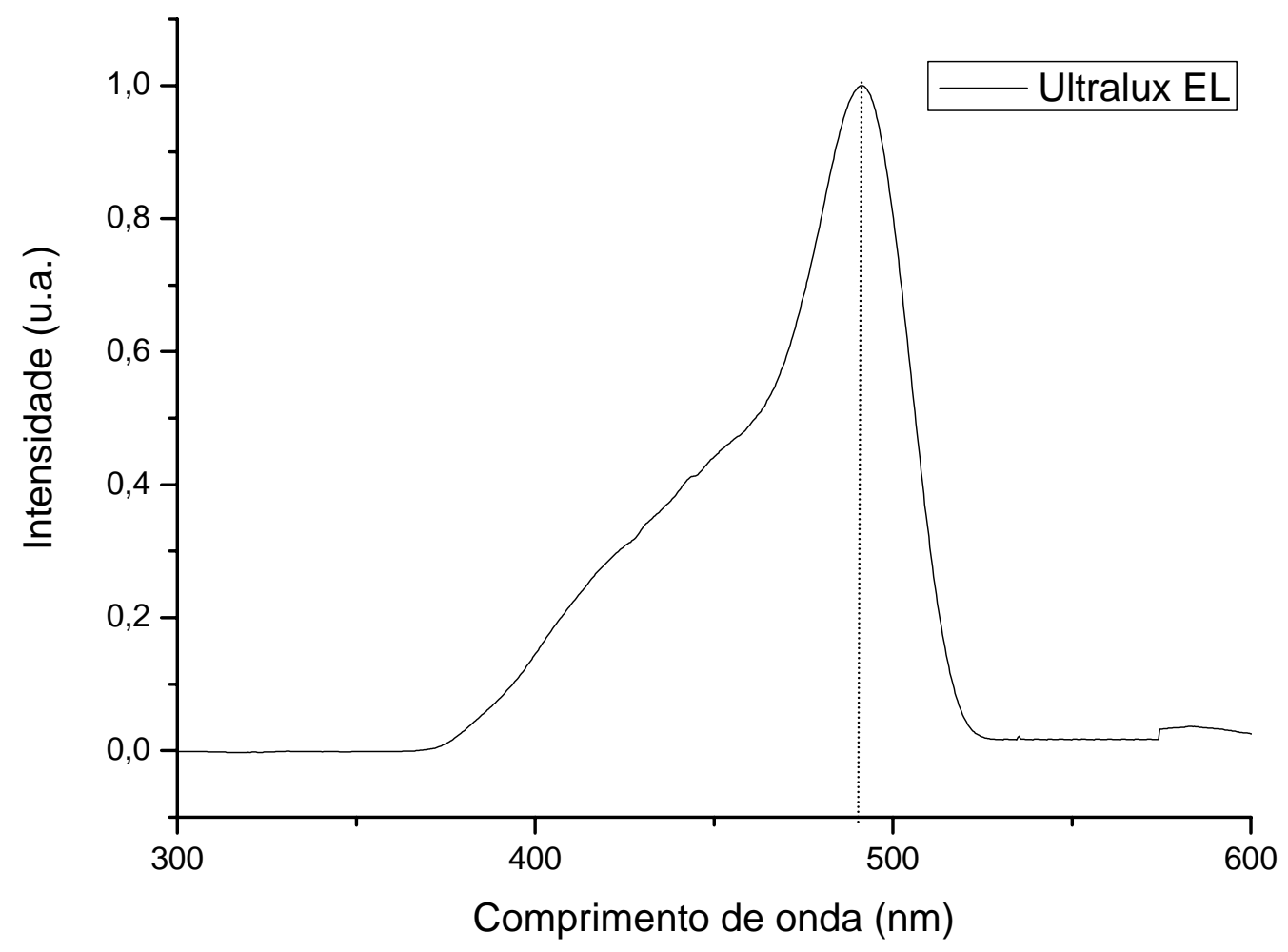

Gráfico 5.2 - Curva de intensidade do Ultralux EL (halógena)

\subsection{Microdureza Knoop}

Os valores individuais de cada espécime ou seja, 3 para cada situação experimental, estão presentes na tabela 5.1. A tabela 5.2 contém as médias da microduredureza Knoop (KHN) e os respectivos desvios padrão para os diferentes grupos em função do tipo de polimerização e do tempo. Os resultados da análise de variância da tabela 5.3 mostram, pelo baixo valor de "p" (zero para ambos), que as diferenças entre os tipos de polimerização e o tempo de armazenagem foram altamente significantes estatisticamente. Os valores das médias apresentados na tabela 5.2 e representados no gráfico 5.3 mostram que os valores da microdureza Knoop dos cimentos fotopolimerizados 
pelo aparelho LED tiveram, em todos os intervalos de tempo, os maiores valores númericos e o cimento autopolimerizado obteve os menores valores da microdureza Knoop por todos os tempos de armazenagem. Entretanto, todos demonstraram um aumento da dureza no primeiro dia e um amolecimento nos demais períodos.

Os maiores valores encontrados para a polimerização com o diodo emissor de luz $(81,63)$ e com a autopolimerização $(48,07)$ foram encontrados com 24 horas de reação. Para a polimerização com a lâmpada halógena $(75,23)$ os valores foram observados 48 horas após o início da reação de presa.

O teste de Tukey foi aplicado para comparações múltiplas, visando à localização das diferenças entre as médias dos valores da microdureza (KHN) dos grupos dos cimentos de ionômero de vidro modificados por resina em função do tempo e da forma de polimerização (Tabela 5.4). O teste de Tukey revelou a existência de diferenças estatisticamente significantes $(p<0,05)$, na comparação aos pares, de cada grupo com cada um dos demais.

A comparação aos pares demonstrou que, entre os tempos de armazenagem, as formas de polimerização fotoativadas após 24 horas não tiveram diferença estatisticamente significante. No entanto, para o cimento autopolimerizável, não houve significância entre o primeiro período testado (6horas) e o período de 14 dias deste estudo. Entre as formas de polimerização ocorreram diferenças em todos os instantes, e somente os períodos de 1 e 2 dias da lâmpada halógena não tiveram significância quando comparados aos valores de microdureza da tecnologia LED apresentados a partir do primeiro dia. 
Tabela 5.1 - Valores unitários da microdureza Knoop (KHN) de todos espécimes

\begin{tabular}{|c|c|c|c|c|c|c|c|c|c|}
\hline Tempo & RL1 & RL2 & RL3 & VTL1 & VTL2 & VTL3 & VTH1 & VTH2 & VTH3 \\
\hline 6h & 45,7 & 43,2 & 46,6 & 70,2 & 73,2 & 67,5 & 56,9 & 59,4 & 57,8 \\
\hline 1d & 47,1 & 50,6 & 46,5 & 79,3 & 81,7 & 83,9 & 72,0 & 76,9 & 73,7 \\
\hline 2d & 50,0 & 46,0 & 47,4 & 83,4 & 79,9 & 77,3 & 75,8 & 72,7 & 77,2 \\
\hline 3d & 52,1 & 44,9 & 43,1 & 79,7 & 74,8 & 78,7 & 67,0 & 66,4 & 66,5 \\
\hline 7d & 47,7 & 45,4 & 43,7 & 76,7 & 72,0 & 78,0 & 65,4 & 62,6 & 63,3 \\
\hline $14 d$ & 45,4 & 48,8 & 47,0 & 75,3 & 72,0 & 74,8 & 69,7 & 67,8 & 66,1 \\
\hline
\end{tabular}


Tabela 5.2 - Valores das médias e respectivos desvios padrão da microdureza Knoop $(\mathrm{KHN})$ referentes à interrelação tipo de polimerização $\mathrm{x}$ tempo

\begin{tabular}{|c|c|c|c|c|c|c|}
\hline \multirow{3}{*}{ Tempo } & \multicolumn{6}{|c|}{ Tipo de polimerização } \\
\hline & \multicolumn{2}{|c|}{ Halógena } & \multicolumn{2}{|c|}{ LED } & \multicolumn{2}{|c|}{ Autopolimerizável } \\
\hline & Média & DP & Média & DP & Média & DP \\
\hline $6 h$ & 58,03 & 1,27 & 70,30 & 2,85 & 45,17 & 2,01 \\
\hline 1d & 74,20 & 2,49 & 81,63 & 2,30 & 48,07 & 2,21 \\
\hline $2 d$ & 75,23 & 2,30 & 80,20 & 3,06 & 47,80 & 2,03 \\
\hline $3 d$ & 66,63 & 0,32 & 77,73 & 2,59 & 46,70 & 4,76 \\
\hline $5 d$ & 63,77 & 1,46 & 75,57 & 3,16 & 45,60 & 2,01 \\
\hline $7 d$ & 64,93 & 3,00 & 74,83 & 0,12 & 44,20 & 0,61 \\
\hline 11d & 63,90 & 3,06 & 73,23 & 2,20 & 43,73 & 0,47 \\
\hline 14d & 67,87 & 1,80 & 74,03 & 1,78 & 47,06 & 1,70 \\
\hline
\end{tabular}

Tabela 5.3 - Análise de variância da microdureza Knoop

\begin{tabular}{cccccccc}
\hline Fonte de variação & $\begin{array}{c}\text { Soma de } \\
\text { quadrados }\end{array}$ & G. L. & Quadrado médio & "F" & Probabilidade \\
\hline TEMPO & 776.83652778 & 7 & 110.97664683 & 21.01443 & 0,00000 \\
\hline POLIMERIZAÇÃO & 11271.786944 & 2 & 5635.89347222 & 1067.207 & 0,00000 \\
\hline INTERAÇÃO & 246.95305556 & 14 & 17.63950397 & 3.340200 & 0,00090 \\
\hline RESÍDUO & 253.48666667 & 48 & 5.28097222 & - & - \\
\hline TOTAL & 12549.06319444 & 71 & - & - & - \\
\hline
\end{tabular}




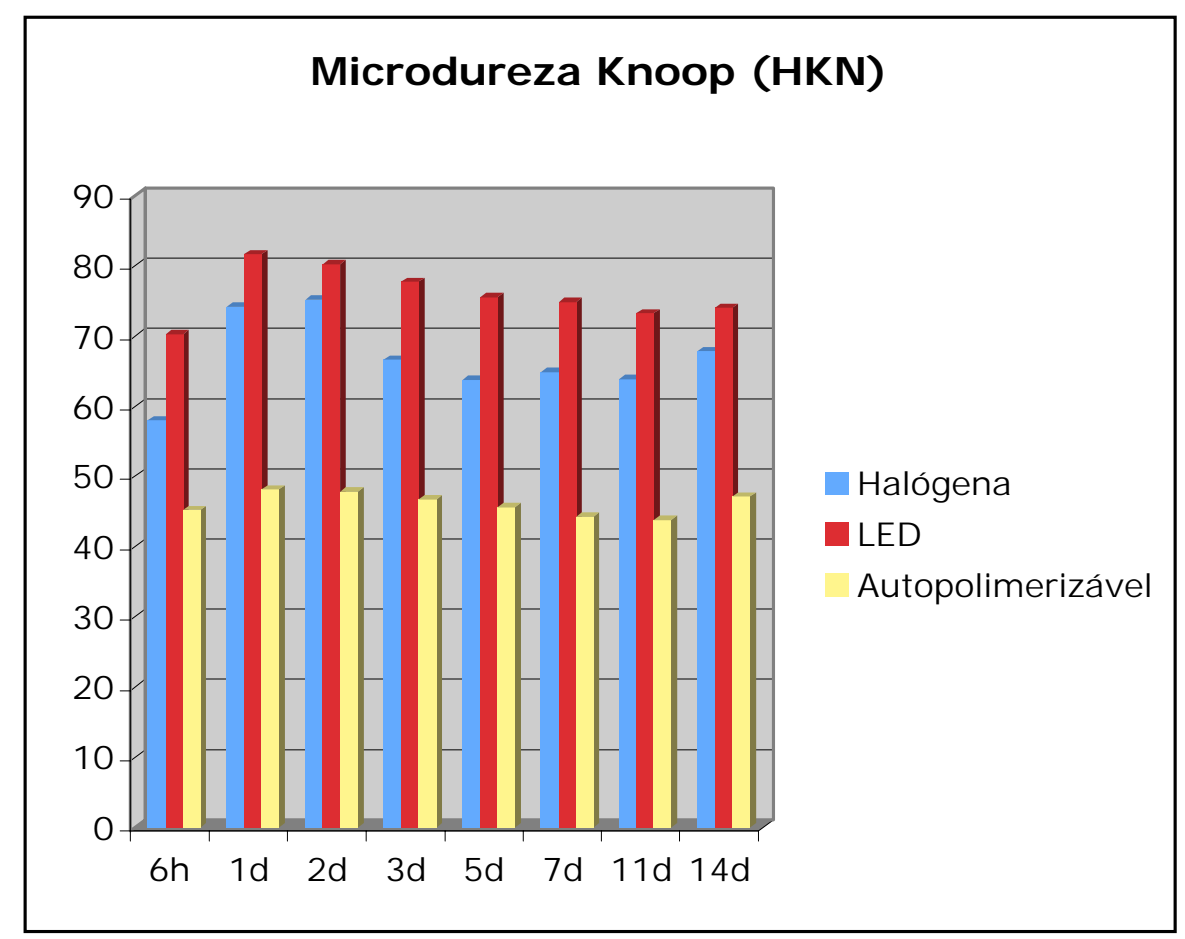

Gráfico 5.3 - Médias da microdureza Knoop nos diferentes tempos de armazenagem

Tabela 5.4 - Teste de Tukey para comparações múltiplas entre as médias dos valores de microdureza Knoop (KHN) entre todos os grupos* (médias com letras iguais são semelhantes)

\begin{tabular}{|c|c|c|c|}
\hline \multirow{3}{*}{ Tempo } & \multicolumn{3}{|c|}{ Tipo de polimerização } \\
\hline & Halógena & LED & Autopolimerizável \\
\hline & Média & Média & Média \\
\hline $6 h$ & $58,03 \mathrm{a}$ & $70,30 \mathrm{~b}$ & $45,17 \mathrm{c}$ \\
\hline 1d & $74,20 d$ & 81,63 e & $48,07 \mathrm{c}$ \\
\hline 2d & $75,23 d$ & $80,20 \mathrm{de}$ & $47,80 \mathrm{c}$ \\
\hline 3d & $66,63 \mathrm{~g}$ & $77,73 \mathrm{de}$ & $46,70 \mathrm{c}$ \\
\hline $5 d$ & $63,77 \mathrm{~g}$ & $75,57 \mathrm{de}$ & $45,60 \mathrm{c}$ \\
\hline $7 d$ & $64,93 \mathrm{~g}$ & 74,83 de & $44,20 \mathrm{c}$ \\
\hline 11d & $63,90 \mathrm{~g}$ & $73,23 \mathrm{de}$ & $43,73 \mathrm{c}$ \\
\hline 14d & $67,87 \mathrm{~g}$ & 74,03 de & $47,06 \mathrm{c}$ \\
\hline
\end{tabular}

* Diferença estatisticamente significante $(p<0,05)$, valor critico 7,233623 


\subsection{Grau de conversão}

A tabela 5.5 mostra os valores do grau de conversão (\%) de cada espécime testado. Esses números serviram como base para o cálculo das médias e dos respectivos desvios padrão presentes na tabela 5.6 para os diferentes grupos em função do tipo de polimerização e do tempo. Os resultados da análise de variância da tabela 5.8 mostram, pelo baixo valor de "p" (zero para ambos), que as diferenças o tipo de polimerização e o tempo de armazenagem foram altamente significantes estatisticamente. Os valores das médias apresentados na tabela 5.6, e representados no gráfico 5.4, mostram que o grau de conversão dos cimentos de ionômero de vidro modificados por resina foi crescente em todos os intervalos de tempo independente da forma de polimerização, e que os cimentos fotopolimerizados obtiveram valores maiores que o autopolimerizado nas primeiras 6 horas. $O$ fotopolimerizador com tecnologia LED apresentou os maiores valores numéricos até o quinto dia após o início da reação, entretanto, no sétimo dia, a lâmpada halógena obteve o resultado maior. O cimento autopolimerizável mostrou em todos os períodos os menores valores, exceto no primeiro dia onde apresentou um valor maior que os espécimes polimerizados com a lâmpada halógena.

Os maiores valores encontrados para os tipos de polimerização foram no $14^{\circ}$ dia, com o diodo emissor de luz (97,63\%), com a lâmpada halógena $(97,78 \%)$ e com a autopolimerização (90,83\%).

O teste de Tukey foi aplicado para comparações múltiplas, visando à localização das diferenças entre as médias dos valores do grau de conversão (\%) dos grupos dos cimentos de ionômero de vidro modificados por resina em função do tempo e da forma de polimerização (Tabela 5.4). O teste de Tukey revelou a existência de diferenças estatisticamente significantes $(p<0,05)$ na comparação aos pares de cada grupo com cada um dos demais.

A comparação aos pares demonstrou que entre os tempos de armazenagem as formas de polimerização fotoativada com lâmpada Halógena e química após o sétimo dia não tiveram diferenças estatisticamente significantes. Para o LED não ocorreu diferença significante após o décimo primeiro dia. Já entre as formas de polimerização ocorreram diferenças em todos os instantes, somente no sétimo dia após o início da reação de presa os 
materiais fotoativados pela lâmpada halógena não tiveram significância quando comparados aos valores do grau de conversão da tecnologia LED.

Tabela 5.5 - Valores unitários do grau de conversão (\%) de todos os espécimes

\begin{tabular}{|c|c|c|c|c|c|c|c|c|c|}
\hline Tempo & RL1 & RL2 & RL3 & VTL1 & VTL2 & VTL3 & VTH1 & VTH2 & VTH3 \\
\hline $6 \mathrm{~h}$ & 15,00 & 14,27 & 16,26 & 32,88 & 30,07 & 30,24 & 22,93 & 23,88 & 24,86 \\
\hline $1 d$ & 41,23 & 40,02 & 42,23 & 40,30 & 42,08 & 46,80 & 33,65 & 30,81 & 28,76 \\
\hline $2 d$ & 44,76 & 47,92 & 45,72 & 49,63 & 47,07 & 48,10 & 46,93 & 47,12 & 48,27 \\
\hline $3 d$ & 49,44 & 48,46 & 50,72 & 57,81 & 54,57 & 57,43 & 52,23 & 51,19 & 53,35 \\
\hline $5 d$ & 67,20 & 68,82 & 63,17 & 77,57 & 76,55 & 72,87 & 72,23 & 71,20 & 73,35 \\
\hline $7 d$ & 82,73 & 87,28 & 86,83 & 91,76 & 90,35 & 88,76 & 93,83 & 91,49 & 91,82 \\
\hline $11 d$ & 88,72 & 91,61 & 92,16 & 98,46 & 95,92 & 97,74 & 95,77 & 96,59 & 96,53 \\
\hline $14 d$ & 91,17 & 92,75 & 88,57 & 98,39 & 97,30 & 97,20 & 98,13 & 97,37 & 97,84 \\
\hline
\end{tabular}


Tabela 5.6 - Valores das médias e respectivos desvios padrão do grau de conversão (\%) referente à interrelação tipo de polimerização $x$ tempo

\begin{tabular}{|c|c|c|c|c|c|c|}
\hline \multirow{3}{*}{ Tempo } & \multicolumn{6}{|c|}{ Tipo de polimerização } \\
\hline & \multicolumn{2}{|c|}{ Halógena } & \multicolumn{2}{|c|}{ LED } & \multicolumn{2}{|c|}{ Autopolimerizáve } \\
\hline & Média & DP & Média & DP & Média & DP \\
\hline $6 h$ & 23,89 & 0,97 & 31,06 & 1,58 & 15,18 & 1,01 \\
\hline $1 d$ & 31,08 & 2,45 & 43,06 & 3,36 & 41,16 & 1,11 \\
\hline $2 d$ & 47,44 & 0,72 & 48,27 & 1,29 & 46,13 & 1,62 \\
\hline $3 d$ & 52,26 & 1,08 & 56,60 & 1,77 & 49,54 & 1,14 \\
\hline $5 d$ & 72,25 & 1,10 & 75,66 & 2,48 & 66,40 & 2,91 \\
\hline $7 d$ & 92,38 & 1,27 & 90,29 & 1,50 & 85,57 & 2,58 \\
\hline 11d & 96,30 & 0,46 & 97,37 & 1,31 & 89,67 & 1,71 \\
\hline 14d & 97,78 & 0,38 & 97,63 & 0,66 & 90,83 & 2,11 \\
\hline
\end{tabular}

Tabela 5.7 - Análise de variância do grau de conversão

\begin{tabular}{cccccccc}
\hline Fonte de variação & $\begin{array}{c}\text { Soma de } \\
\text { quadrados }\end{array}$ & G. L. & Quadrado médio & "F" & Probabilidade \\
\hline TEMPO & 47908.233772 & 7 & 6844.03339603 & 2364.245 & 0,00000 \\
\hline POLIMERIZAÇÃO & 577.82855833 & 2 & 288.91427917 & 99.80433 & 0,00000 \\
\hline INTERAÇÃO & 538.33088611 & 14 & 38.45220615 & 13.28316 & 0,0000 \\
\hline RESÍDUO & 138.95073333 & 48 & 2.89480694 & - & - \\
\hline TOTAL & 49163.34395000 & 71 & - & - & - \\
\hline
\end{tabular}


Tabela 5.8 - Teste de Tukey para comparações múltiplas entre as médias dos valores do grau de conversão (\%) entre todos os grupos* (médias com letras iguais são semelhantes)

\begin{tabular}{r|ccc}
\hline & \multicolumn{3}{c}{ Tipo de polimerização } \\
\hline & Hempo & LÉógena & Autopolimerizável \\
\cline { 2 - 4 } & Média & Média & Média \\
\hline 6h & $23,89 \mathrm{a}$ & $31,06 \mathrm{~b}$ & $15,18 \mathrm{c}$ \\
\hline 1d & $31,08 \mathrm{~b}$ & $43,06 \mathrm{~d}$ & $41,16 \mathrm{~d}$ \\
\hline 2d & $47,44 \mathrm{~d}$ & $48,27 \mathrm{~d}$ & $46,13 \mathrm{~d}$ \\
\hline 3d & $52,26 \mathrm{de}$ & $56,60 \mathrm{e}$ & $49,54 \mathrm{~d}$ \\
\hline 5d & $72,25 \mathrm{f}$ & $75,66 \mathrm{f}$ & $66,40 \mathrm{~g}$ \\
\hline 7d & $92,38 \mathrm{hi}$ & $90,29 \mathrm{hj}$ & $85,57 \mathrm{j}$ \\
\hline 11d & $96,30 \mathrm{i}$ & $97,37 \mathrm{i}$ & $89,67 \mathrm{hj}$ \\
\hline 14d & $97,78 \mathrm{i}$ & $97,63 \mathrm{i}$ & $90,83 \mathrm{hj}$ \\
\hline
\end{tabular}

*Diferença estatisticamente significante $(p<0,05)$, valor critico 5,355607

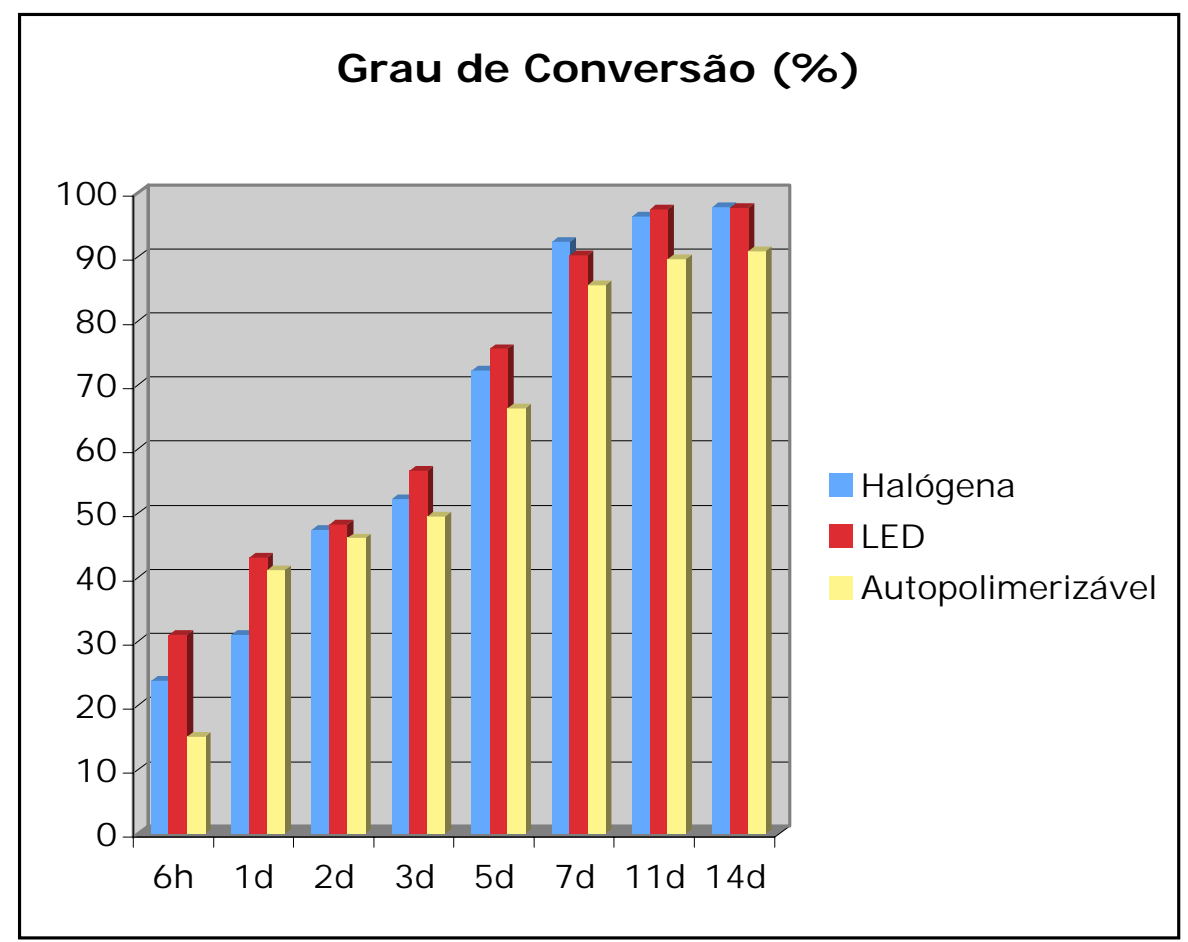

Gráfico 5.4 - Médias do grau de conversão nos diferentes tempos de armazenagem 


\subsection{Correlação entre a microdureza Knoop e o grau de conversão}

A correlação de Pearson foi realizada para cada tipo de polimerização separadamente nos diversos tempos. As tabelas 5.9, 5.10 e 5.11 e os gráficos 5.5, 5.6 e 5.7 apresentam a correlação da microdureza e do grau de conversão da lâmpada halógena, LED e do cimento autopolimerizável, respectivamente.

Os valores de microdureza e grau de conversão para todas as formas de polimerização não demonstaram uma interrelação nos diversos tempos de armazenagem.

Tabela 5.9 - Coeficiente de correlação de Pearson da lâmpada halógena

\begin{tabular}{cccccc}
\hline Variáveis & Correlação & Prob. (bicaudal) & Interseção & Coef. ang. & Número \\
\hline \multirow{2}{*}{ Dureza x Conversão } & $-0,132566$ & 0,754334 & 110.5230 & $-0,69215$ & 8 \\
\hline
\end{tabular}

Tabela 5.10 - Coeficiente de correlação de Pearson do LED

\begin{tabular}{cccccc}
\hline Variáveis & Correlação & Prob. (bicaudal) & Interseção & Coef. ang. & Número \\
\hline & & & & & \\
\hline
\end{tabular}

Tabela 5.11 - Coeficiente de correlação de Pearson do cimento autopolimerizável

\begin{tabular}{cccccc}
\hline Variáveis & Correlação & Prob. (bicaudal) & Interseção & Coef. ang. & Número \\
\hline & & & & & \\
\hline
\end{tabular}




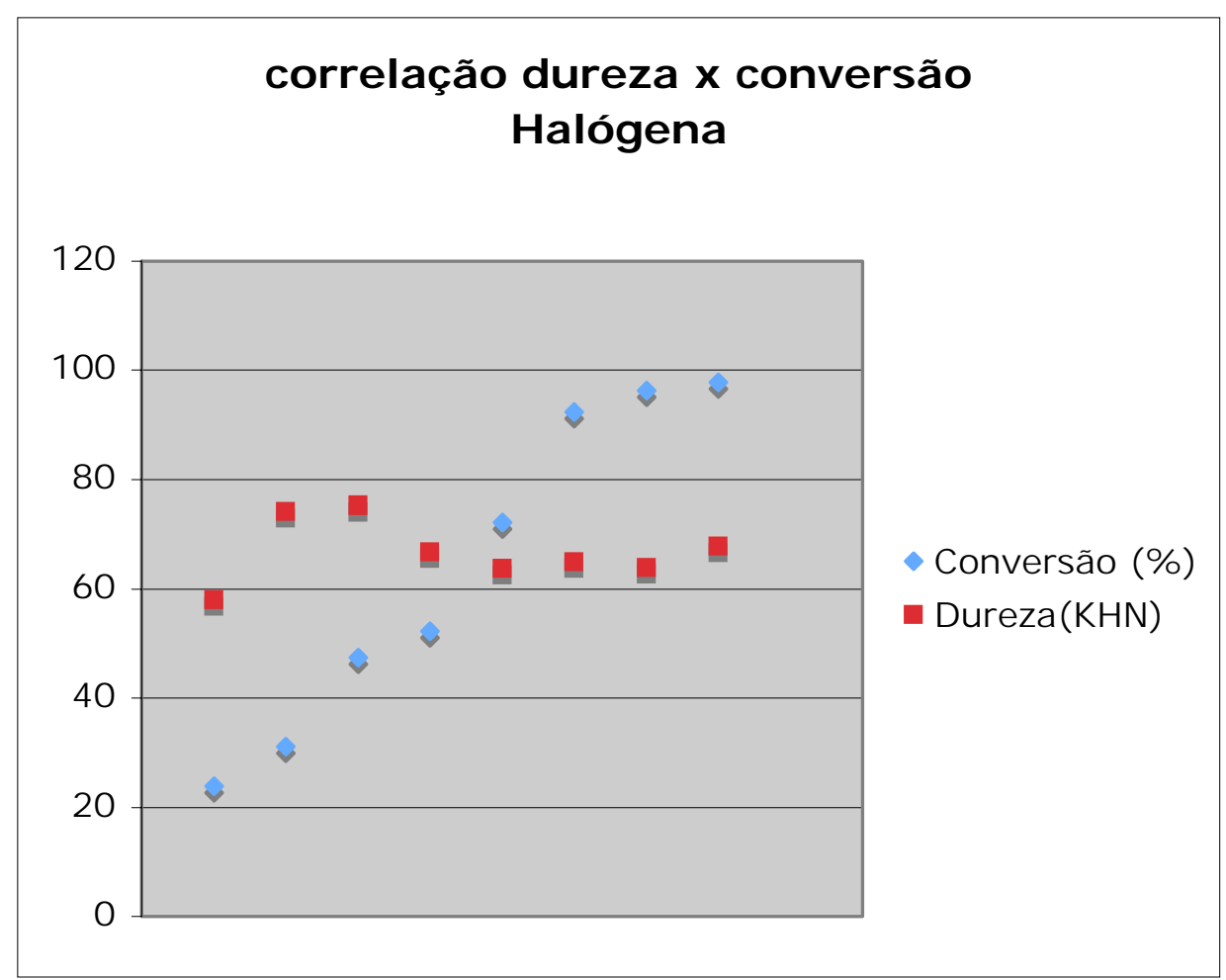

Gráfico 5.5 - Correlação dos valores de dureza e correlação da lâmpada halógena

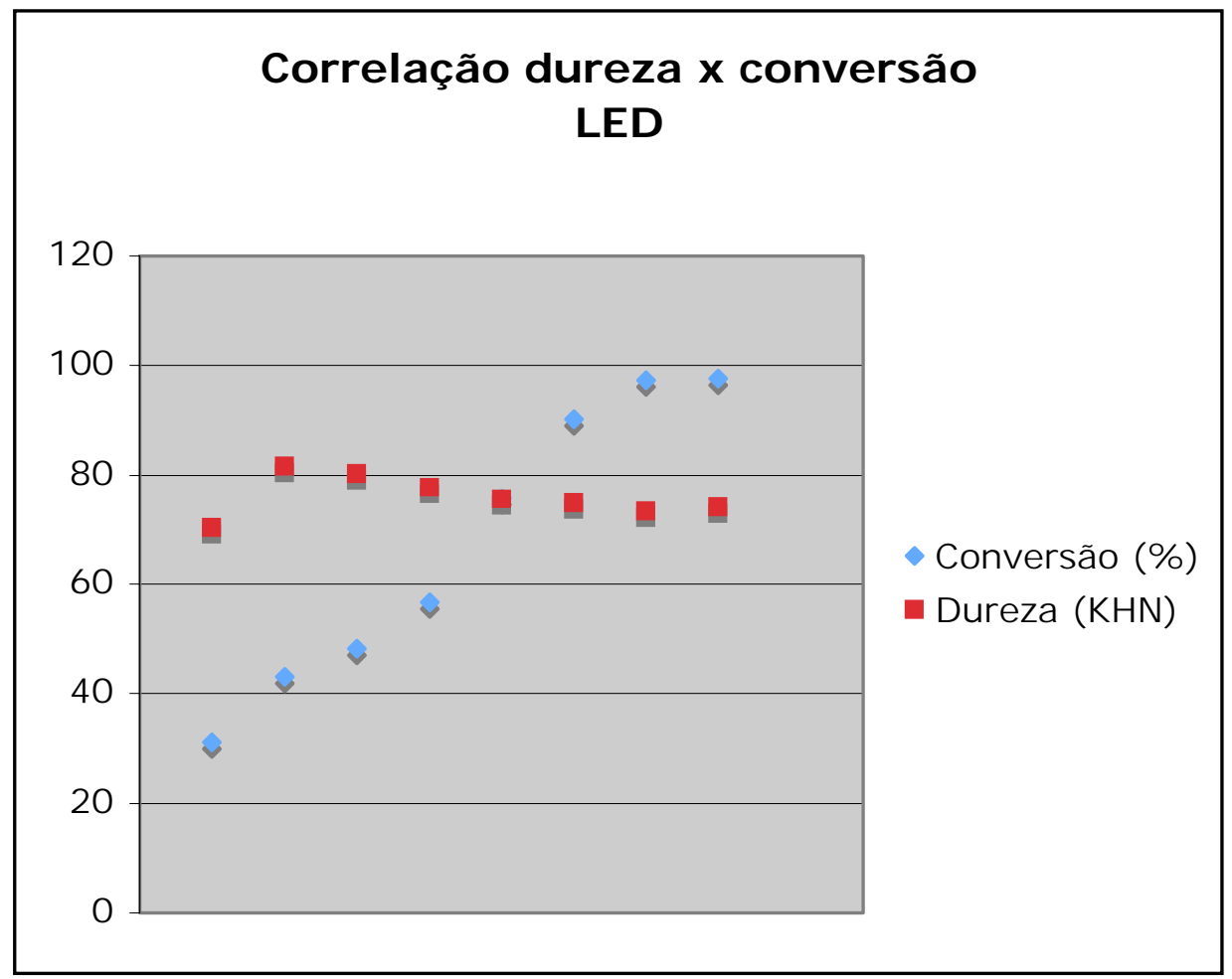

Gráfico 5.6 - Correlação dos valores de dureza e correlação do LED 


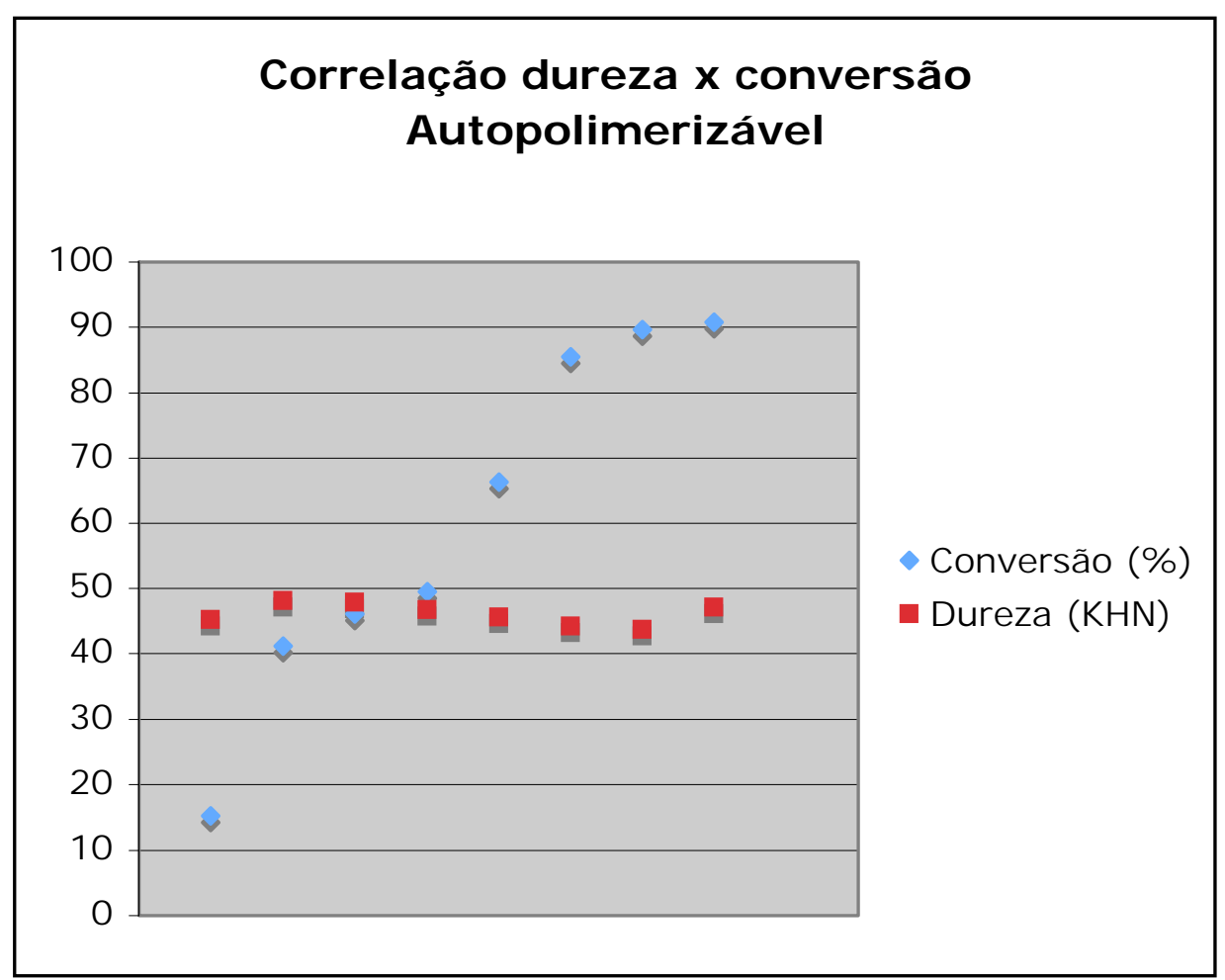

Gráfico 5.7 - Correlação dos valores de dureza e correlação do cimento autopolimerizável 
6 DISCUSSÃO 


\section{DISCUSSÃO}

Um dos motivos da escolha dos cimentos de ionômero de vidro para a realização deste estudo foi a sua composição e popularidade de uso pelas conhecidas propriedades de liberação de flúor, coeficiente de expansão térmica e módulo de elasticidade similar ao da dentina, adesividade e biocompatibilidade (KAWAHARA, IMANISHI e OSHIMA ${ }^{29}$, IMANISHI e OSHIMA $^{29}, 1979$ e SOUZA et al. $\left.{ }^{46}, 2006\right)$.

Foram conseguidas algumas melhorias para as falhas existentes nas propriedades dos cimentos de ionômero de vidro com a incorporação de componentes resinosos, os quais permitiram uma redução nos problemas de sensibilidade à umidade e baixa resistência mecânica inicial bem como a melhora das características de manipulação e de trabalho (WOOLFORD \& CHADWICK ${ }^{54}, 1992$, HAMID et al. ${ }^{20}, 1998$, XIE et al. $^{55}, 2004$, ARANHA et al. ${ }^{5}$, 2006). O 2-hidroxietil metacrilato (HEMA) presente nos materiais utilizados neste estudo tem sido um dos maiores componentes do CIVMR por atuar tanto como solvente quanto como comonômero (XIE et al. ${ }^{55}$, 2004).

Entretanto, a incorporação dos componentes resinosos nos cimentos de ionômero de vidro, como o HEMA e o fotoiniciador DPICL, devido à lixiviação, podem acarretar efeitos citotóxicos a esses materiais (HAMID et al. ${ }^{20}$, 1998, XIE et al. $^{55}$, 2004, VERMEERSCH et al. ${ }^{50}, 2005$, SOUZA et al. $\left.{ }^{46}, 2006\right)$. Essa toxicidade pode ser provocada pelo fato de o HEMA ser um monômero de baixo peso molecular (130) e, com isso, difundir-se prontamente através da dentina a uma taxa dependente da espessura da dentina, da concentração e da pressão (SCHUSTER, CAUGHMAN e RUEGGEBERG ${ }^{43}$, 2000, ABOUT et al. $^{1}, 2002$, MICHELSEN et al. $^{34}, 2003$, XIE et al. ${ }^{55}$ et al. $\left.{ }^{55}, 2004\right)$.

Os cimentos de ionômero de vidro modificados por resina têm dois mecanismos de presa: a reação ácido-base dos cimentos convencionais e reação de polimerização dos constituintes monoméricos, tal reação de polimerização é exotérmica (KANCHANAVASITA, PEARSON e ANSTICE ${ }^{28}$, 1996, e PALMER, ANSTICE e PEARSON ${ }^{38}$, 1999). Um aumento de $5^{\circ} \mathrm{C}$ (temperatura crítica) no órgão dental pode provocar danos aos tecidos pulpares. Esse aumento produzido pela polimerização dos CIVMRs é 
substancialmente maior que o da resina composta, provavelmente como resultado de seu baixo peso molecular. O aquecimento das fontes fotopolimerizadoras pode também contribuir para o aumento total da temperatura observada (KANCHANAVASITA, PEARSON e ANSTICE ${ }^{28}$, 1996).

Como citado anteriormente por outros estudos, a presença de monômeros resinosos pode provocar alterações celulares e metabólicas (INOUE \& HAYASHI ${ }^{25}, 1982$, SCHUSTER, CAUGHMAN e RUEGGEBERG ${ }^{43}$, 2000, XIE et al. ${ }^{55}$, 2004). Contudo, o polímero derivado da polimerização do HEMA (poliHEMA) não foi citado como responsável pela citotoxicidade, cabendo essa culpa somente ao monômero não reagido. A quantidade de monômeros residuais e aditivos liberados pode ser minimizada pela redução da mobilidade de monômeros na restauração polimerizada, pelo alto grau de cura ou pela redução da quantidade de monômeros solúveis em água e aditivos (GEURSTSEN $\left.{ }^{19}, 1998\right)$.

Estudos também comprovaram a eficácia da dentina como barreira protetora de danos pulpares. A dentina intacta exerce uma modificação do efeito ou da disponibilidade dos componentes tóxicos (HUME \& MOUNT ${ }^{23}$, 1988, e ABOUT et al. ${ }^{1}$, 2002). Entretanto, a espessura da dentina muitas vezes é determinada pela extensão da lesão cariosa ou pela destruição coronária. Nem sempre existe uma situação onde a quantidade de dentina remanescente é suficiente para a neutralização das substâncias tóxicas e por isso, é de extrema importância o esforço para obtenção de uma boa polimerização.

Para reforçar a idéia da necessidade de um maior grau de conversão durante a polimerização dos cimentos de ionômero de vidro modificados por resina para melhorar as propriedades físicas e reduzir a quantidade de monômeros residuais, GEURSTSEN ${ }^{19}$, em 1998, e PALMER, ANSTICE e PEARSON $^{38}$, em 1999, relataram que a conversão monômero-polímero determina a quantidade de componentes lixiviados. ABOUT et al. ${ }^{1}$, em 2002, perceberam que esses componentes lixiviados podem difundir através da dentina e chegar à polpa poucos minutos após a colocação do material. SCHUSTER, CAUGHMAN e RUEGGEBERG ${ }^{43}$, em 2000, perceberam que, mesmo na ausência da citotoxicidade, o HEMA pode causar significante alteração no metabolismo e no crescimento celular. Na utilização de sistemas resinosos contendo HEMA tem sido recomendado o uso de capeamento pulpar 
direto. Os efeitos de componentes destes sistemas em tecidos celulares devem ser considerados, mesmo quando em concentrações julgadas insuficientes para causar citotoxicidade.

O maior grau de conversão encontrado durante a polimerização de resinas compostas foi de 88\% (MICHELSEN et al. ${ }^{34}$, 2003, XIE et al. ${ }^{55}$, 2004), entretanto, PALMER, ANSTICE e PEARSON ${ }^{38}$, em 1999, relataram a falta de estudos que determinem o grau de conversão dos cimentos de ionômero de vidro modificados por resina.

Diferentes métodos podem ser empregados para a verificação do grau de conversão dos materiais poliméricos. A análise térmica diferencial (DTA), que utiliza uma fonte de luz com fibra ótica dividida para medir a razão da variação da temperatura inicial e final da polimerização dos metacrilatos monofuncionais (IMAZATO et al. $^{24}$, 2001), e a ressonância magnética, que mede as mudanças químicas por meio de espectro (XIE et al. ${ }^{55}$, 2004), permitem calcular a conversão monomérica. A determinação das resistências mecânicas também foi utilizada para a obtenção do grau de conversão dos materiais poliméricos odontológicos (RUEGGEBERG \& CRAIG ${ }^{40}, 1988, \mathrm{LI}$, BEETZEN e SUNDSTROM ${ }^{33}, 1995$, SWIFT JR et $\mathrm{al}^{47}, 1995$, YOUNG $^{59}, 2002$, BRAGA, CONDON e FERRACANE ${ }^{8}, 2002$, ASMUSSEM \& PEUTZFELDT ${ }^{6}$, 2003, SOH, YAP e SIOW ${ }^{45}, 2003$, XIE et al. ${ }^{55}, 2004$, VILJANEN et al. $\left.{ }^{51}, 2005\right)$. Contudo, a espectroscopia com infravermelho é o método mais frequentemente utilizado para medir o grau de conversão por ser capaz de quantificar diretamente os grupos de metacrilatos não reagidos no material. Dentre as espectrometrias, a Transformada de Fourier tem sido utilizada em cimentos de ionômero de vidro desde 1974 (CRISP et al. ${ }^{14}$, 1974). O FT-IR tem sido preferido, em relação à espectroscopia Raman, por solucionar problemas da fluorescência dos materiais, consistindo na utilização de um raio infravermelho com um comprimento de onda maior $\left(1064 \mathrm{~cm}^{-1}\right)$, um interferômetro e detectores de radiação infravermelha altamente sensíveis (CORRÊA ${ }^{13}$, 2003). O sinal de Raman, conhecido como o efeito Raman, é a mudança na frequência dos fótons espalhados pelas moléculas após a irradiação infravermelha. Muitas vezes esse sinal é mascarado pela fluorescência dos materiais. 
Neste estudo, a espectrometria infravermelha transformada de Fourier (FT-IR) foi empregada como o método direto de verificação do grau de conversão. Como realizado por WAN, YAP e HASTINGS ${ }^{52}$, em 1999, os discos de cimentos foram pulverizados e transformados em discos novamente com sal de brometo de potássio $(\mathrm{KBr})$. A proporção por peso para a mistura CIVMR-KBr utilizada foi de 1:20. Essa proporção foi determinada por testes pilotos que demonstraram que devido à grande opacidade desses materiais era necessária grande quantidade do sal por ser translúcido e, com isso inerte ao infravermelho. ASMUSSEM \& PEUTZFELDT ${ }^{6}$, em 2003, confeccionaram espécimes em torno de $40 \mu \mathrm{m}$ de espessura para a medição do grau de conversão de resinas compostas. Tal reprodução não pôde ser realizada nesse estudo para a confecção de espécimes somente de CIVMR pela falta de equipamento específico. A verificação do grau de conversão nos minutos iniciais não foi possível pelo alto consumo de tempo na realização das pastilhas utilizando o $\mathrm{KBr}$ (WAN, YAP e HASTINGS ${ }^{52}$, 1999). As pastilhas também não podem ser aproveitadas para estudos a longo prazo pelo fato de o $\mathrm{KBr}$ ser um cristal que absorve água facilmente do meio e do cimento e, com isso, a alta quantidade de água pode mascarar o pico da dupla ligação carbono-carbono alifática em $1636 \mathrm{~cm}^{-1}$, por possuir um pico de comprimento de onda a $1640 \mathrm{~cm}^{-1}$ (WAN, YAP e HASTINGS ${ }^{52}, 1999$, YOUNG $\left.^{59}, 2002\right)$. A absorção de grande quantidade de água do cimento também prejudicaria a reação ácido-base presente nos cimentos de ionômero de vidro que é dependente dela. Outro problema relacionado à incorporação do $\mathrm{KBr}$ é a tendência do cimento soltar-se do cristal durante a presa, resultando em uma perda de intensidade do espectro (WAN, YAP e HASTINGS ${ }^{52}$, 1999).

O FT-IR é capaz de mostrar distintas diferenças entre as taxas das bandas dos materiais (Nicholson, 1988). O grau de conversão é calculado pela razão de monômeros curados pelos não curados (BRAGA, CONDON e FERRACANE $^{8}, 2002$, VILJANEN et al. $^{51}$, 2005). Para verificar os picos dos cimentos, o FT-IR gera um gráfico absorbância $X$ comprimento de onda e, sabendo-se a composição do material, identifica-se as ligações químicas presentes em seus componentes por seus comprimentos de onda característicos e assim é obtida a absorbância. 
A maior parte dos estudos de grau de conversão presentes na literatura refere-se às resinas compostas, que possuem como principal componente monomérico, na maioria das vezes, o Bis-GMA (RUEGGEBERG \& CRAIG ${ }^{40}$, 1988, Izmato, 2001, BRAGA, CONDON e FERRACANE ${ }^{8}$ 2002, ASMUSSEM \& PEUTZFELDT ${ }^{6}$, 2003, GAUTHIER et al. ${ }^{18}$, 2005). A fórmula química do bisfenol-glicidil-metacrilato (Bis-GMA) possui dois anéis aromáticos (Figura 6.1) e por isso possui a dupla ligação carbono-carbono alifática (cadeia aberta) e a ligação aromática. Com isso, todos os estudos referidos acima, utilizaram o pico analítico de $1638 \mathrm{~cm}^{-1}$ da dupla ligação alifática e o pico de padrão interno, ou seja, o que não se modifica durante a reação, de $1608 \mathrm{~cm}^{-1}$ das duplas ligações presentes no anel aromático. Entretanto, quando estudamos os cimentos de ionômero de vidro modificados por resina, esse monômero (BisGMA) não está presente e o HEMA torna-se o principal componente monomérico desses materiais. Em alguns produtos também pode ocorrer a presença do Trietileno-glicol-dimetacrilato (TEGDMA), como é o caso do cimento Fuji II LC (GC), no qual YOUNG ${ }^{59}$, em 2002, utilizou as frequências de $1322 \mathrm{~cm}^{-1}$ e $1300 \mathrm{~cm}^{-1}$ para não sofrer influência do pico da água em $1640 \mathrm{~cm}^{-1}$.

Os monômeros HEMA e TEGDMA (Figura 6.1) não possuem anel aromático em sua formulação, o que impossibilita a utilização do padrão interno a $1608 \mathrm{~cm}^{-1}$ (LI, BEETZEN e SUNDSTROM ${ }^{33}$, 1995). Por isso, neste estudo, em concordância com os estudos de ELIADES \& PALAGHIAS ${ }^{16}$ (1993), LI, BEETZEN e SUNDSTROM ${ }^{33}$ (1995), KAKABOURA, ELIADES e PALAGHIAS ${ }^{26}$ (1996) e VILJANEN et al. $^{51}$ (2005) o comprimento de onda utilizado como padrão interno foi o da dupla ligação carbono-oxigênio $(C=0)$, um éster em $1712 \mathrm{~cm}^{-1}$, e o pico $1636 \mathrm{~cm}^{-1}$ foi a referência analítica correspondente ao grupo metacrilato. Esta técnica tem sido utilizada para determinar a eficiência de cura de resinas não aromáticas (ELIADES \& PALAGHIAS ${ }^{16}, 1993$ ). 
<smiles>C=C(C)C(=O)OCC(C)COc1ccc(C(C)(C)c2ccc(OCC(C)COC(=O)C(=C)C)cc2)cc1</smiles>

Bis-GMA<smiles>C=C(C)C(=O)OCCOCCOCCOC(=O)C(=C)C</smiles>

TEGDMA<smiles>C=C(C)C(=O)OCCO</smiles>

HEMA

Figura 6.1 - Fórmula estrutural dos monômeros Bis-GMA, TEGDMA e HEMA

A microdureza superficial é a resistência a identações localizadas na superfície de um material. A carga aplicada resulta em deformações plásticas e elásticas, ocorridas normalmente na matriz resina-poliacrilato (YAP et al. ${ }^{56}$, 2001). Segundo ELLAKURIA et al. ${ }^{17}$, em 2003, a microdureza é uma das mais importantes características para um estudo comparativo entre materiais. Por isso, neste estudo, a microdureza superficial foi utilizada para verificar a influência do tipo de polimerização e do tempo em dois cimentos de ionômero de vidro. Contudo, não existe na literatura um consenso quanto ao tipo de ponta, a carga e ao tempo que devem ser utilizados para a aferição da microdureza.

Diversos estudos, realizados por RUEGGEBERG \& CRAIG $^{40}$ (1988), HOTTA \& HIRUKAWA ${ }^{22}$ (1994), LI, BEETZEN e SUNDSTROM ${ }^{33}$ (1995), SWIFT JR et al $^{47}$ (1995), YAP et al. $^{56}$ (2001), BASTING, SERRA e RODRIGUES JR. ${ }^{7}$ (2002), ELLAKURIA et al. ${ }^{17}$ (2003), ASMUSSEM \& PEUTZFELDT ${ }^{6}$ (2003), SOH, YAP e $\mathrm{SIOW}^{45}$ (2003), YLI-URPO et al. ${ }^{58}$ (2005), 
empregaram os ensaios de microdureza Vickers, Knoop, Tukon e Wallace. As cargas variaram de 10 a 200 gramas e os tempos de 5 a 60 segundos. Neste estudo a dureza Knoop foi utilizada por possuir um penetrador de diamante com forma piramidal de base alongada, que permite a utilização em regiões mais finas, já que para uma mesma carga, a profundidade da impressão Knoop é menor do que a metade da profundidade obtida com a impressão Vickers. Além disso, por possuir diâmetros diferentes, diminui a possibilidade de recuperação elástica. A carga e o tempo devem ser baseados no material a ser testado, por isso a carga de 50 gramas foi utilizada com o intuito de obter impressões regulares, sem deformações e de tamanhos compatíveis com o visor do computador, e o tempo foi de 30 segundos. Como não existiu consenso sobre os tipos de microdureza, carga e tempo, os resultados aqui encontrados não serão discutidos em valores, mas sim em relação ao comportamento dos materiais quando relacionados aos outros estudos.

A microdureza Knoop exige espécimes de superfícies extremamente polidas, que torna possível a identação e visualização no microscópio (Ruegeberg \& Craig, 1988). Para isso, para se obter uma superfície mais plana, foi realizado o procedimento de embutimento para tornar o polimento mais fácil.

Os períodos para as realizações dos ensaios de microdureza foram selecionados tanto para acompanhar os períodos de medição do FT-IR para uma possível correlação entre os métodos, como também por demandar tempo para a confecção da amostras, o que impediria a verificação dos valores de microdureza nos períodos iniciais da fotopolimerização.

$\mathrm{Na}$ presente pesquisa, foram utilizadas duas fontes polimerizadoras com diferenças no mecanismo de geração de luz e no perfil da emissão luminosa. A intensidade e o tempo de irradiação de ambas as luzes foram igualadas para que fossem avaliadas suas capacidades curadoras, pois o grau de conversão dos materiais poliméricos é afetado pelo tempo de irradiação e intensidade da luz (YAZICl et al. $\left.{ }^{57}, 2006\right)$.

Embora neste estudo o objetivo seja avaliar a eficácia curadora das lâmpadas, alguns autores relataram sérios problemas decorrentes da utilização de filamentos espiralados de tungstênio (lâmpada halógena) como o limitado tempo de vida (40-100 horas), degradação do refletor, do bulbo, do filtro e significante aumento de temperatura (KURACHI et al. ${ }^{32}, 2001, \mathrm{SOH}$, YAP e 
SIOW $^{45}, 2003$, TARLE et al. $\left.{ }^{48}, 2006\right)$. Todos esses problemas têm origem na emissão espectral que inclui comprimentos de onda que induzem o aumento de temperatura do aparelho, do material e do dente durante a polimerização. Este aspecto é percebido nos resultados da análise espectrométrica, na qual foram comparadas as emissões espectrais de ambas as luzes utilizadas, mostradas nas figuras 5.1 e 5.2. Como apresentado por KURACHI et al. ${ }^{32}$, em 2001, os espectros encontrados no LED foram curtos (440-510nm) e o máximo de irradiação ocorre próximo de 470nm. A lâmpada halógena teve um amplo espectro (370-510nm) e o máximo de irradiação próximo a 490nm.

Sabe-se que o fotoiniciador dos materiais testados (canforoquinona) é sensível à luz na região azul do espectro visível, com um pico de absorção a 470nm e a mais adequada banda de comprimento de onda está entre 450490nm (KURACHI et al. ${ }^{32}, 2001, \mathrm{SOH}$, YAP e SIOW ${ }^{45}, 2003$, TARLE et al. ${ }^{48}$, 2006, YAZICl et al. ${ }^{57}$, 2006). Os resultados encontrados pela espectrofotometria FT-IR e pela microdureza Knoop, presentes nas tabelas 5.8 e 5.4, respectivamente, mostram que nos momentos iniciais são maiores para o LED. Estes valores confirmam os dados da literatura de KURACHI et al. ${ }^{32}$ (2001) e SOH, YAP e SIOW ${ }^{45}$ (2003) de que quase $100 \%$ da luz emitida do LED está dentro do espectro da canforoquinona, enquanto que apenas $20 \%$ da energia da lâmpada halógena está dentro desse campo. Entretanto esses resultados diferem dos trabalhos citados de KURACHI et al. ${ }^{32}, 2001$, SOH, YAP e SIOW ${ }^{45}, 2003$, YAZICI et al. ${ }^{57}, 2006$, TARLE et al. ${ }^{48}, 2006$, por estes fazerem uma comparação da eficiência dos diodos emissores de luz e das lâmpadas halógenas utilizando intensidades maiores para as lâmpadas convencionais.

Tendo como referência o tipo de polimerização, é esperado que os sistemas duais melhorarem as propriedades físicas (ELIADES \& PALAGHIAS ${ }^{16}, 1993$ ). Devido ao perfil de emissão luminosa dos dois aparelhos fotopolimerizadores, o que aumentou o total da quantidade de luz recebida pelo material (ASMUSSEM \& PEUTZFELDT ${ }^{6}$, 2003), o LED obteve os melhores resultados na fotopolimerização do Vitremer (3M-ESPE). Entretanto, o sistema autopolimerizável Rely X Luting (3M-ESPE) obteve valores de grau de conversão não diferentes estatisticamente dos encontrados pela fotopolimerização com LED em 24 horas. A fotoativação do RL não é recomendada, uma vez que sua ativação é iniciada quimicamente pela 
presença de persulfato de potássio, iniciador da polimerização baseada em redox que diminui a quantidade de monômeros residuais, e com isso explica 0 seu excelente resultado (SOUZA et al. ${ }^{46}$, 2006). Entretanto, em função do tempo, pelo fato de o VT ter a polimerização química na sua fase resinosa (KAKABOURA, ELIADES e PALAGHIAS ${ }^{26}$, 1996), o aumento do grau de conversão permaneceu até o $11^{\circ}$ dia para todas as situações experimentais. Por possuir duas formas de polimerização da fase resinosa, o VT fotocurado por ambas as fontes luminosas obteve uma maior conversão, em comparação como o Rely X Luting. A fotopolimerização com LED, além de trazer um acréscimo na conversão quando comparados ao sistema autopolimerizável, também melhorou os valores no períodos iniciais, que são momentos de grande desafio para os materiais até que o cimento possa ter sua resistência máxima alcançada (24 horas). PALMER, ANSTICE e PEARSON ${ }^{38}$, em 1999, concordando com os resultados, citaram que a maior liberação de HEMA ocorre nos cimentos não fotopolimerizados.

As lâmpadas halógenas tiveram menores valores na primeiras 24 horas, mas, a continuação da polimerização química, no segundo dia conseguiu igualar os valores do GC e teve valores iguais aos do sistema LED e maiores que o sistema autopolimerizável, até os 14 dias testados nessa pesquisa. Os graus de conversão encontrados para o HEMA em 24 horas foram entre 3143\%, valores de acordo com o estudo de KAKABOURA, ELIADES e PALAGHIAS $^{26}$, em 1996, que encontraram que a imediata eficiência de cura nos CIVMRs após a mistura é de 30-55\%. A conversão total foi entre 90 e 97\%, ou seja, de 3 a 10\% de monômeros residuais. ANDRZEJEWSKA et al. ${ }^{2}$, em 2003, relataram que, durante a polimerização, o HEMA pode converter $90 \%$ e YOUNG ${ }^{59}$, em 2002 e YOUNG, RAFEEKA e HOWLETT ${ }^{60}$, em 2004, encontraram que o Vitremer apresentou menos de 3\% de monômeros residuais. Os resultados do presente estudo estão plenamente de acordo com os poucos estudos que avaliaram o grau de conversão dos CIVMRs por meio da espectroscopia.

Com relação aos resultados referentes à microdureza Knoop encontrados na tabela 5.8 foi observada a maior eficácia para a fonte polimerizadora LED frente aos outros tipos de polimerização. Entretanto, a lâmpada halógena, que havia se mostrado menos eficaz que o sistema 
autopolimerizável quanto ao grau de conversão, foi superior em todos os momentos testados. Vale ressaltar que os melhores resultados de microdureza foram encontrados para o LED e a lâmpada halógena quando relacionados à polimerização química. A maior microdureza se dá pela composição e estrutura dos materiais, tamanho das partículas e suas distribuições, que são fatores responsáveis por essas diferenças (BASTING, SERRA e RODRIGUES JR. ${ }^{7}$, 2002). Como relatado por YAP et al. ${ }^{56}$, em 2002, sabe-se que o aumento da proporção pó:líquido melhora as propriedades físicas, portanto o Vitremer é naturalmente mais resistente que 0 Rely $X$ Luting por apresentar uma proporção pó:líquido maior (2,1:1 do Vitremer e 1,6:1 do Rly X Luting). Por isso, não se deve comparar os valores do cimento Rely $X$ Luting em função do tipo de polimerização (sentido horizontal da tabela), mas em função do tempo (sentido vertical da tabela) para futura correlação entre os métodos.

A maioria dos estudos avalia as propriedades mecânicas em um dia e poucos estudos a fazem por tempos mais longos (YAP et al. ${ }^{56}, 2001$ ). Com a análise feita em função do tempo, pode-se perceber que os maiores valores foram encontrados em 24-48 horas para todas as formas de polimerização, acontecendo a estabilização da microdureza, após esse período, com algum amolecimento em água. Este número não é estatisticamente significativo, como relatado por SWIFT JR et al ${ }^{47}$, em 1995, e ELLAKURIA et al. ${ }^{17}$, em 2003, a não ser para a lâmpada halógena que sofreu uma queda significante no terceiro dia e então estabilizou até o último período desta pesquisa.

A presa inicial deste cimento ocorre como resultado da polimerização, enquanto a reação ácido-base serve para endurecer e dar resistência à matriz polimérica já formada (WAN, YAP e HASTINGS ${ }^{52}$,1999). Considerando que a reação ácido-base seja responsável pelo aumento da dureza no período da geleificação, é explicado o maior valor entre 24 a 48 horas, por este ser o tempo necessário para a formação do policarboxilato de alumínio que é mais estável e aumenta as propriedades mecânicas (CRISP et al. ${ }^{14}$, 1974, SWIFT JR et $\mathrm{al}^{47}, 1995$, CEFALY et al. ${ }^{10}, 2001$, DE GEE et al. ${ }^{15}, 2001$, ELLAKURIA et al. ${ }^{17}$, 2003, XIE et al. $^{55}$, 2004), enquanto o poliHEMA proporciona uma resistência inicial durante a formação do policarboxilato de cálcio do cimento convencional (LI, BEETZEN e SUNDSTROM ${ }^{33}$, 1995). Contudo, YAP et al. ${ }^{56}$, em 2001, indicou que os CIVMRs alcançaram suas propriedades máximas em 
uma semana, o que poderia ser explicado pelos achados de estudos de ELIADES \& PALAGHIAS ${ }^{16}$ (1993), KAKABOURA, ELIADES e PALAGHIAS ${ }^{26}$ (1996), WAN, YAP e HASTINGS ${ }^{52}$ (1999), CEFALY et al. ${ }^{10}$ (2001), YAP et al. ${ }^{56}$ (2001), de que a reação ácido-base ocorre mais lentamente e pode durar até uma semana devido à falta de água nesses cimentos.

Nos cimentos de ionômero de vidro modificados por resina a presa consiste em uma interpenetração da cadeia de poliHEMA, sais poliacidos e partículas de vidro não reagidos (DE GEE et al. ${ }^{15}, 1998$ e YAP et al. ${ }^{56}, 2001$ ). Este tipo de matriz parece ter menor resistência mecânica devido às propriedades elásticas do poliHEMA, que reduzem a rigidez da rede de polialcenoato. Com isso, esses materiais são vulneráveis e permitem que as partículas de vidro se desloquem mais facilmente da matriz sob tensão, podendo atuar como carga ou como foco de tensão (DE GEE et al. ${ }^{15}, 1998$, YAP et al. ${ }^{56}, 2001$ e ELLAKURIA et al. ${ }^{17}$, 2003). Esse tipo de matriz pode justificar a diminuição na microdureza encontrada, pois quando o espécime é imerso em água ocorre sua absorção e sorpção pela fase resinosa (YAP et al. ${ }^{56}$, 2001). Essa absorção, facilitada pela natureza hidrofílica do HEMA, promove uma hidrólise e plastificação na matriz polialcenoato-poliHEMA do cimento e assim ocorre uma diminuição de suas propriedades mecânicas (HOTTA \& HIRUKAWA ${ }^{22}$, 1994, YAP et al. ${ }^{56}, 2001$, ELLAKURIA et al. ${ }^{17}$, 2003, YLI-URPO et al. ${ }^{58}$, 2005). SWIFT JR et $\mathrm{al}^{47}$, em 1995, observaram que pode ocorrer um amolecimento até 7 dias após a polimerização inicial. HOTTA \& HIRUKAWA ${ }^{22}$, em 1994, encontraram propriedades inferiores quando as superfícies foram expostas ao ar e água. Entretanto, MITRA ${ }^{36}$, em 1990, não encontrou diferenças nos valores da resistência à compressão e tração diametral obtidos após a cura e após extensa armazenagem em água, e BASTING, SERRA e RODRIGUES JR. ${ }^{7}$, em 2002, num estudo in situ, não observou esse efeito plastificante na presença de saliva.

Segundo SOH, YAP e SIOW ${ }^{45}$ (2003), a efetiva polimerização é importante não somente para assegurar boas propriedades mecânicas, mas também para que problemas clínicos não apareçam devido à citotoxicidade dos materiais, e essa efetividade pode ser medida direta ou indiretamente. A microdureza superficial (método indireto) apresentou boa correlação com o FT-IR e possui as vantagens de ser um método simples e consumir menos tempo. O mesmo 
pensamento de que as propriedades mecânicas seriam um bom preditor do grau de conversão dos materiais poliméricos foi compartilhado por RUEGGEBERG \& CRAIG $^{40}$, em 1988, onde observaram que a microdureza Knoop pode ser o melhor método indireto para medir a conversão. Todavia, no presente estudo, após a realização da correlação de Pearson não foi encontrada relação entre os dois métodos testados, pelo menos para os cimentos de ionômero de vidro Vitremer e Rely X Luting (3M-ESPE). É importante ressaltar que a utilização dos mesmos espécimes em ambos os métodos não foi possível pela necessidade da pulverização dos espécimes para a análise no espectrofotômetro FT-IR. O baixo desvio padrão tornou possível a análise e, para isso, foram utilizadas as médias de cada condição experimental (tipo de polimerização e tempo de armazenagem) e não seus valores individuais, por se tratar de espécimes diferentes.

O grau de conversão, que aumentou significantemente durante uma semana após a fotopolimerização, não foi acompanhado pelo aumento da microdureza Knoop onde, após o aumento entre 24-48 horas, a mesma foi estável até o $14^{\circ}$ dia (último período testado). Apesar de não haver diferenças estatísticas, pode-se perceber uma redução numérica na microdureza. Existem diversas explicações para essa falta de correlação, como a polimerização não homogênea (VILJANEN et al. $\left.{ }^{51}, 2005\right)$. Outra explicação para o declínio da dureza pode ser atribuído ao aumento da conversão como resultado do calor gerado durante o polimento dos espécimes (RUEGGEBERG \& $\mathrm{CRAIG}^{40}$, 1988). Entretanto o motivo dos cimentos testados serem materiais híbridos e por isso, difícil correlacionar já que possuem uma reação de polimerização e outra ácido-base dita como responsável pelo aumento na propriedades mecânicas (YOUNG ${ }^{59}, 2002$ e YOUNG, RAFEEKA e HOWLETT ${ }^{60}$, 2004), parece ser a mais plausível. Além disso, a dureza não pode predizer os valores de conversão, pois as propriedades mecânicas são dependentes da formação das cadeias poliméricas, o que pode não ser equivalente ao grau de conversão do material. Por isso, CASSU \& FELISBERTI ${ }^{9}$, em 2005, relataram que a ocorrência de relaxações está normalmente associada a mudanças conformacionais de grupos ou segmentos das cadeias poliméricas, resultantes de rotações em torno das ligações químicas, e que esses rearranjos podem alterar as propriedades mecânicas sem alterar o grau de conversão. 
BRAGA, CONDON e FERRACANE ${ }^{8}$, em 2002, testando a resistência à abrasão de resinas compostas e cimentos de ionômero de vidro modificados por resina, também encontraram falta de correlação entre o grau de conversão e desgaste em cimentos duais. ASMUSSEM \& PEUTZFELDT ${ }^{6}$, em 2003, observaram que as propriedades mecânicas não alteram com a taxa de polimerização, mas foram dependentes da conversão da dupla ligação, e que polímeros com mesmo grau de conversão responderam diferentemente à ação do etanol (dureza Wallace), o que torna o GC um codeterminante das propriedades mecânicas dos polímeros. Sendo assim, IMAZATO et al. ${ }^{24}$, em 2001, relataram que a espectrofotometria é o melhor método para a mensuração da conversão da dupla ligação C=C (carbono-carbono). 


\section{CONCLUSÕES}




\section{CONCLUSÕES}

De acordo com os resultados obtidos e após a análise estatística, pôde-se concluir, para os materiais e situações experimentais testados que:

7.1. Os sistemas fotopolimerizados apresentaram melhores resultados do grau de conversão e da microdureza durante o tempo de armazenagem;

7.2. Dentre as tecnologias fotopolimerizadoras, o LED alcançou os maiores valores de conversão iniciais e a maior microdureza em todos os intervalos de tempo;

7.3. O tempo pareceu interferir no grau de conversão, aumentando com a maturidade dos cimentos para todos os sistemas de polimerização;

7.4. A microdureza sofreu alteração pelo tempo (envelhecimento) e meio de armazenagem;

7.5. A microdureza se mostrou ineficiente para medição do grau de conversão, sendo o FT-IR o método mais indicado. 


\section{REFERÊNCIAS BIBLIOGRÁFICAS}

1. ABOUT, I. et al. Influence of resinous monomers oh the differntiation in vitro of human pulp cells into odontoblasts. J. Biomed. Mat. Res., v. 63, p. 418-423, 2002.

2. ANDRZEJEWSKA, E., et al.. Effect of polyacid aqueous solutions on photocuring of polymerizable components of resin-modified glass ionomer cements. Dent. Mat., v. 19, p. 501-509, 2003.

3. ANTONUCCI, J. M.; McKINNEY, J. E.; STANSBURY, J. W.. Resinmodified glass ionomer cement. US Pat. Appln. $N^{\circ}$ 160856, 1988.

4. ANUSAVICE, K. J. Materiais dentários. 10 ed. Rio de Janeiro: Guanabara Koogan, 1998.

5. ARANHA, A, M. F. et al. Effect of curing regime on the citotoxicity of resinmodified glass-ionomer lining cements applied to an odontoblast-cell line. Biomaterials, v. 22, p. 864-869, 2006.

6. ASMUSSEM, E. \& PEUTZFELDT, A. Two-step curing: influence on conversion and softening of a dental polymer. Dent. Mat., v. 19, p. 466470, 2003.

7. BASTING, R. T.; SERRA, M. C.; RODRIGUES JR., A. L. In situ microhardness evaluation of glass-ionomer/composite resin hybrid materials at diferent post-irradiation times. J. Oral Rehab., v. 29, n. 12, p. 1187-1193, 2002.

8. BRAGA, R. R.; CONDON, J. R.; FERRACANE, J. L. In vitro wear simulation measurements of composite versus resin-modified glass ionomer luting cements for all-ceramic restorations. J. Esthet. Rest. Dent., v. 14, n. 6, p. 368-376, 2002. 
9. CASSU, S. N. \& FELISBERTI, M. I. Comportamento dinâmico-mecânico e relaxações em polímeros e blendas poliméricas. Quim. Nova, v. 28, n. 2, p. 255-263, 2005.

10. CEFALY, D. F. G.; et al.. Effect of time on the diametral tensile strength of resin-modified restorative glass ionomer cements an compomer. Braz. Dent. J., v. 12, n. 3, p. 201-204, 2001.

11. CHAIN, M.C.. Cimentos de Ionômero de Vidro. Revista Gaúcha de Odontológica, 38; p. 351-57, 1990.

12. COATES, J. Interpretation of infrared spectra, a pratical approach. In Encyclopedia of analytical chemistry, ed. R. A. Meyers, p. 10815-10837, 2000.

13. CORRÊA, I. C.. Análise do Grau de Conversão de uma Resina Experimental Fotopolimerizável: um estudo espectrométrico em função de diferentes fotoiniciadores e fontes de luz. Tese de Doutorado, USP, 2003.

14. CRISP, S. et al.. Reactions in glass ionomer cements: II. An infrared spectroscopic study. J. Dent. Res., v. 53, n. 6, p. 1414-1419, 1974.

15. DE GEE, A. J. et al. Structural integrity of resin-modified glass ionomers as affected by the delay or omission of light activation. J. Dent. Res., v. 77, n. 8, p. 1658-1663, 1998.

16. ELIADES, G. \& PALAGHIAS, G. In vitro characterization of visible lightcured glass ionomer liners. Dent. Mater., v.9, p. 198-203, 1993.

17. ELLAKURIA, J. et al. Effect of one-year water storage on the surface microhardness of resin-modified versus conventional glass-ionomer cements. Dent. Mat., v. 19, n. 4, p. 286-290, 2003. 
18. GAUTHIER, M. A. et al. A new method for quantifying the intensity of the $\mathrm{C}=\mathrm{C}$ band of dymethacrylate dental monomers in their FTIR an Raman spectra. Biomaterials, v. 26, n. 33, p. 6440-6448, 2005.

19. GEURTSEN, W. Substances released from dental resin composites and glass ionomer cements. Eur. J. Oral Sci., v. 106, p. 687-695, 1998.

20. HAMID, A. et al. Component release from light-activated glass ionomer and compomer cements. J. Oral Rehab., v. 25, p. 94-99, 1998.

21. HOFMANN, N. et al. Comparison between a plasma arc light plasma source and conventional halogen curing units regarding flexural strength, modulus, and hardness of photoactivated resin composites. Clin Oral Invest, v. 4, p. 140-147, 2000.

22. HOTTA, M. \& HIRUKAWA, H. Abrasion resistance of restorative glassionomer cements with a light-cured surface coating. Oper. Dent., v. 19, n. 3, p. 42-46, 1994.

23. HUME, W. R. \& MOUNT, G. J. In vitro studies on the potencial for pulp citotoxicity of glass-ionomer cements. J. Dent. Res., v. 67, n. 6, p. 915918, 1988.

24. IMAZATO, S. et al. Degree of conversion of composites measured by DTA and FTIR. Dent. Mat., v. 17, p. 178-183, 2001.

25. INOUE, K. \& HAYASHI, I. Residual monomer (BIS-GMA) of composite resin. J. Oral Rehab., v. 9, p. 493-497, 1982.

26. KAKABOURA, A.; ElIADES, G.; PALAGHIAS, G. An FTIR study on the setting mechanism of resin-modified glass ionomer restorative. Dent. Mater., v. 12, p.173-178, 1996. 
27. KANCA III, J. Laboratory evaluation of LED lights. J Dent Res, Chicago, v. 81, 2003. ( Resumo AADR n. 38 ).

28. KANCHANAVASITA, W.; PEARSON, G. J.; ANSTICE, H. M. Factors contributing to the temperature rise during polymerization of resin-modified glass-ionomer cements. Biomaterials, v. 17, n. 24, p. 2305-2312, 1996.

29. KAWAHARA, H.; IMANISHI, Y.; OSHIMA, H. Biological evaluation on glass ionomer cement. J. Dent. Res., v. 58, n. 3, p. 1080-1086, 1979.

30. KIDD, E.A.M. Cavity sealing ability of composite anda glass ionomer cement restorations. Brit. Dent. J., 144, p. 139-42, 1978.

31. KURACHI, C. Estudo comparativa do LASER, do LED azul e da lâmpada convencional no processo de polimerização da resina composta dental. 2000. 82f. Dissertação ( Mestrado em ciências e Engenharia de Materiais ) - Instituto de Física de São Carlos, USP.

32. KURACHI, C. et al.. Hardness evaluation of a dental composite polymerized with experimental LED-base devices. Dent. Mat., v. 17, p. 309-315, 2001.

33. LI, J.; BEETZEN, M. V.; SUNDSTROM, F. Strengh and setting behavior of resin-modified glass ionomer cements. Acta Odontl. Scand., v. 53, n. 5, p. 311-317, 1995.

34. MICHELSEN, V. B. et al. Identification of orgânica eluates from four polymer-based dental filling materials. Eur. J. Oral Sci., v. 111, p. 263-271, 2003.

35. MITRA, S.B.. Photocurable ionomer cement systems. Eur. Pat. Appln. $\mathrm{N}^{\circ} 032120$ A2, 1989. 
36. MITRA, S. B. Adhesion to dentin and physical properties of a light-cured glass ionomer liner/base. J. Dent. Res., v. 70, n. 1, p. 72-74, 1991.

37. NAVARRO, M. F. L.. Cimento de Ionômero de Vidro, Editora Artes médicas Ltda, 1997.

38. PAlMER, G.; ANSTICE, H. M.; PEARSON, G. J. The effect of curing regime on the release of hydroxyethyl methacrylate (HEMA) from resinmodified glass-ionomer cements. J. Dent., v. 27, p. 303-311, 1999.

39. PIANELLI, C. et. al.. The micro-Raman spectroscopy, a useful tool to determine the degree of conversion of light-activated composite resin. $\mathrm{J}$ Biomed Mater Res, New York, v. 48, n. 5, p. 675-81, 2000.

40. RUEGGEBRG, F. A. \& CRAIG, R. G. Correlation of parameters used to estimate monomer conversion in a light-cured composite. J. Dent. Res., v. 67, n.6, p. 932-937, 1988.

41. RUGGEBERG, F.A. Contemporary issues in photocuring. Compendium, New Town, v. 20, n. 25, p. 4-15, 1999. Suplemento.

42. RUGGEBERG, F.A. Spectral irradiance of contemporary photo-curing units. J Dent Res, Chicago, v. 79, p. 333, 2000.

43. SCHUSteR, G. S.; CAUGHMAN, G. B.; RUEGGEBERG, F. A. Changes in cell phospholipid metabolism in vitro in the presence of HEMA and its degradation products. Dent. Mat., v. 16, p. 297-302, 2000.

44. SILVERSTEIN, R. M. \& WEBSTER F. X., Identificação espectrométrica de compostos orgânicos. 6ed. Rio de Janeiro: livros técnicos e científicos editora, p. 67-135, 2000. 
45. SOH, M. S.; YAP, A. U. J.; SIOW, K. S. The effectiveness of cure of LED and halogen curing lights at varying cavity depths. Oper. Dent., v. 28, n. 6, p. 707-715, 2003.

46. SOUZA, P. P. C. et al. In vitro citotoxicity and in vivo biocompability of contemporary resin-modified glass-ionomer cements. Biomaterials, v. 22, p. 838-844, 2006.

47. SWIFT JR.; E. J.; PAWLUS, M. A.; VARGAS, M. A.; FORTIN, D. Depth of cure of resin-modified glass ionomers. Dent. Mater., v. 11, p. 196-200, 1995.

48. TARLE, Z. et al. Comparison of composite curing parameters: effects of light source and curing mode on conversion, temperature rise and polimerization shrinkage. Oper. Dent., v. 31, n.2, p. 219-226, 2006.

49. VAN NOORT, R.. Introdução aos materiais dentários. ed. Artmed, 2 ed., 2004.

50. VERMEERSCH, G. et al. Antibacterial activity of glass-ionomer cements, compomers and resin composites: relationship between acidity and material setting phase. J. Oral Rehab., v. 32, p. 368-374, 2005.

51. VILJANEN, E. K. et al. Degree of conversion and flexural properties of a dendrimer/methyl methacrylate copolymer: design of experiments and statistical screening. Dent. Mat., v. 21, p. 172-177, 2005.

52. WAN, A. C.; YAP, A. U. J.; HASTINGS, G. W. Acid-base complex reactions in resin-modified an convetional glass ionomer cements. $\mathrm{J}$. Biomed. Mat. Res. (Appl. Bimoaterial), v. 48, p. 700-704, 1999.

53. WILSON, A.D. \& KENT, B.E. The glass ionomer cement. A new translucent dental filling material. J. Appl. Chem. Biotech., v 21, p. 313, 1971. 
54. WOOLFORD, M.J. \& CHADWICK, R. G. Surface pH of resin-modified glass polyalkenoate (ionomer) cements. J. Dent., v. 20, n. 6, p. 359-364, 1992.

55. XIE, D. et al. Synthesis and evaluation of HEMA-free glass ionomer cements for dental aplications. Dent. Mat., v. 20, p. 470-478, 2004.

56. YAP, A. U. J et al.. Mechanical properties of an improved visible lightcured resin-modified glass ionomer cement. Oper. Dent., v. 26, n. 3, p. 295-301, 2001.

57. YAZICI, A. R. et al. Comparison of temperature changes in the pulp chamber induced by various light curing units, in vitro. Oper. Dent., v. 31, n. 2, p. 261-265, 2006.

58. YLI-URPO, $\mathrm{H}$. et al. Compressive strenth and surface caracterization of glass ionomer cements modified by particles of bioactive glass. Dent. Mat., v. 21, p. 201-209, 2005.

59. YOUNG, A. M. FTIR investigation of polymerisation and polyacid neutralisation kinetics in resin-modified glass ionomer dental cements. Biomaterials, v. 23, p. 3289-3295, 2002.

60. YOUNG, A. M. RAFEEKA, S. A., HOWLETT, J. A. FTIR investigation of monomer polymerization and polyacid neutralisation kinetics and mechanisms in various aesthetic dental restorative materials. Biomaterials, v. 25, p. $823-833,2004$. 
ABSTRACT 


\section{ABSTRACT \\ Evaluation of the Knoop microhardness and the degree of conversion of two resin-modified glass ionomer in function of the type of polymerization and the time}

Glass ionomer cement have been widely used for many functions. Over the years, some alterations have been made to improve some physicomechanical properties and to prolong working time. The purpose of this study was to evaluate the relation of the degree of conversion (DC) and Knoop microhardness of resin modified glass ionomer cements (Rely $X$ Luting and Vitremer - 3M ESPE) with polymerization type (chemical curing and light curing reactions, using halogen light or LED) and time of storage. Three specimens of each material, self-cured and light-cured, and light-curing type (halogen light or LED) were prepared for each period of time $(n=72)$. Specimens were stored in dark and dry conditions, at $37^{\circ} \mathrm{C}$, during 6 hours, 1 , $2,3,5,7,11$ and 14 days. All the specimens were analyzed by FT-IR spectroscopy to measure the DC. Three specimens of each material and polimeryzation type $(n=9)$ were prepared for the microhardness determination, equipped with a Knoop indenter, $50 \mathrm{~g}$ load for 30 seconds. Results showed that higher values of DC and Knoop microhardness were found on the LED light-cured material. DC values increased with storage time while the Knoop microhardness achieved its higher values between 24-48 hours. Results showed that the LED light-curing unit used to polymerize the resin modified glass ionomer cement Vitremer achieved better values of DC, between light and self-cured materials, and that the Knoop microhardness could not predict the DC.

Keywords: Resin modified glass ionomer cement. FT-IR spectroscopy Knoop microhardness. Polymerization. Storage time. 